UNIVERSIDADE DE SÃO PAULO

FACULDADE DE ECONOMIA, ADMINISTRAÇÃO E CONTABILIDADE DEPARTAMENTO DE ADMINISTRAÇÃO

UTILIZAÇÃO DE SISTEMAS DE INTELIGÊNCIA DE

NEGÓCIOS EM EMPRESAS DE SERVIÇOS

Eric Bacconi Gonçalves

SÃo PAULO

2017 
Prof. Dr. Marco Antonio Zago

Reitor da Universidade de São Paulo

Prof. Dr. Adalberto Américo Fischmann

Diretor da Faculdade de Economia, Administração e Contabilidade

Prof. Dr. Roberto Sbragia

Chefe do Departamento de Administração

Prof. Dr. Moacir de Miranda Oliveira Júnior

Coordenador do Programa de Pós-Graduação em Administração 


\section{UTILIZAÇÃO DE SISTEMAS DE INTELIGÊNCIA DE NEGÓCIOS EM EMPRESAS DE SERVIÇOS}

Tese apresentada ao Departamento de Administração da Faculdade de Economia, Administração e Contabilidade da Universidade de São Paulo como requisito parcial para obtenção do título de Doutor em Ciências.

Orientadora: $\operatorname{Prof}^{\mathrm{a}} \mathrm{Dr}^{\mathrm{a}}$ Maria Aparecida Gouvêa

\section{Versão Corrigida}

ão original disponível na Faculdade de Economia, Administração e Contabilidade)

\section{SÃO PAULO}




\section{FICHA CATALOGRÁFICA}

\section{Elaborada pela Seção de Processamento Técnico do SBD/FEA/USP}

Gonçalves, Eric Bacconi

Utilização de sistemas de inteligência de negócios em empresas de serviços / Eric Bacconi Gonçalves. - São Paulo, 2017

$125 \mathrm{p}$.

Tese (Doutorado) - Universidade de São Paulo, 2018.

Orientador: Maria Aparecida Gouvêa.

1. Inteligência empresarial 2. Sistemas de informação gerencial 3. Serviços 4. Estratégia organizacional I. Universidade de São Paulo. Faculdade de Economia, Administração e Contabilidade. II. Título.

CDD -658.47 
Para Simião, Cleide, Mariana, Júlia e Helena. 



\section{AGRADECIMENTOS}

Não foi fácil e, apesar de eu estar sendo o único creditado como autor desta tese, muitas pessoas colaboraram para tornar viável a finalização, a quem eu dedico meu sincero "Muito Obrigado". A Deus por ter me permitido chegar até aqui.

À professora Cida, por confiar no meu potencial, acreditar no tema deste trabalho, compartilhar seu conhecimento e dar uma luz quando tudo parecia confuso.

À Mariana por incentivar a minha candidatura ao doutorado, segurar as pontas na minha ausência e permitir minha dedicação à pesquisa; sem você certamente eu não teria conseguido. Às minhas filhas, Júlia e Helena pela paciência (nem sempre presente) e a compreensão de verem o pai sendo "roubado" delas.

Aos meus pais Simião e Cleide e à minha irmã Paula por serem os pilares da minha formação como ser humano e sempre me apoiarem.

Aos meus familiares, que sempre torcem por mim.

Aos professores Daielly Mantovani e Milton Farina, membros da banca de qualificação que contribuíram com preciosos conselhos no direcionamento deste trabalho.

Aos que responderam à pesquisa de campo e aos que ajudaram a divulgá-la, especialmente Cesinha, Oliver, Robson, Carlão, Alexandre e Katalina.

Aos meus colegas de trabalho, que me ajudaram sempre que possível.

Aos funcionários, professores e alunos da FEA que tornaram agradáveis esses quatro anos que passei cursando o doutorado. 

"Voa coração, que a minha força te conduz." Toquinho (música "da Júlia”) "Você não sabe o quanto eu caminhei, pra chegar até aqui." Cidade Negra (música “da Helena”) 



\section{RESUMO}

O presente trabalho teve como objetivo entender os fatores que facilitam a utilização de sistemas de Business Intelligence em empresas de serviços. Para isso utilizou um modelo Expectation-Confirmation Theory (ECT) adaptado para avaliar o que favorece a aceitação do sistema, além dos constructos do modelo original proposto por Bhattacherjee (2001b): Confirmação, Satisfação, Utilidade Percebida, Intenção Comportamental de Uso e Continuidade de Uso; foram incluídos três constructos no modelo adaptado: Hábito, Qualidade da Informação e Estratégia Direcionada pela Tecnologia.

Após a validação de um questionário do tipo survey por especialistas, o instrumento foi enviado para usuários de Sistemas de BI e obteve 81 respondentes funcionários de empresas de serviços. As conclusões apontam que a maior parte das hipóteses foi confirmada, exceto o efeito moderador do Hábito na Continuidade de Uso e a influência da Estratégia Direcionada pela Tecnologia.

Podem-se destacar as contribuições acadêmicas e gerenciais deste trabalho. Como contribuição acadêmica, destacam-se: a construção do referencial teórico sobre Business Intelligence, Big Data, Aceitação de Tecnologia, Estratégia e Empresas de Serviços; e o entendimento sobre a relação dos fatores que influenciam a aceitação de um sistema de BI no mercado brasileiro de serviços. Na implicação gerencial, ressalta-se a conclusão que o fato de a estratégia da empresa ser direcionada pela tecnologia não afetar positivamente a utilidade percebida do sistema de $\mathrm{BI}$, isto pode ser um indício que, independentemente de como o empregado identifica a estratégia da empresa, ele percebe o valor do sistema de BI, o que indica que a ferramenta é útil não apenas para cenários de empresas tecnológicas.

O trabalho permitirá diversos desdobramentos e análises alternativas, por seu ineditismo e detalhamentos obtidos sobre os aspectos teóricos selecionados.

Palavras-chave: Inteligência empresarial, Sistemas de informação gerencial, Serviços, Estratégia organizacional 


\begin{abstract}
The objective of this study was to understand the factors that facilitate the use of Business Intelligence systems in Service companies. To do this, it used an Expectation-Confirmation Theory (ECT) model adapted to evaluate what helps the acceptance of the system, besides the constructs of the original model proposed by Bhattacherjee (2001b): Confirmation, Satisfaction, Perceived Utility, Behavioral Intention of Use and Continuity of Use; three constructs were included in the adapted model: Habit, Information Quality and Technology Driven Strategy.

After the validation of a survey questionnaire by specialists, the instrument was sent to users of BI Systems and obtained 81 respondents from service companies. The conclusions indicate that most of the hypotheses were confirmed, except for the moderating effect of the Habit in Continuity of Use and the influence of the Technology Driven Strategy.

It is possible to emphasize the academic and managerial contributions of this work. As an academic contribution, the construction of the theoretical reference on Business Intelligence, Big Data, Acceptance of Technology, Strategy and Service Companies; and the understanding of the relationship between the factors that influence the acceptance of a BI system in the Brazilian services market. In the managerial implication, the conclusion is that the fact that the company's strategy is driven by the technology does not positively affect the perceived utility of the BI system, this may be an indication that, regardless of how the employee identifies the company's strategy, it realizes the value of the BI system, which indicates that the tool is useful not only for technology companies.
\end{abstract}

The work will allow many developments and alternative analyzes, for its originality and details obtained on selected theoretical aspects.

Keywords: Business Intelligence, Management Information Systems, Strategy. 


\section{SUMÁRIO}

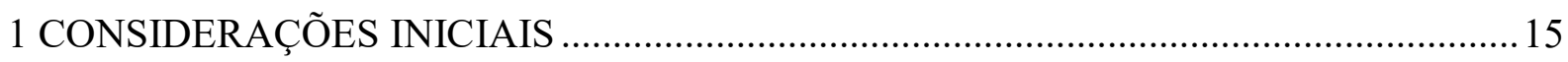

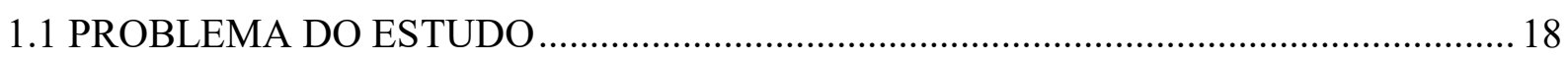

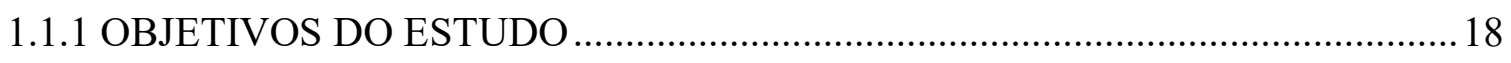

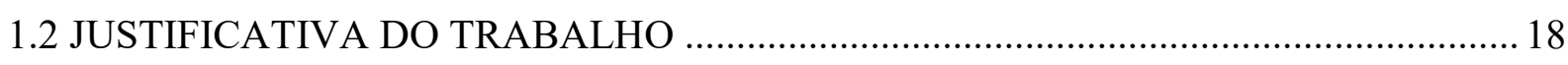

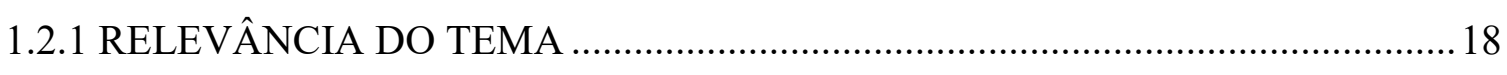

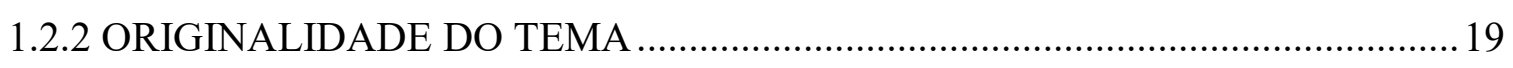

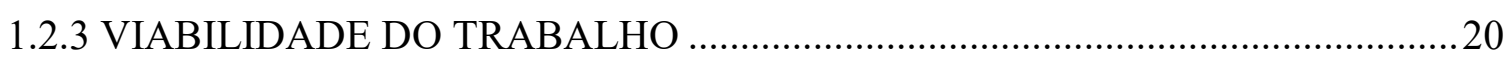

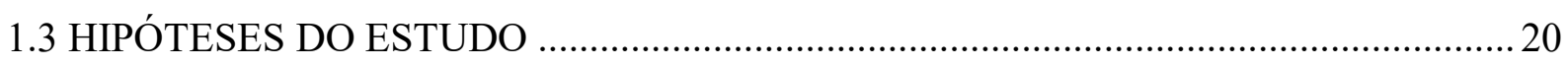

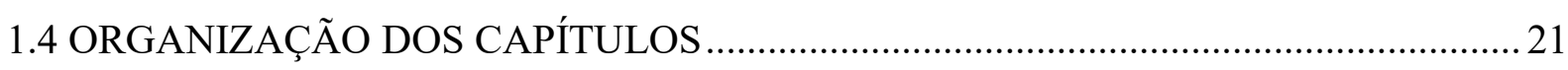

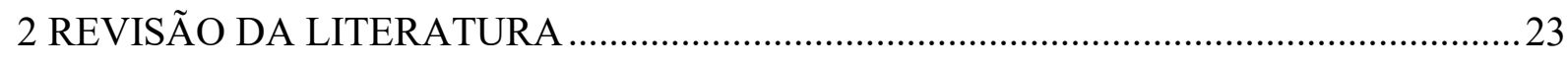

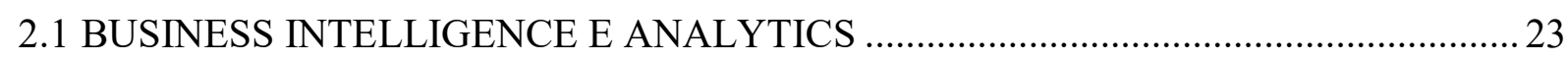

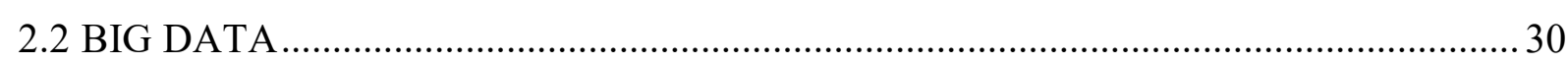

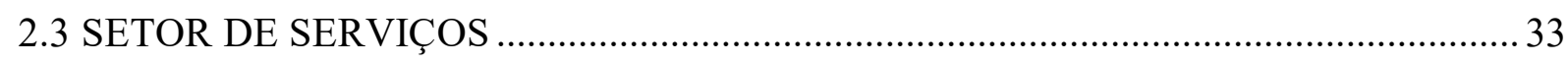

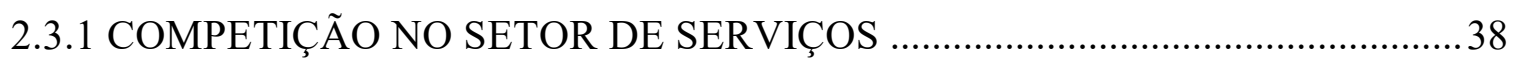

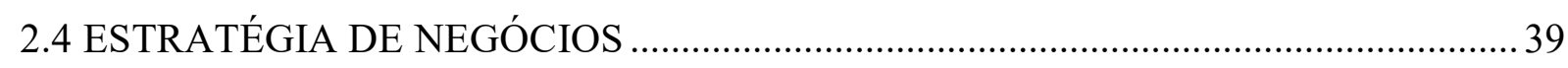

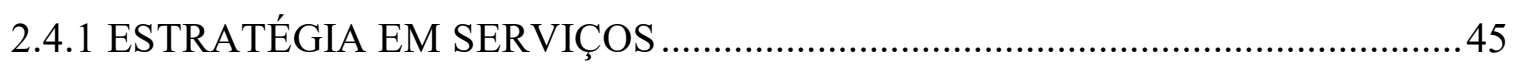

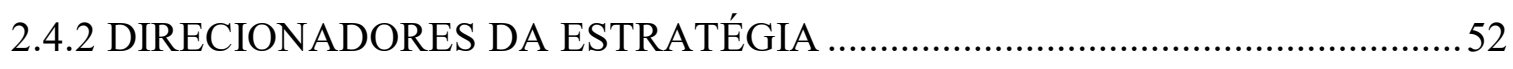

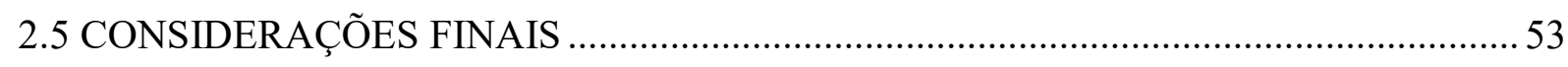

3 MODELOS DE ACEITAÇÃO DE TECNOLOGIA ………………………………..........

3.1 MODELO TRA - THEORY OF REASONED ACTION …………………………..........5

3.2 MODELO TPB - THEORY OF PLANNED BEHAVIOUR ……………………………....56

3.3 MODELOS TAM E TAM2 - TECNOLOGY ACCEPTANCE MODEL ……………........57

3.4 MODELO MPCU - MODEL OF PC UTILIZATION …………………………...........5

3.5 MODELO IDT - INNOVATION DIFFUSION THEORY …………………..................5

3.6 MODELO DTPB - DECOMPOSED THEORY OF PLANNED BEHAVIOR …..................... 60

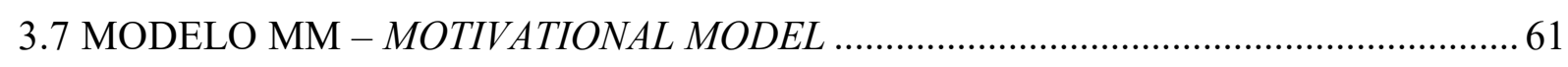

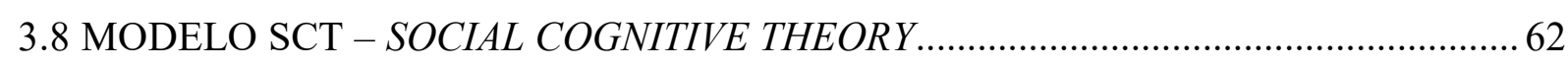

3.9 MODELO UTAUT - UNIFIED THEORY OF ACCEPTANCE AND USE OF

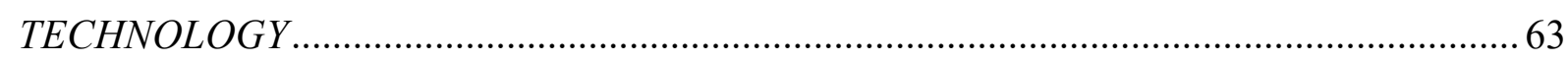

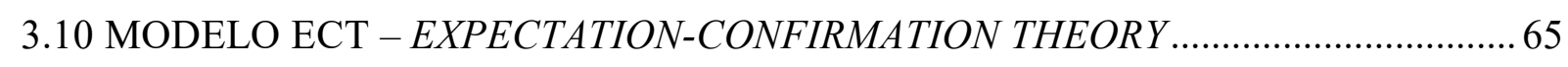

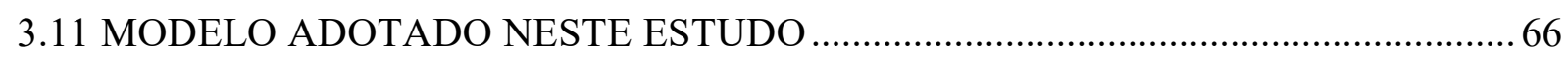


4 ASPECTOS METODOLÓGICOS 69

4.1 POPULAÇÃO E AMOSTRA 69

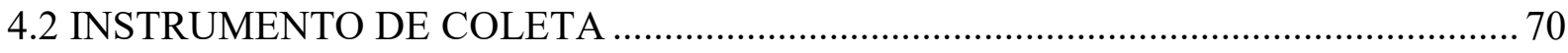

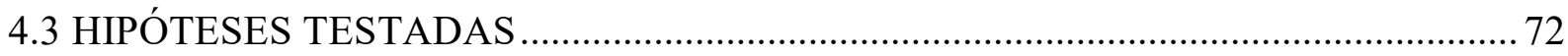

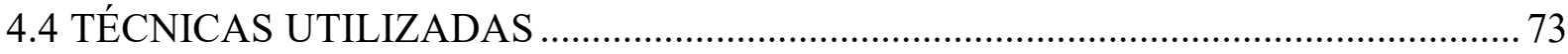

4.4.1 MODELAGEM DE EQUAÇÕES ESTRUTURAIS .............................................. 73

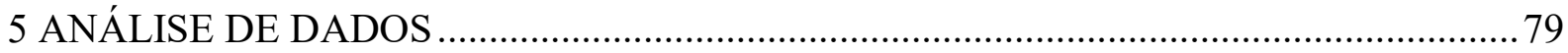

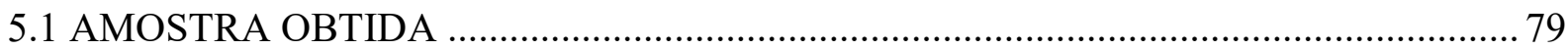

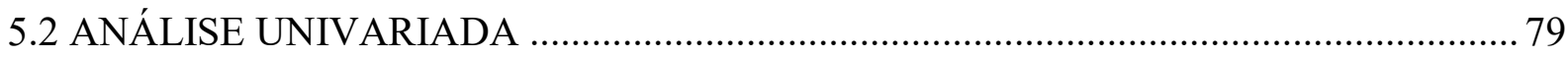

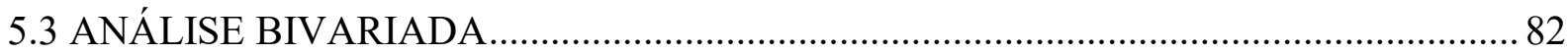

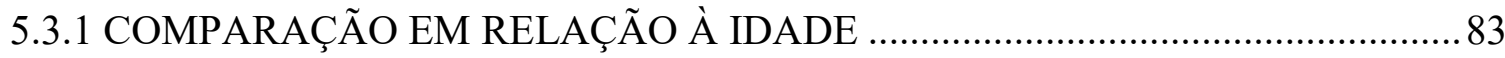

5.3.2 COMPARAÇÃO EM RELAÇÃO AO GRAU DE INSTRUÇÃO .......................... 85

5.3.3 COMPARAÇÃO EM RELAÇÃO AO CARGO .................................................... 87

5.3.4 COMPARAÇÃO EM RELAÇÃO AO RAMO DA EMPRESA..............................89

5.3.5 COMPARAÇÃO EM RELAÇÃO AO DEPARTAMENTO DE ATUAÇÃO ........91

5.3.6 COMPARAÇÃO EM RELAÇÃO AO TEMPO DE EXPERIÊNCIA COM BI.....93

5.4 MODELO DE EQUAÇÕES ESTRUTURAIS

5.5 AVALIAÇÃO DAS HIPÓTESES DO MODELO E COMPARAÇÃO COM ESTUDOS ANTERIORES 100

6 CONCLUSÕES, IMPLICAÇÕES, LIMITAÇÕES E CONTRIBUIÇÕES PARA FUTURAS PESQUISAS. 105

6.1 CONCLUSÕES A PARTIR DA DISCUSSÃO DOS RESULTADOS E IMPLICAÇÕES ACADÊMICAS 105

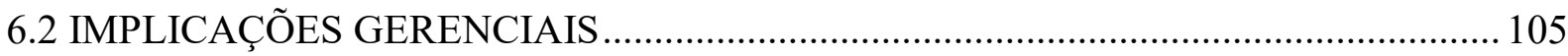

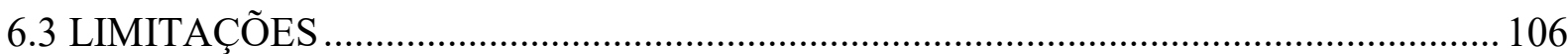

6.4 CONTRIBUIÇÕES PARA FUTURAS PESQUISAS ................................................ 107

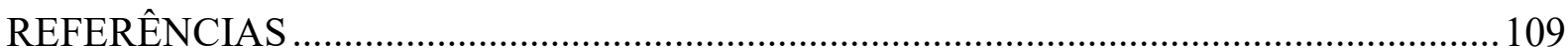

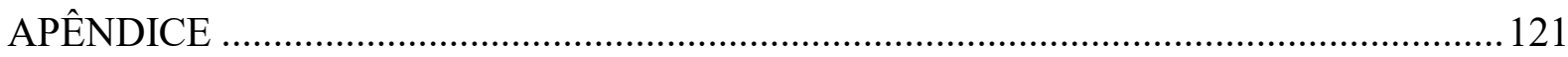

APÊNDICE 1: QUESTIONÁRIO DA PESQUISA.......................................................... 121 


\section{LISTA DE FIGURAS}

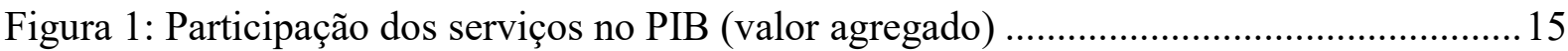

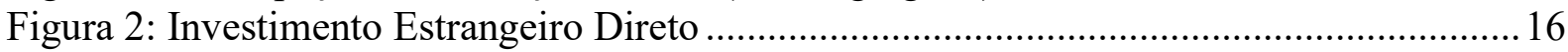

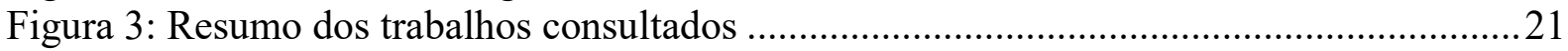

Figura 4: Modelo Pressões - Reações - Suporte do Negócio ...............................................24

Figura 5: Valor para o negócio das aplicações analíticas de BI ...........................................26

Figura 6: Diferenças entre Modelos Explanatórios e Modelos Preditivos ..............................28

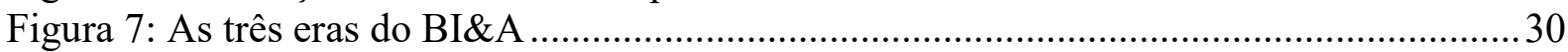

Figura 8: Cegos e o Elefante, a visão parcial de cada cego leva a conclusões enviesadas .......31

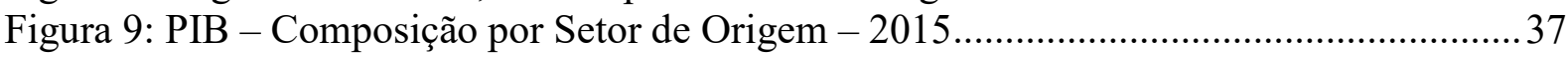

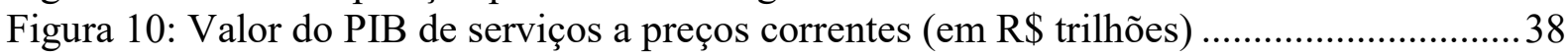

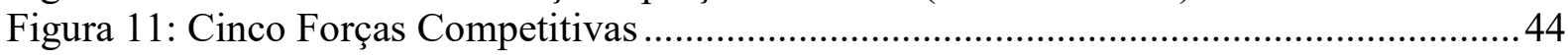

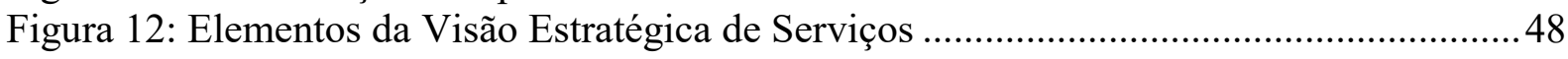

Figura 13: Modelo de Estratégia de Johnston, Clark e Shulver ............................................49

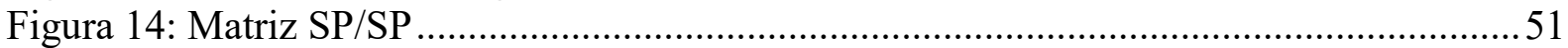

Figura 15: Focos Básicos para a Estratégia de Serviços ...........................................................52

Figura 16: Conceitos Básicos de Modelos de Aceitação de Tecnologia ...................................55

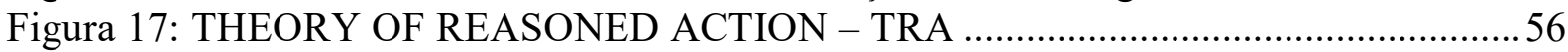

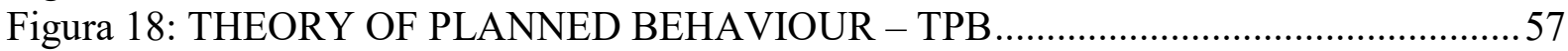

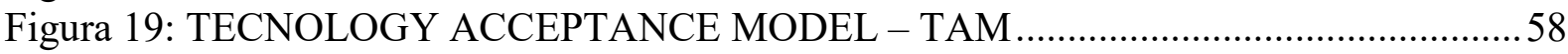

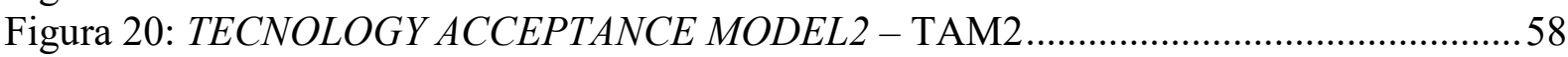

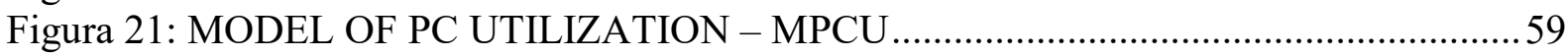

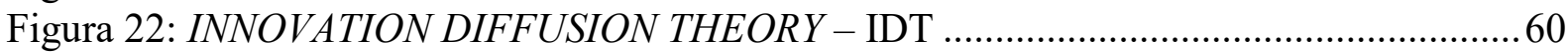

Figura 23: DECOMPOSED THEORY OF PLANNED BEHAVIOR - DTPB .......................61

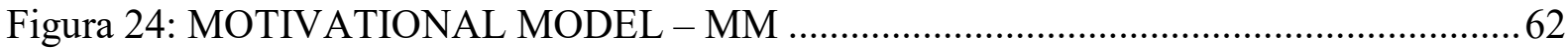

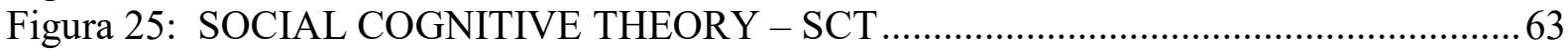

Figura 26: UNIFIED THEORY OF ACCEPTANCE AND USE OF TECHNOLOGY-

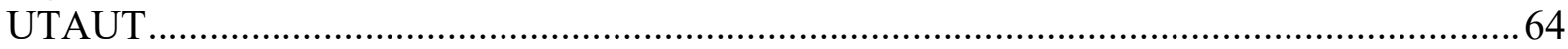

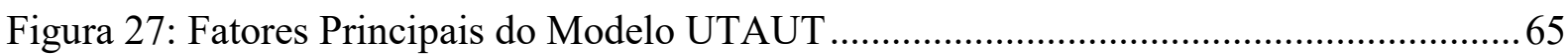

Figura 28: EXPECTATION-CONFIRMATION THEORY - ECT ….......................................65

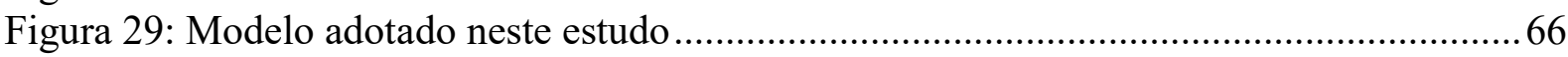

Figura 30: Hipóteses testadas no modelo proposto ............................................................ 72

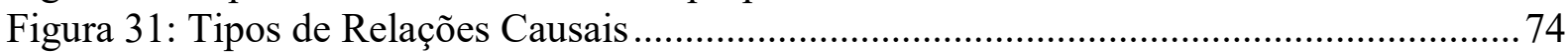

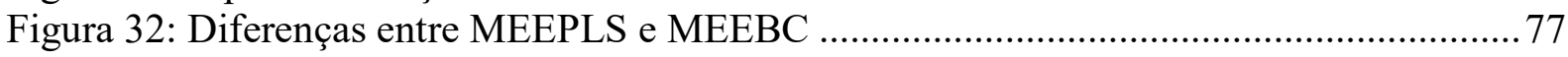

Figura 33: Tela do G*Power 3.1.9.2 com cálculo do tamanho da amostra............................95

Figura 34: Modelo ajustado por equações estruturais ............................................................ 96

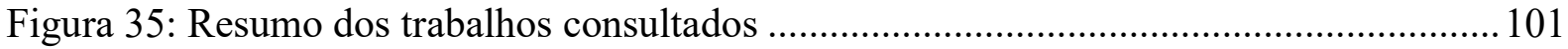

Figura 36: Conclusões de pesquisas similares - considerando nível de significância de 5\% 104 


\section{LISTA DE TABELAS}

Tabela 1: Porcentagem de empregos no setor de serviços nas 10 maiores nações pósindustriais (1965-2012)

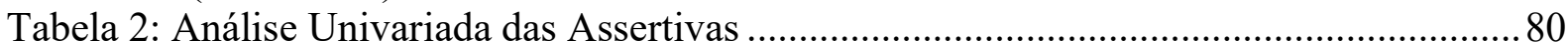

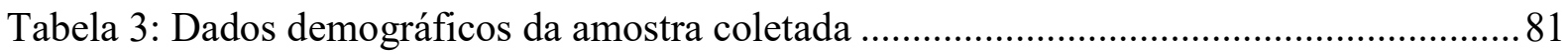

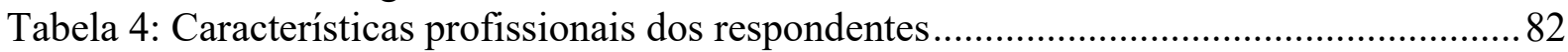

Tabela 5: Teste t para comparação das médias de cada assertiva em relação à faixa etária ....84 Tabela 6: Teste t para comparação das médias de cada assertiva em relação ao grau de instrução

Tabela 7: Teste t para comparação das médias de cada assertiva em relação ao cargo ...........88

Tabela 8: Teste t para comparação das médias de cada assertiva em relação ao ramo da empresa

Tabela 9: Teste t para comparação das médias de cada assertiva em relação ao departamento de atuação

Tabela 10: Teste t para comparação das médias de cada assertiva em relação ao tempo de

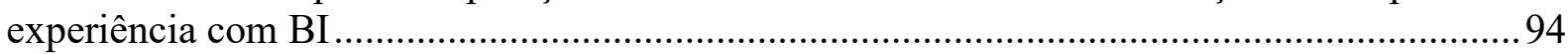

Tabela 11: Variância Média Extraída (AVE) de cada constructo ...........................................97

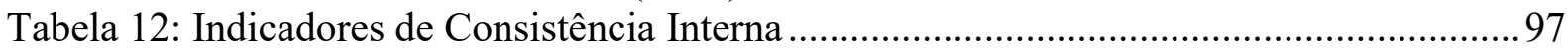

Tabela 13: Validade Discriminante do Modelo (Critério de Fornell-Larcker) .........................98

Tabela 14: Coeficientes de Determinação de Pearson $\left(\mathrm{R}^{2}\right)$...................................................99

Tabela 15: Fator de Inflação de Variância (VIF) ....................................................................99

Tabela 16: Indicador de Validade Preditiva $\left(\mathrm{Q}^{2}\right)$ e Tamanho do efeito $\left(\mathrm{f}^{2}\right)$.......................... 100

Tabela 17:Verificação das hipóteses - nível de significância de 5\%...................................... 101 


\section{CONSIDERAÇÕES INICIAIS}

De acordo com Fitzsimmons \& Fitzsimmons (2014), nenhuma economia pode funcionar sem a infraestrutura que os serviços proporcionam na área de transportes e comunicações, e, menos ainda, sem serviços estatais como educação e saúde. À medida que uma economia se desenvolve, mais importante se torna a área de serviços, que logo passa a empregar a maioria da população ativa nas suas atividades. A importância da indústria de serviços cresceu nas Economias dos diversos países ao longo dos anos (Lovelock, Patterson, \& Wirtz, 2014). A Figura 1, a seguir, mostra o crescimento da participação do setor de serviços na economia brasileira.

Figura 1: Participação dos serviços no PIB (valor agregado)

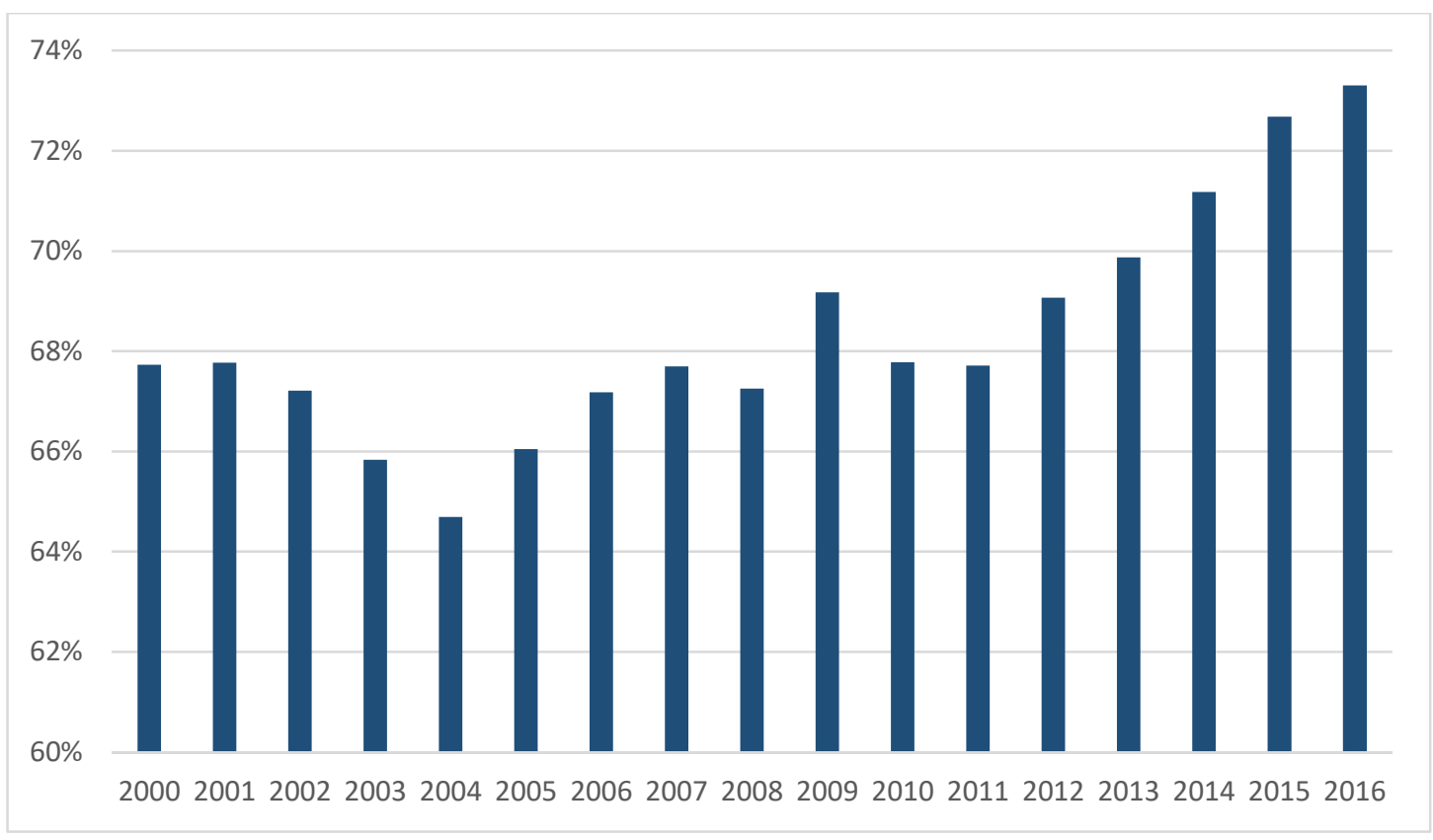

Fonte: Contas Nacionais Trimestrais (IBGE, s.d.)

A Figura 1 mostra que a participação do setor de serviços no PIB brasileiro apresenta tendência de crescimento nos últimos anos sendo que, desde 2011, o percentual de participação dos serviços no total do PIB só cresce.

Na Figura 2, é apresentado o volume de investimentos estrangeiros diretos (IED), no qual o setor de serviços tem grande representatividade na economia nacional, tendo seu ápice em 2014, 
quando foi responsável por 60\% do IED referente a um volume superior a U\$ 30 bilhões (Banco Central, s.d.)

Figura 2: Investimento Estrangeiro Direto

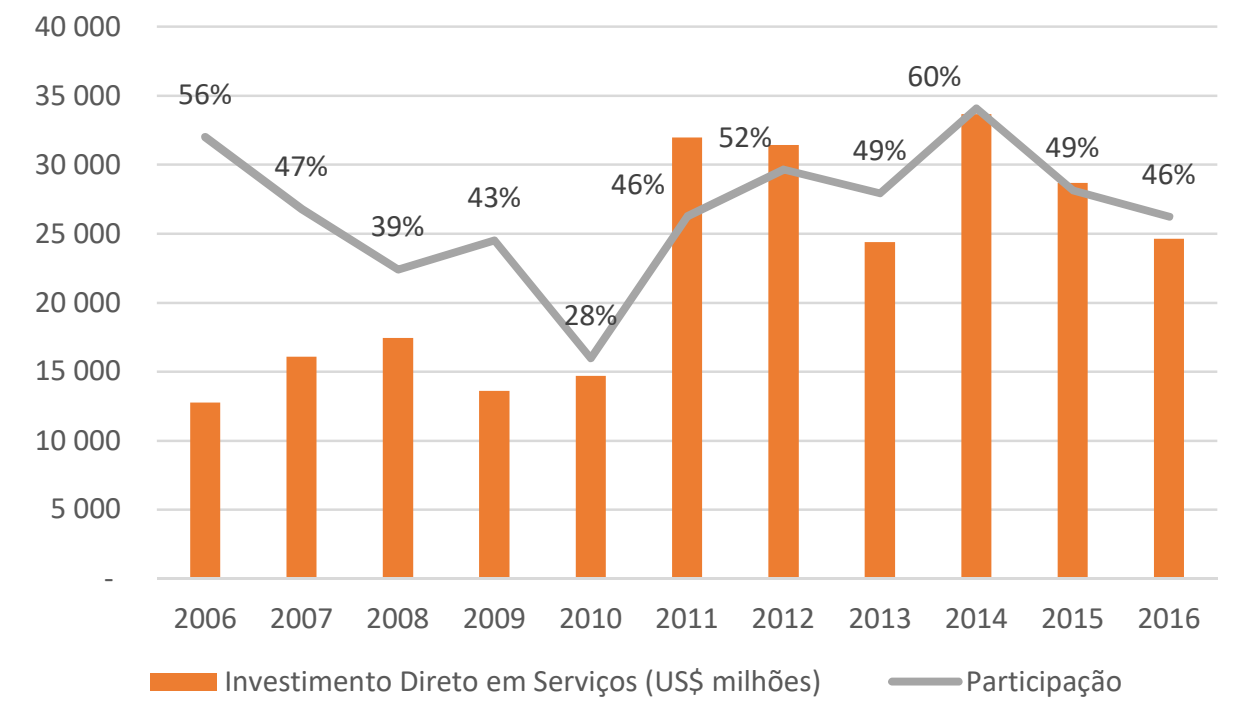

Fonte: Série histórica dos fluxos de investimento direto (Banco Central, s.d.)

O volume de investimento estrangeiro direto em serviços, mostrado na Figura 2, mudou de patamar nos últimos anos. Se até 2010 o investimento era da ordem de U\$ 15 bilhões, a partir de 2011 o valor foi sempre superior a U\$ 20 bilhões.

Aliado a essa quantidade de recursos financeiros, o setor de serviços é o que mais cresce em quantidade de empresas (SEBRAE, 2012; Serasa Experian, 2015), tornando esse setor muito competitivo.

A partir dos anos 80, a competição nos mercados cresceu e as empresas passaram a necessitar de agilidade para responder às rápidas mudanças de mercado (Dutta, 2015; Ghemawat, 2002; Porter, 1996). Nesse aspecto, a estratégia da companhia tem um papel preponderante para atingir seus objetivos e ter domínio sobre as forças de mercado (Camargos \& Dias, 2003; Ghemawat, 2002). Segundo Liao, Welsch, \& Stoica (2008), em um ambiente de negócios dinâmico, estratégias devem estar em constante adaptação para uma empresa atingir sucesso a longo prazo.

Para sobreviver em mercados competitivos as empresas necessitam conhecer cada vez melhor seus clientes (Flint, Blocker, \& Boutin, 2011). Essa necessidade fez com que, desde o início do século XXI, as companhias passassem a armazenar mais dados, oriundos de praticamente todas as atividades humanas, visto o uso crescente dos dispositivos de tecnologia da informação 
(Dias \& Vieira, 2013). Wu, Zhu, Wu, \& Ding (2014) apontam que em cada dia, um volume de 2,5 quintilhões de bytes é gerado. Big Data é um termo que surgiu no fim do século XX (Diebold, 2012), na concepção de Zikopoulos, Eaton, DeRoos, Lapis, \& Deutsch (2012), criado para designar o crescimento das informações que se caracterizam por serem: grandes em volume; diversificadas em formato; e recebidas em tão alta velocidade de forma que os sistemas tradicionais de processamento não conseguissem armazená-las e analisá-las.

Quando se fala em grandes volumes de dados, é inevitável não se pensar em ferramentas de análise que permitam tomar decisões efetivas (Loveman, 2004). O conceito de Business Intelligence e Analytics relacionado ao campo de Big Data cresceu de importância, tanto no campo acadêmico quanto nas empresas ao longo das duas primeiras décadas do século XXI (Chen, Chiang, \& Storey, 2012). De acordo com Cohen, Dolan, Dunlap, Hellerstein, \& Welton (2009), o grande volume de dados armazenados requer uma variada gama de métodos estatísticos para efetuar sofisticadas análises de dados. Sistemas de Business Intelligence são utilizados no intuito de analisar dados transformando-os em informação e conhecimento que permita às empresas melhorar a qualidade das decisões em diferentes processos da empresa (Pejić Bach, Čeljo, \& Zoroja, 2016).

A evolução tecnológica a partir da década de 1970, aliada a problemas em implantação de sistemas nas organizações, fez com que o estudo sobre aceitação ou rejeição de tecnologia se tornasse um tópico de interesse de pesquisadores (Chuttur, 2009). A compreensão da tecnologia associada à identificação das condições e fatores facilitadores de sua integração com o negócio são cruciais para otimizar resultados no uso dos sistemas (Teo, 2009). De acordo com Davis, Bagozzi, \& Warshaw (1989) para melhor prever, explicar e incrementar a aceitação pelo usuário, precisa-se compreender as razões pelas quais as pessoas aceitam ou rejeitam sistemas.

Sendo assim, este trabalho versará sobre o uso de sistemas que utilizam técnicas analíticas em empresas do setor de serviços, avaliando um cenário em que a quantidade de dados cresce exponencialmente ao longo dos anos. Para a análise será utilizado um modelo ECT Expectation-Confirmation Theory (Bhattacherjee, 2001a, 2001b) adaptado pelo autor. 


\subsection{PROBLEMA DO ESTUDO}

A partir da contextualização apresentada na introdução deste trabalho, formula-se então a situação-problema: Quais os fatores influentes na utilização de ferramentas de Business Intelligence e Analytics por empresas de serviços e sua relação com as estratégias de negócios?

\subsubsection{OBJETIVOS DO ESTUDO}

Com base nas respostas da pesquisa feita com as empresas de serviços, pretende-se:

Verificar como as empresas de serviços fazem uso de ferramentas de Business Intelligence e Analytics e sua relação com a estratégia da companhia;

Identificar condições facilitadoras da utilização das técnicas de análise;

Levantar quais fatores influenciam o comportamento de uso das ferramentas Business Intelligence e Analytics.

\subsection{JUSTIFICATIVA DO TRABALHO}

A justificativa da escolha do tema deste trabalho pode ser compreendida em termos de relevância, originalidade e viabilidade.

\subsubsection{RELEVÂNCIA DO TEMA}

Segundo o relatório Siemens (2014), a capacidade de todos os data centers do mundo em 2002 era de 1 petabyte (equivalente a $10^{15}$ bytes); em 2014 apenas os data centers da Siemens possuíam uma capacidade de armazenamento de 11 Petabyte; estimativas apontam que o volume de informações armazenadas atinja, em 2020, 40 zettabytes (equivalente a $10^{21}$ bytes). De acordo com Manyika, Chui, Brown, Bughin, Dobbs, Roxburgh, \& Byers (2011), uma boa utilização do Big Data traz valor para as corporações de diferentes formas:

- Cria transparência, tornando os dados acessíveis aos Stakeholders 
- Permite avaliar indicadores da operação de forma a otimizar os processos

- Segmenta a população para ações customizadas

- Auxilia na decisão humana com algoritmos automatizados

- Permite inovações nos modelos de negócio, produtos e serviços.

O desafio das empresas é transformar esse grande volume de dados em informações úteis para a tomada de decisões da empresa, sendo que a utilização de ferramentas que avaliam o grande volume de dados existentes é de vital importância para o negócio de uma companhia. Shmueli \& Koppius (2011) apontam que a análise de dados possui dois papéis: análise explanatória que é aquela que visa entender porque um fenômeno ocorre e análise preditiva que procura prever comportamentos futuros.

De acordo com a revista Melhores e Maiores (Exame, 2017), no fechamento de 2016, o volume de vendas das 50 maiores empresas de serviços, que atuavam no Brasil, foi da ordem de $\mathrm{R} \$ 445$ bilhões. Devido à importância desse segmento no cenário econômico brasileiro e à relevância das ferramentas de análise no dia-a-dia das companhias de serviços, vem o interesse de se investigarem as práticas analíticas adotadas nesse mercado.

\subsubsection{ORIGINALIDADE DO TEMA}

Na literatura pesquisada, foram encontrados alguns trabalhos que abordam a utilização de sistemas de Business Intelligence em empresas (Grubljesic \& Jaklic, 2015; Han, Shen, \& Farn, 2016; Hou, 2014a, 2014b, 2016; Oei, 2014); outros trabalhos pesquisam sobre fatores que direcionam a estratégia da empresa (Gatignon \& Xuereb, 1997; Gebauer, Gustafsson, \& Witell, 2011; Hakala, 2011; Hakala \& Kohtamäki, 2011; Mu \& Di Benedetto, 2011). A contribuição deste trabalho é considerar simultaneamente as duas linhas de pesquisa, com o ineditismo de analisar o mercado brasileiro com enfoque no segmento de serviços, com a participação de empresas que têm atuação nacional. 


\subsubsection{VIABILIDADE DO TRABALHO}

A maior dificuldade para realização deste trabalho foi o acesso aos respondentes; o autor contatou alguns líderes de empresas do mercado de serviços para solicitar acesso aos funcionários das respectivas empresas e sua participação como respondentes na pesquisa desde que se adequassem ao perfil pré-estabelecido. Devido ao perfil específico, a coleta de dados durou um pouco mais que o cronograma inicialmente planejado; os questionários foram respondidos de forma online em um intervalo de quatro meses e meio.

\subsection{HIPÓTESES DO ESTUDO}

Considerando os objetivos da pesquisa, apresentados no item 1.1.1, estabeleceram-se as seguintes hipóteses, que foram testadas nesta tese:

H1: A Estratégia direcionada pela Tecnologia influencia de forma positiva a Utilidade Percebida.

H2: A Qualidade da Informação influencia de forma positiva a Utilidade Percebida.

H3: Confirmação afeta de forma positiva a Utilidade Percebida.

H4: Confirmação afeta de forma positiva a Satisfação.

H5: A Utilidade Percebida tem efeito positivo na Satisfação.

H6: A Utilidade Percebida impacta de forma positiva a Intenção Comportamental de Uso.

H7: Satisfação tem impacto positivo na Intenção Comportamental de Uso.

H8: Satisfação influencia de forma positiva o Hábito.

H9: A Intenção Comportamental de Uso afeta de forma positiva a Continuidade de Uso.

H10a: O Hábito tem efeito moderador na relação entre Intenção Comportamental de Uso e Continuidade de Uso.

H10b: O Hábito tem efeito positivo na Continuidade de Uso. 


\subsection{ORGANIZAÇÃO DOS CAPÍTULOS}

Após este capítulo introdutório, que contextualiza o estudo, o capítulo 2 faz uma revisão bibliográfica para suportar os propósitos teóricos deste trabalho. Versa sobre Business Intelligence, Big Data, Mercado de Serviços e Estratégia.

O capítulo 3 aborda os modelos de aceitação de tecnologia, explicando sua evolução, conceitos e apresentando o framework adotado nesta pesquisa. Na sequência, o capítulo 4 apresenta os aspectos metodológicos: amostra, instrumento de pesquisa e análises estatísticas utilizadas.

O capítulo 5 discute os resultados obtidos com os dados da pesquisa e finalmente, o capítulo 6 , apresenta conclusões, limitações e sugestões para futuros trabalhos.

A Figura 3, na sequência, mostra como os capítulos subsequentes se interligam com o problema em estudo

Figura 3:Ligação dos capítulos com o problema em estudo.

\begin{tabular}{|c|c|c|c|c|c|}
\hline $\begin{array}{l}\text { Pergunta } \\
\text { Problema }\end{array}$ & $\begin{array}{l}\text { Capítulo } 2 \\
\text { Revisão } \\
\text { Bibliográfica }\end{array}$ & $\begin{array}{l}\text { Capítulo } 3 \\
\text { Modelos de } \\
\text { Aceitação de } \\
\text { Tecnologia }\end{array}$ & $\begin{array}{l}\text { Capítulo } 4 \\
\text { Aspectos } \\
\text { Metodológicos }\end{array}$ & $\begin{array}{l}\text { Capítulo } 5 \\
\text { Análise de Dados }\end{array}$ & $\begin{array}{l}\text { Capitulo } 6 \\
\text { Conclusões }\end{array}$ \\
\hline $\begin{array}{l}\text { Quais os fatores } \\
\text { influentes na } \\
\text { utilização de } \\
\text { ferramentas de } \\
\text { Business } \\
\text { Intelligence e } \\
\text { Analytics por } \\
\text { empresas de } \\
\text { serviços e sua } \\
\text { relação com as } \\
\text { estratégias de } \\
\text { negócios? }\end{array}$ & $\begin{array}{l}\text { Baseado nos } \\
\text { elementos da } \\
\text { pergunta } \\
\text { problema, será } \\
\text { feita a revisão dos } \\
\text { seguintes tópicos: } \\
\text { Business } \\
\text { Intelligence e } \\
\text { Analytics, Big Data } \\
\text { (subitem de BI) } \\
\text { Empresas de } \\
\text { Serviços, } \\
\text { Estratégia }\end{array}$ & $\begin{array}{l}\text { Visto que para } \\
\text { responder a } \\
\text { pergunta problema } \\
\text { será adotado um } \\
\text { modelo de aceitação } \\
\text { de tecnologia, o } \\
\text { capítulo abordará os } \\
\text { principais existentes }\end{array}$ & $\begin{array}{l}\text { Esse capítulo } \\
\text { versa sobre } \\
\text { quais } \\
\text { ferramentas } \\
\text { foram utilizadas } \\
\text { para a obtenção } \\
\text { dos dados e } \\
\text { explana sobre as } \\
\text { técnicas de } \\
\text { análise adotadas }\end{array}$ & $\begin{array}{l}\text { Após a adoção do } \\
\text { modelo } \\
\text { apresentado no } \\
\text { capítulo 3, com a } \\
\text { posterior utilização } \\
\text { das técnicas de } \\
\text { análise } \\
\text { apresentadas no } \\
\text { capítulo 4, os } \\
\text { resultados obtidos } \\
\text { são apresentados e } \\
\text { analisados. }\end{array}$ & $\begin{array}{l}\text { Apresentação } \\
\text { das análises, } \\
\text { comentários } \\
\text { finais, } \\
\text { limitações e } \\
\text { propostas para } \\
\text { novos estudos }\end{array}$ \\
\hline
\end{tabular}

Fonte: Autor 


\section{REVISÃO DA LITERATURA}

Este capítulo apresenta a revisão bibliográfica que serve como base de fundamentação teórica para o desenvolvimento desta pesquisa. Os tópicos abordados neste capítulo serão:

- Business Intelligence e Analytics

- Big Data

- Setor de Serviços

- Competição no Setor de Serviços

- Estratégia de Negócios

- Estratégia em Serviços

- Orientadores da Estratégia

\subsection{BUSINESS INTELLIGENCE E ANALYTICS}

Empresas geram diariamente uma enorme quantidade de dados que podem conter padrões, relações, tendências e outras informações; no intuito de otimizar seu processo de decisão, as companhias cada vez mais buscam ferramentas que permitam transformar seus dados em informação e informação em decisão (Pejić Bach et al., 2016; Yoon, Ghosh, \& Jeong, 2014).

Business Intelligence (BI) pode ser definido como um conjunto de métodos e sistemas, utilizados para permitir a análise de informações históricas de uma empresa, com o intuito de direcionar estratégias das companhias a fim de incrementar lucros (Işik, Jones, \& Sidorova, 2013); para Grubljesic \& Jaklic (2015) BI é a habilidade da empresa em atuar de maneira efetiva, explorando seus recursos humanos e de informações. Alguns autores associam o termo BI a métodos computacionais de processamento de dados que os transformam em conhecimento e, posteriormente, em decisões para as instituições (Popovič, Hackney, Coelho, \& Jaklič, 2012).

De acordo com Turban, Sharda, Aronson, \& King (2009), as raízes do BI são provenientes da década de 1970 quando as empresas passaram a gerar relatórios - os Sistemas de Informações Gerenciais (SIG). Estes relatórios eram estáticos e bidimensionais e não possuíam recurso de análise. Na década seguinte surgiram os Sistemas de Informações Executivas (SIE), onde os 
relatórios passaram a ser dinâmicos e multidimensionais, com recursos de previsão, análise e tendências. Na década de 1990, o termo BI foi proposto pelo Gartner Group e dezenas de produtos comerciais surgiram, popularizando o conceito; na década seguinte, foram aperfeiçoadas as técnicas de análises permitindo a utilização de um grande volume de dados (Big Data).

Para entender como o BI se aplica no cotidiano de uma empresa, Turban, Sharda, Aronson, \& King (2009) propuseram um modelo chamado Pressões - Reações - Suporte do Negócio, conforme apresentado na Figura 4, a seguir.

Figura 4: Modelo Pressões - Reações - Suporte do Negócio

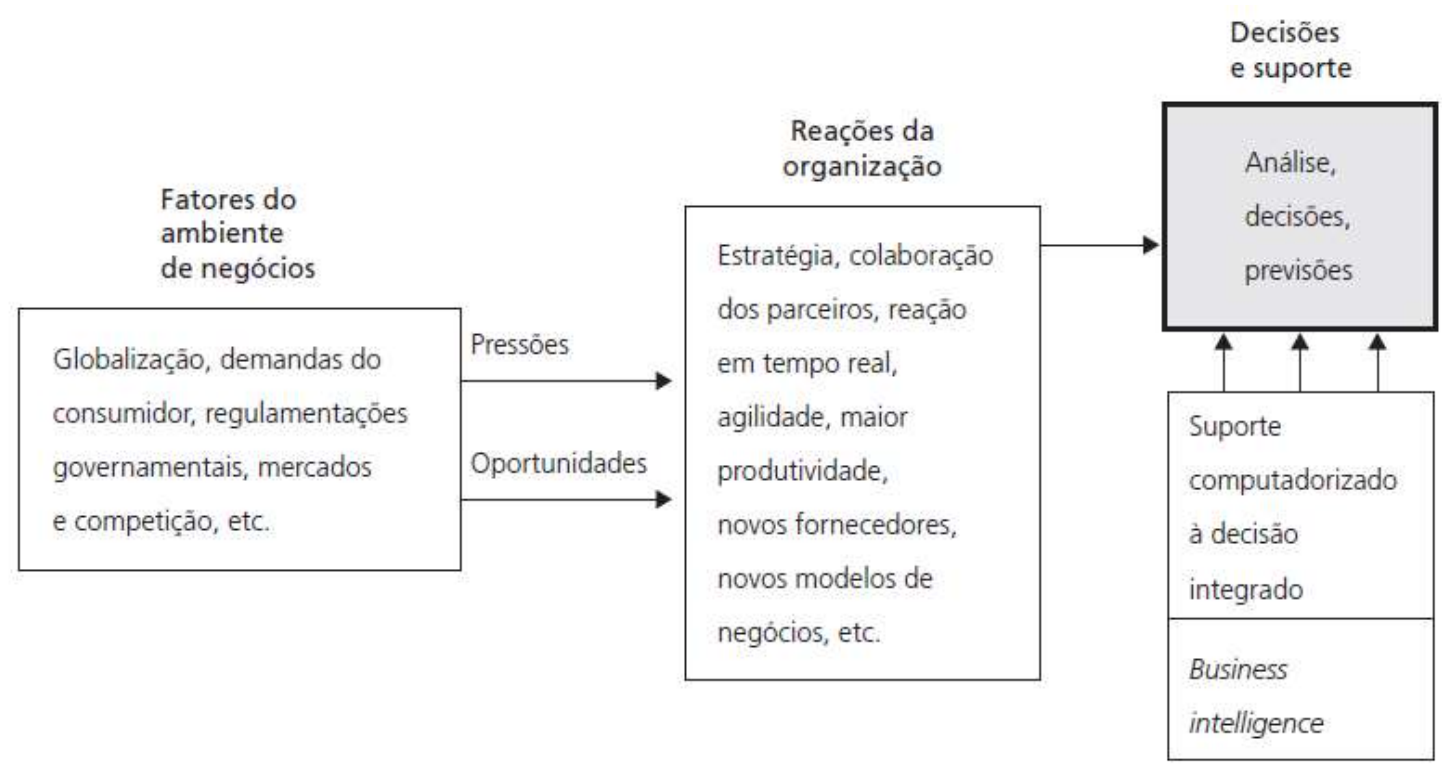

Fonte: Turban, Sharda, Aronson, \& King (2009)

Segundo os autores, a pressão advém da complexidade do ambiente em que as organizações operam; se, por um lado, a complexidade traz oportunidades, por outro, cria problemas. Tomando como exemplo a globalização, esta permite encontrar clientes e fornecedores em vários países, trazendo mais opções para a empresa; entretanto, a concorrência fica maior e mais forte; um agravante é que a intensidade desses fatores tende a aumentar com o tempo, gerando mais pressões. 
Nesse tipo de ambiente, os gestores devem tomar decisões rápidas e demonstrar inovação e agilidade. Os autores propõem algumas ações que podem ser adotadas para a "reação", a saber:

- Emprego de planejamento estratégico

- Uso de modelos de negócios novos e inovadores

- Reestruturação de processos de negócios

- Participação em alianças de negócios

- Aprimoramento dos sistemas de informações corporativos

- Aprimoramento das relações de parceria

- Incentivo à inovação e à criatividade

- Aprimoramento do serviço e relacionamentos com clientes

- Adoção do comércio eletrônico

- Adoção da manufatura sob encomenda e da produção e serviços sob demanda

- Uso de novas tecnologias de informação para melhorar a comunicação, o acesso aos dados e a colaboração

- Rápida reação às ações dos concorrentes, como em precificação, promoções e novos produtos e serviços

- Automatização de muitas tarefas do pessoal administrativo

- Automatização de certos processos de decisão, principalmente os que envolvem clientes

- Aprimoramento da tomada de decisões

Uma análise das ações propostas, revela que muitas delas, se não, todas, necessitam de suporte computadorizado. É nessa fase que entram os sistemas de BI, permitindo a consulta de informações em tempo real, criando análises ricas que permitam a condução das estratégias de negócio (Hou, 2016). Os usuários de sistemas de BI têm a possibillidade de tomar melhores decisões utilizando as informações certas (Han et al., 2016). Ziama \& Kasher (2004), apontam alguns exemplos de perguntas que podem ser respondidas com o auxílio de BI, conforme apresentado na Figura 5. 
Figura 5: Valor para o negócio das aplicações analíticas de BI

\begin{tabular}{|c|c|c|}
\hline $\begin{array}{l}\text { Aplicação } \\
\text { analítica }\end{array}$ & Pergunta de negócios & Valor para o negócio \\
\hline $\begin{array}{l}\text { Segmentação } \\
\text { dos clientes }\end{array}$ & $\begin{array}{l}\text { Em quais segmentos de mercado } \\
\text { meus clientes se encaixam e } \\
\text { quais são suas características? }\end{array}$ & $\begin{array}{l}\text { Personalizar os relacionamentos } \\
\text { com clientes para obter maior } \\
\text { satisfação e retenção destes. }\end{array}$ \\
\hline $\begin{array}{l}\text { Propensão à } \\
\text { compra }\end{array}$ & $\begin{array}{l}\text { Quais clientes são mais } \\
\text { propensos a responderem à } \\
\text { minha promoção? }\end{array}$ & $\begin{array}{l}\text { Visar os clientes com base nas } \\
\text { necessidades que eles têm de } \\
\text { aumentar a fidelidade à sua linha de } \\
\text { produtos. } \\
\text { Aumentar também a lucratividade } \\
\text { da promoção enfocando quem tem } \\
\text { mais possibilidades de comprar. }\end{array}$ \\
\hline $\begin{array}{l}\text { Lucratividade } \\
\text { dos clientes }\end{array}$ & $\begin{array}{l}\text { Qual é a lucratividade vitalícia } \\
\text { de meu cliente? }\end{array}$ & $\begin{array}{l}\text { Tomar decisões individuais de } \\
\text { interação de negócios com base na } \\
\text { lucratividade geral dos clientes. }\end{array}$ \\
\hline $\begin{array}{l}\text { Detecção de } \\
\text { fraudes }\end{array}$ & $\begin{array}{l}\text { Como posso saber quais } \\
\text { transações provavelmente serão } \\
\text { fraudulentas? }\end{array}$ & $\begin{array}{l}\text { Determinar a fraude com rapidez e } \\
\text { agir imediatamente para minimizar } \\
\text { os custos. }\end{array}$ \\
\hline $\begin{array}{l}\text { Perda de } \\
\text { clientes }\end{array}$ & Qual cliente está a ponto de sair? & $\begin{array}{l}\text { Evitar a perda de clientes de grande } \\
\text { valor e abandonar os de menor } \\
\text { valor. }\end{array}$ \\
\hline $\begin{array}{l}\text { Otimização do } \\
\text { canal }\end{array}$ & $\begin{array}{l}\text { Qual é o melhor canal para } \\
\text { chegar a meu cliente em cada } \\
\text { segmento? }\end{array}$ & $\begin{array}{l}\text { Interagir com os clientes com base } \\
\text { nas preferências deles e em sua } \\
\text { necessidade de gerenciar os custos. }\end{array}$ \\
\hline
\end{tabular}

Fonte: Ziama \& Kasher (2004)

Na primeira década do século XXI, o BI penetrou em vários segmentos da economia tais como finanças, telecomunicações, seguros, bancos, manufatura e comércio (Ramakrishnan, Jones, \& Sidorova, 2012); muitas empresas desses segmentos conseguiram aumentar a lealdade de seus clientes e, consequentemente aumentar seus lucros. Segundo Turban, Sharda, Aronson, \& King (2009), as organizações passaram a obter mais valor do BI ao estender as informações existentes a muitos funcionários, maximizando o ativo de dados existentes. Ainda segundo esses autores, pesquisas e projeções apontam que a tendência é que cada vez mais pessoas utilizem ferramentas de BI. Dentro do conceito de BI, há o conceito de Analytics (Payandeh, 2013) ou 
também chamado de Business Analytics, que se refere ao foco mais estatístico da apreciação dos dados, segundo Davenport (2006), representando o componente analítico chave de BI.

Estatística se inicia com a obtenção de dados (Breiman, 2001); esses dados são analisados de forma a se obterem resultados. De acordo com Troilo, Bouchet, Urban, \& Sutton (2016), a coleta de dados é o insumo inicial para as análises, enquanto as análises podem direcionar futuras fontes para novas coletas de dados. No cenário de Analytics, existem dois modelos principais na análise de dados (Breiman, 2001): modelos explanatórios e modelos preditivos.

De acordo com Shmueli \& Koppius (2011), desejavelmente todos os modelos devem ser explanatórios e preditivos; contudo, na prática é mais adequado separar esses dois objetivos pois, embora esses objetivos não sejam mutuamente excludentes, pode haver tensão entre eles. O melhor modelo explanatório quase sempre difere do melhor modelo preditivo (Forster, 2002; Shmueli, 2010); modelos que tentam buscar os dois objetivos comprometem de alguma forma os resultados (Shmueli, 2010).

Modelos explanatórios são aqueles que buscam, quase que exclusivamente, por meio de análises estatísticas, comprovar uma teoria ou hipótese (Shmueli, 2010), sendo muito usados em ciências sociais. Um modelo explanatório explica como, porque e quando algo acontece (Gregor, 2006); são utilizados para aumentar a compreensão do fenômeno de interesse.

Por outro lado, modelos preditivos são um processo em que se aplicam técnicas estatísticas com o objetivo de prever novos ou futuros acontecimentos (Shmueli, 2010). Um modelo preditivo é aquele que aponta o que pode acontecer no futuro se algumas pré-condições estabelecidas se mantiverem, havendo uma probabilidade associada à ocorrência da previsão (Gregor, 2006); Forster (2002) advoga que o aumento da acurácia dos modelos preditivos é um dos objetivos principais da ciência.

Na Figura 6, a seguir, Shmueli \& Koppius (2011) apontam as principais diferenças entre estes dois tipos de modelo. 
Figura 6: Diferenças entre Modelos Explanatórios e Modelos Preditivos

\begin{tabular}{|l|l|l|}
\hline & Modelos Explanatórios & Modelos Preditivos \\
\hline Objetivo & Testar hipóteses & Prever comportamentos futuros \\
\hline Variáveis & $\begin{array}{l}\text { Variáveis que permitam o } \\
\text { entendimento dos constructos e a } \\
\text { relação entre eles }\end{array}$ & $\begin{array}{l}\text { Variáveis observáveis e } \\
\text { mensuráveis }\end{array}$ \\
\hline $\begin{array}{l}\text { Função que } \\
\text { otimiza a } \\
\text { construção } \\
\text { do modelo }\end{array}$ & $\begin{array}{l}\text { Minimizar erros do modelo, } \\
\text { diminuir erros tipo I e tipo II }\end{array}$ & $\begin{array}{l}\text { Evitar overfitting (modelo } \\
\text { estatístico se ajusta demais ao } \\
\text { conjunto de dados, não sendo útil } \\
\text { para replicação) }\end{array}$ \\
\hline $\begin{array}{l}\text { Restrições } \\
\text { para } \\
\text { Construção }\end{array}$ & $\begin{array}{l}\text { Modelos devem ser } \\
\text { interpretáveis, suportar as } \\
\text { hipóteses de interesse }\end{array}$ & $\begin{array}{l}\text { Devem ser utilizadas variáveis } \\
\text { disponíveis no momento do } \\
\text { desenvolvimento do modelo }\end{array}$ \\
\hline $\begin{array}{l}\text { Avaliação do } \\
\text { Modelo }\end{array}$ & $\begin{array}{l}\text { Testes estatísticos (como, por } \\
\left.\text { exemplo, R }{ }^{2}\right)^{2}\end{array}$ & $\begin{array}{l}\text { Avaliação de performance em um } \\
\text { outro conjunto de dados (amostra } \\
\text { de validação) }\end{array}$ \\
\hline
\end{tabular}

Fonte: Shmueli \& Koppius (2011)

Chen et al. (2012) cunham o termo Business Intelligence e Analytics (BI\&A) e apontam que a popularidade deste, relacionado ao conceito de Big Data, aumentou tanto no campo acadêmico quanto nas empresas ao longo das duas primeiras décadas do século XXI. Esses mesmos autores defendem que se está entrando na terceira geração de BI\&A. Eles definem as três fases como BI\&A 1.0, BI\&A 2.0 e BI\&A 3.0.

- Business Intelligence e Analytics 1.0 (BI\&A 1.0)

É o mais largamente utilizado no mercado, trabalha com dados estruturados, provenientes de sistemas legados das empresas. Foi popularizado na década de 1990 sendo que utiliza principalmente técnicas estatísticas desenvolvidas nos anos 1970 e métodos de mineração de dados desenvolvidos na década de 1980.

\footnotetext{
${ }^{1}$ Em Estatística, o erro tipo I consiste em rejeitar a hipótese nula quando esta é verdadeira; esse erro também é conhecido como falso positivo; a probabilidade de este erro ocorrer é representada por $\alpha$ (Pestana \& Gageiro, 2008). O erro tipo II consiste em não rejeitar a hipótese nula dado que ela é falsa, cuja probabilidade é representada por $\beta$ (Norusis, 2011).

${ }^{2} \mathrm{O} \mathrm{R}^{2}$, chamado de coeficiente de determinação, é uma medida de ajuste de modelos estatísticos. Seus valores variam de 0 a 1 e quanto mais próximo de 1 maior a precisão do modelo e sua capacidade de explicação dos dados (Lapponi, 2005).
} 
$\mathrm{O}$ armazenamento e gerenciamento das bases de dados são a sustentação do BI\&A 1.0. O desenvolvimento de ferramentas de extração, transformação e carga dos dados, conhecido como ETL (extraction, transformation and load) é essencial para a integração dos dados. Gráficos são utilizados para explorar as características da base de dados, relatórios e dashboards auxiliam no monitoramento do negócio, adicionalmente técnicas estatísticas e de mineração de dados são utilizadas para segmentação, análise de regressão, análise de conglomerados e detecção de anomalias.

- Business Intelligence e Analytics 2.0 (BI\&A 2.0)

No começo dos anos 2000, a popularização da internet trouxe novas fontes de dados que permitiram novas oportunidades de negócio. Sítios de busca, como Yahoo e Google ou de comércio eletrônico como Amazon ou Ebay permitem a apresentação online com os clientes e a interação é direta. Essa nova realidade descobriu uma nova "mina de ouro" no entendimento das necessidades dos clientes e exploração de novas formas de negócio.

A era do BI\&A 2.0 está centrada em análise de texto e análise de conteúdos não estruturados da web. A análise do comportamento de "cliques" do cliente revela seu perfil e comportamento de compra. A expansão das redes sociais, a partir de 2004, permitiu uma compreensão maior do indivíduo por meio da análise dos fóruns, $b \log s$, grupos, sítios multimídia (fotos e vídeos).

- Business Intelligence e Analytics 3.0 (BI\&A 3.0)

Enquanto a era do BI\&A 2.0 atrai muitos pesquisadores da academia e da indústria, o BI\&A 3.0 vem emergindo na década de 2010. Essa nova era é baseada em dispositivos pessoais acessando a internet, como tablets e smartphones. Esses dispositivos centralizam o acesso à internet e o fazem em tempo real. De acordo com Chen et al. (2012), o número de dispositivos pessoais com acesso à internet superou o número de computadores pessoais e laptops pela primeira vez em 2011. A estimativa é que estes dispositivos cheguem a 10 bilhões em 2020. Além disso, outros dispositivos pessoais como relógios, GPS, sensores, códigos de barra podem transmitir dados.

A Figura 7, a seguir resume estas três eras do BI\&A. 
Figura 7: As três eras do BI\&A

\begin{tabular}{|l|l|l|}
\hline BI\&A 1.0 & BI\&A 2.0 & BI\&A 3.0 \\
\hline $\begin{array}{l}\text { Informações internas das } \\
\text { empresas estruturadas e }\end{array}$ & $\begin{array}{l}\text { Conteúdo baseado em } \\
\text { informações não- } \\
\text { controladas }\end{array}$ & $\begin{array}{l}\text { Conteúdo baseado em } \\
\text { dispositivos móveis e } \\
\end{array}$ \\
\hline
\end{tabular}

Fonte: Chen et al. (2012)

\section{$2.2 B I G D A T A$}

A evolução dos computadores, principalmente a partir da década de 1970, permitiu o aumento da velocidade de processamento e maior capacidade de armazenamento de dados (Hamann, 2016). Além disso, a proliferação da internet cria vasta informação nova de forma muito veloz. Segundo Zikopoulos et al. (2012), no começo da década de 2010 o Twitter gerava 7 terabytes diários de informação, enquanto o Facebook por volta de $10 \mathrm{~Tb}$. Na mesma linha, Manyika et al. (2011) afirmam que 15 de 17 setores da economia norte-americana possuíam, em 2010, mais informação armazenada do que a biblioteca do Congresso Americano.

Big data pode ser definido como uma informação que é muito grande, muito veloz ou muito difícil de ser processada com as ferramentas existentes (Madden, 2012). O conceito de grande refere-se ao crescente volume de dados armazenados, veloz significa que os dados além de serem grandes devem ser processados de forma rápida; a dificuldade é apresentada, pois muitas vezes os dados não são estruturados. Na mesma linha, Laney (2001) foi o pioneiro em defender que o big data tem três características principais, o chamado modelo dos três V: Volume, Velocidade e Variedade.

Na questão de Volume, Dumbill (2012) define que o principal ganho proporcionado pelo conceito big data é trazer mais dados para a análise, permitindo a construção de modelos analíticos melhores. Por outro lado, muitos dados representam um grande desafio para as áreas de tecnologia da informação em termos de armazenamento, integração e disponibilidade (Vitolo, Elkhatib, Reusser, Macleod, \& Buytaert, 2015). Muitas empresas conseguem guardar um grande volume de dados, porém, não são capazes de processá-los (Dumbill, 2012).

A importância da Velocidade pode ser observada num processo de compra online (Dumbill, 2012): antes mesmo de um pedido ser fechado o portal de compras já consegue avaliar sua solicitação e sugerir produtos ao comprador. Velocidade implica quão rapidamente as 
informações são coletadas, armazenadas e utilizadas na tomada de decisão (Zikopoulos et al., 2012).

Esta grande quantidade de dados vem de diferentes fontes, com periodicidades diversas e formatos distintos (Laney, 2001); o desafio nessa Variedade, é fazer a integração de forma a convergirem todos os dados. Raramente os dados recebidos de fontes diversas apresentam a mesma estrutura, ordenados e prontos para serem processados, fato que resulta em situações complicadas (Dumbill, 2012; Wu et al., 2014), que é onde reside boa parte das dificuldades de implantação de um big data numa empresa.

As características do Big Data podem ser resumidas no acrônimo HACE sugerido por Wu et al. (2014); pois, de acordo com os autores, o Big Data se inicia com um grande volume de dados, Heterogêneo, de fontes Autônomas distribuídas e descentralizadas, Complexas e Envolvendo relações entre elas. Essas características tornam extremamente desafiador extrair conhecimento útil dos dados. Os autores fazem uma analogia com um grupo de cegos tentando identificar um elefante, conforme apontado na Figura 8.

Figura 8: Cegos e o Elefante, a visão parcial de cada cego leva a conclusões enviesadas

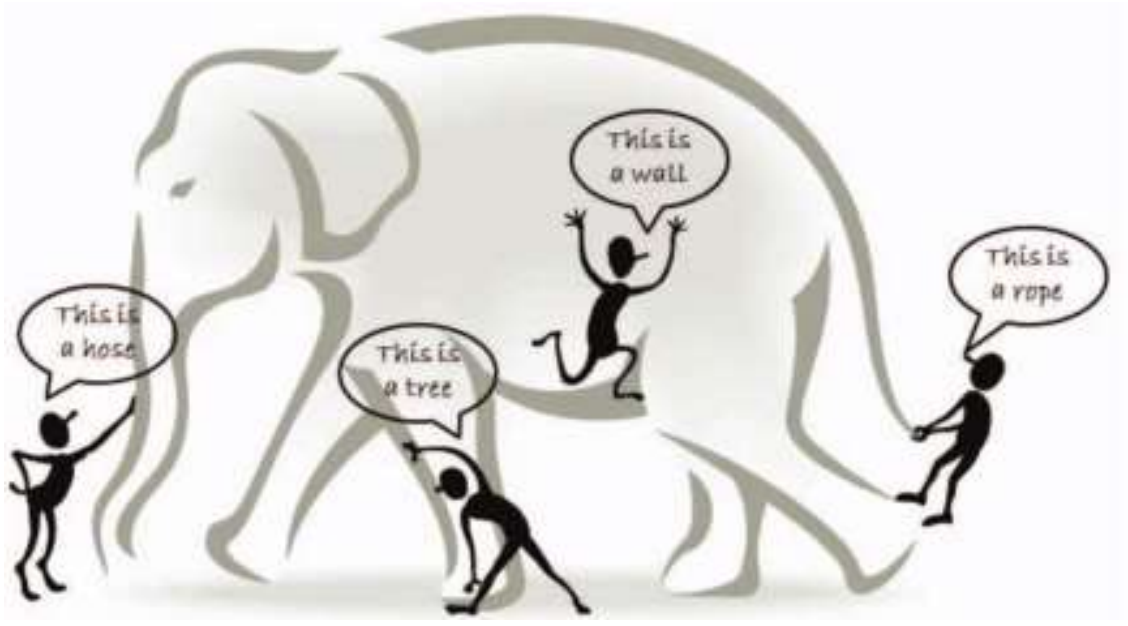

Fonte: Wu, Zhu, Wu, \& Ding (2014)

Da mesma forma que é difícil “enxergar”, o elefante, no Big Data é complexo analisar todos os dados, e uma visão parcial pode trazer conclusões errôneas. Para tornar o problema ainda mais complicado, o "elefante" cresce constantemente e se modifica e cada "cego" tira suas próprias conclusões. A chave para solucionar esse problema é unir a informação dos vários “cegos" para fazer o melhor desenho possível do elefante. 
Esse cenário traz oportunidades para as empresas. Conforme Brown, Chui, \& Manyika (2011), estudos apontam que companhias que utilizam bases de dados e ferramentas analíticas na tomada de decisão apresentam melhores resultados do que companhias que não as utilizam. As mudanças na empresa se dão na transformação dos processos, alteração do ecossistema interno e maiores oportunidades de inovação. Na visão de Biesdorf, Court, \& Willmott (2013) o planejamento para introdução do conceito de big data em uma empresa deve abordar três vertentes principais:

1. Dados: O plano deve prever como coletar e integrar dados de diversas fontes, bem como armazenar histórico para análises futuras.

2. Modelos analíticos: Os dados sozinhos não geram valor. Os modelos analíticos ajudam a entender o contexto dos dados, desenhar cenários e fazer previsões.

3. Ferramentas: Nesse passo é importante fazer com que os resultados obtidos nos modelos analíticos sejam incorporados no dia-a-dia da organização. Segundo os autores, essa é uma falha muito comum nas empresas - não conseguir fazer com que os gestores e funcionários compreendam os resultados obtidos da análise e atuem de maneira rápida e eficiente.

Manyika et al. (2011) realizaram uma pesquisa com diversas indústrias nos mercados europeu e norte-americano e chegaram a sete conclusões principais:

I. Big Data está em todos os setores da Economia e é parte importante da cadeia de produção para as empresas;

II. Big Data cria valor de diversas formas; os autores citam como exemplo: aumentar a transparência visto que os dados são acessíveis aos stakeholders, automatizar decisões, permitir inovações em produtos e serviços, entre outros;

III. A utilização do Big Data se tornou a chave da competitividade e crescimento para as empresas;

IV. Permite aumentar as margens das empresas e a satisfação dos clientes;

V. Ainda que a adoção do Big Data seja importante para todos os setores, alguns são mais propícios a ter ganhos maiores;

VI. É necessário um bom conhecimento estatístico-analítico para extrair mais vantagens;

VII. As empresas buscam aumentar suas fontes de informação para alimentar o Big Data.

Conforme mencionado anteriormente, nesse cenário de Big Data a análise passa a ter um papel muito importante. Por essa razão, o conceito de Business Intelligence e Analytics vem ganhando destaque no século XXI (Wu et al., 2014). 


\subsection{SETOR DE SERVIÇOS}

$\mathrm{O}$ estudo do desenvolvimento das economias dirige-se amplamente à análise do setor de Serviços, tendo em vista que, de forma cada vez mais intensa, a representatividade considerável dos custos de produção de todas as atividades deve-se a insumos de serviços (Lugli, 2015; Negri, Kubota, \& Silva, 2006). A definição de serviços é uma tarefa árdua, pois incorpora uma grande variedade de atividades (Melo, Frederico, Rocha, Sabbato, Di, Dweck, \& Gomes 1997). De acordo com Melo, Rocha, Sabbato, Di, \& Dweck (1998), uma definição usualmente aceita diferencia os serviços de outros bens derivados da produção industrial e agrícola pelo fato de aqueles serem consumidos tal como produzidos e resultantes de um processo no qual produção e consumo são coincidentes no tempo e espaço. Assim, os serviços se caracterizariam pela circunstância de serem intangíveis, intransferíveis, não-estocáveis e apresentarem contato direto entre produtores e consumidores.

Meirelles (2006) destaca que, na visão contemporânea, há três características que distinguem os serviços das demais atividades econômicas, a saber: fluxo, variedade e uso intensivo de recursos humanos. O fluxo refere-se às propriedades de simultaneidade e de continuidade do processo de prestação do serviço. O processo inicia-se com uma solicitação do usuário, de modo que o serviço acontece sob a forma de fluxo contínuo no tempo e no espaço. A variedade está associada às diferentes técnicas produtivas e à diversidade na margem de lucro das empresas prestadoras de serviço. Por fim, o uso intensivo de recursos humanos está relacionado ao fato de que, embora haja a utilização de máquinas e equipamentos, os recursos humanos são o fator produtivo mais importante no processo de prestação de serviço, visto que serviço é uma atividade interativa e relacional.

Como a definição de serviços abrange uma gama de atividades distintas, o relatório SEBRAE (2008) e Melo et al. (1997) propõem a seguinte divisão:

a) Serviços produtivos: atividades intermediárias que as empresas realizam durante o processo produtivo, como serviços financeiros, jurídicos, de informática, engenharia, auditoria, consultoria, propaganda e publicidade, seguro e corretagem;

b) Serviços distributivos: englobam as atividades efetuadas pelas empresas após o término do processo produtivo, como transporte, comércio, armazenagem e comunicação;

c) Serviços sociais: aqueles realizados para a sociedade, entre os quais a administração pública, defesa e segurança nacional, saúde e educação, associações de classe; 
d) Serviços pessoais: atividades realizadas para atender à demanda individual, como hotelaria, bares e restaurantes, lazer, reparação, vigilância, limpeza, higiene pessoal.

Por outro lado, Bryson, Daniels, \& Warf (2013) fazem uma classificação diferente para segmentar os serviços, a saber:

a) Serviços Financeiros, Securitários e Imobiliários;

b) Serviços administrativos - engenharia, arquitetura, serviços legais, pesquisa e desenvolvimento, contabilidade e consultorias;

c) Serviços de transporte e comunicação;

d) Serviços intermediários entre produtores e consumidores - serviços de bar e restaurantes, manutenção e reparo;

e) Entretenimento e hotéis;

f) Governo - serviços públicos em geral;

g) Agências sem fins lucrativos - fundações, igrejas e museus entre outros, que têm um papel muito importante em diversas economias.

Desde 1965 (Tabela 1), presencia-se a maior migração de mão-de-obra a partir da revolução industrial (Fitzsimmons \& Fitzsimmons, 2014). A migração da agricultura e da manufatura decorre da expansão das comunicações globais e aumento do uso da tecnologia. No mundo globalizado, núcleos setoriais se reúnem em busca de soluções comuns para se tornarem mais competitivos (SEBRAE, 2008). Isso implica diminuições de oportunidades de empregos nos setores agrícola e industrial. 
Tabela 1: Porcentagem de empregos no setor de serviços nas 10 maiores nações pós-industriais (1965-2012)

\begin{tabular}{|l|c|c|c|c|c|c|}
\hline País & 1965 & 1975 & 1985 & 1995 & 2005 & 2012 \\
\hline Estados Unidos & 59,5 & 66,4 & 70,0 & 74,1 & 78,6 & 81,2 \\
\hline Reino Unido & 51,3 & 58,3 & 64,1 & 71,4 & 77,0 & 81,2 \\
\hline Holanda & 52,5 & 60,9 & 68,3 & 73,4 & 76,5 & 81,1 \\
\hline Suécia & 46,5 & 57,7 & 66,1 & 71,5 & 76,3 & 79,2 \\
\hline Canadá & 57,8 & 65,8 & 70,6 & 74,8 & 76,0 & 78,6 \\
\hline Austrália & 54,6 & 61,5 & 68,4 & 73,1 & 75,8 & 77,7 \\
\hline França & 43,9 & 51,9 & 61,4 & 70,0 & 74,8 & 76,5 \\
\hline Japão & 44,8 & 52,0 & 57,0 & 61,4 & 68,6 & 71,5 \\
\hline Alemanha & 41,8 & $\mathrm{n} / \mathrm{a}$ & 51,6 & 60,8 & 68,5 & 71,6 \\
\hline Itália & 36,5 & 44,0 & 55,3 & 62,2 & 65,5 & 69,8 \\
\hline
\end{tabular}

Fonte: Elaborado pelo autor com os dados extraídos de Fitzsimmons \& Fitzsimmons (2014) e Bureau of Labor Statistics (n.d.)

Essa migração de empregos apontada na Tabela 1 se deu, de acordo com Kon (2007), porque na década de 1970 houve uma mudança no paradigma produtivo, tornando o sistema de produção flexível com a eliminação gradativa da integração vertical, externalizando atividades de serviços que não constituem o foco central do processo produtivo. Dessa forma, segue a autora, o paradigma fordista, da firma como organização, passa a dar lugar a uma organização de firmas, enquanto economias de escala internas passam a dar lugar às economias de escala externas.

Bryson et al. (2013) apontam seis razões para o crescimento do setor de serviços ao longo dos anos:

1. Aumento da renda - $\mathrm{O}$ crescimento da renda aumenta a demanda por serviços como transporte e entretenimento; o tempo passa a ser um bem valioso e as pessoas também passam a utilizar profissionais para as atividades domésticas (Chand, n.d.) como limpar, cozinhar e pequenos consertos domésticos. Na década de 1990, o gasto da família com serviços pela primeira vez ultrapassou o dispêndio com bens duráveis e não-duráveis. 
2. Demanda por serviços de saúde e educação - A maior expectativa de vida, nos países mais desenvolvidos (América do Norte, Europa e Japão), trouxe uma necessidade maior de consumo de serviços de saúde; além disso, uma necessidade de profissionais mais qualificados, especialmente nas áreas de informática e línguas, como pré-requisito para os empregos, fez aumentar a demanda no setor da educação.

3. Divisão do trabalho - $\mathrm{O}$ crescimento do setor de serviços e a expansão dos mercados força uma divisão do trabalho. Como exemplo, pode-se citar uma multinacional que atinge novos mercados. Há uma gama de leis trabalhistas, tributárias, contábeis e regulatórias que levam a empresa a contratar serviços especializados para se estabelecer no novo mercado. O mesmo cenário tem-se em casos de manutenção de máquinas. Por vezes, as empresas possuem um número muito grande de equipamentos de diversas formas de operação, não fazendo sentido para as mesmas manter um técnico para a manutenção de cada tipo de máquina, sendo mais viável contratar o serviço.

4. O tamanho e o papel do setor público - Mesmo o capitalismo pregando que o mercado deve ser independente do governo, esse último ainda é o maior ator na Economia, definindo tamanho de mercados, criando leis, construindo infraestrutura, regulando a quantidade de dinheiro no mercado. O setor público contribui de duas maneiras para a expansão do setor de serviços. A primeira é contratando diretamente serviços de limpeza, construção, manutenção, pintura, fornecimento de refeições entre outros. A segunda forma é indireta por meio de leis com restrições e regulamentações que, conforme mencionado no item anterior, geram a necessidade da contratação de advogados, especialistas tributários, contadores, consultores e outros especialistas em auxiliar firmas.

5. Expansão de comércio exterior - Com a facilidade das comunicações muitos serviços de consultoria são exportados/importados entre países. Muitas empresas e regiões têm a maior parte das suas receitas provenientes de serviços prestados no exterior. Grandes cidades como Londres, Nova York e Frankfurt exportam muitos serviços.

6. Externalização/Outsourcing de atividades - A última razão apontada pelos autores é a externalização de atividades das empresas. A partir dos anos 1980, as instituições iniciaram um processo de downsizing, reduzindo de tamanho, passando a focar em suas atividades-chave e externalizando atividades menos críticas. A ideia da externalização é produzir resultados melhores visto que é contratada uma empresa especializada (Rubalcaba \& Kox, 2007). 
A Figura 9, a seguir, baseada nos dados do World Fact Book (CIA, n.d.) mostra a distribuição do valor do PIB por setores nas dez maiores economias do planeta.

Figura 9: PIB - Composição por Setor de Origem - 2015

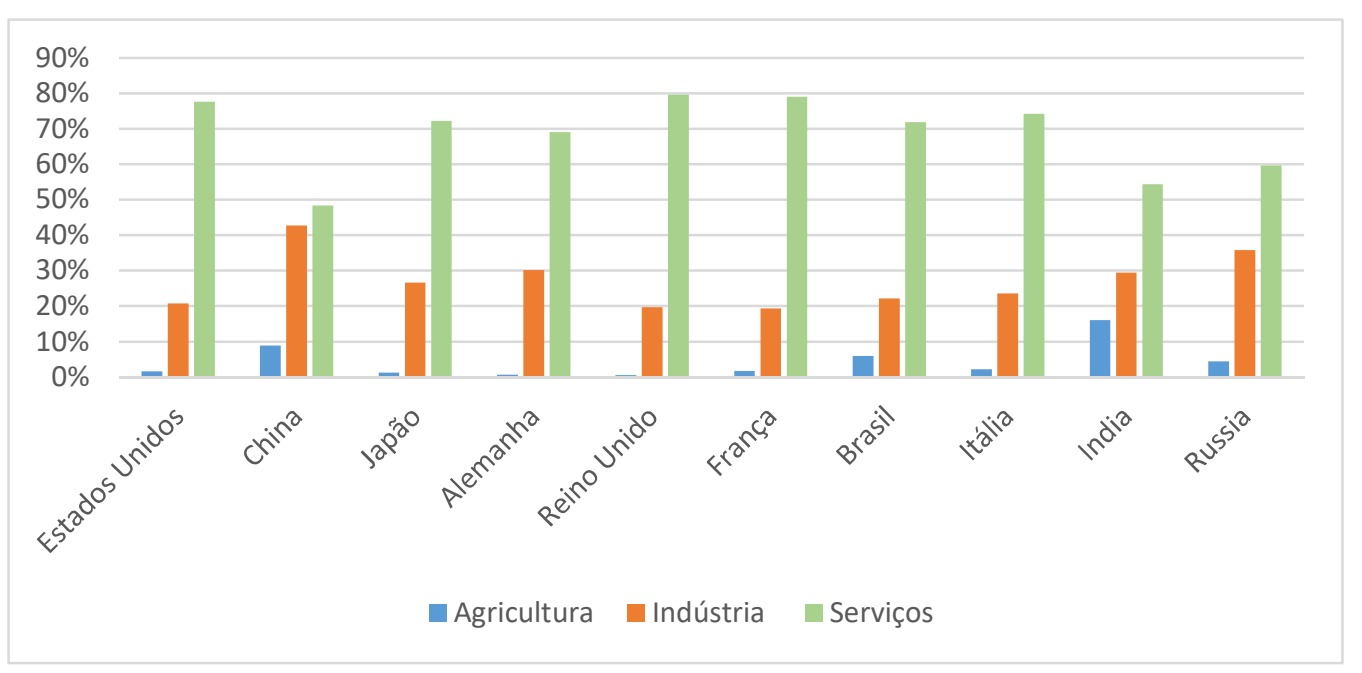

Fonte: World Fact Book (CIA, n.d.)

$\mathrm{Na}$ análise da Figura 9 nota-se que todos os países listados apresentam o setor de serviços como o mais importante na composição do PIB. Com exceção da China, nas maiores economias do mundo a contribuição do setor de serviços para o PIB é maior que a soma dos demais setores (agricultura e indústria); os Estados Unidos, Reino Unido e França têm quase $80 \%$ do PIB advindo de serviços.

No Brasil, entre as décadas de 1950 e 1980, o setor de serviços cresceu em segmentos de apoio às atividades industriais e agropecuárias (SEBRAE, 2008); a partir da década de 1980, quando o país passou por uma grave crise econômica, com a queda dos setores industrial e agropecuário, o setor de serviços cresceu. Esse crescimento se tornou mais intenso a partir da década de 1990, quando as mudanças tecnológicas permitiram a globalização mundial e forçaram os países a se prepararem para o novo cenário (Kon, 2006). Nos momentos de recessão econômica, o setor de serviços tem se mostrado de importância fundamental na geração de empregos - ainda que informais - para absorver a mão-de-obra liberada de outros setores econômicos (Kon, 2004).

O grande salto do setor de serviços a partir da década de 1990 se deu por alguns fatores (Negri et al., 2006):

- Extinção de certas restrições sobre a entrada e operação de empresas estrangeiras;

- Privatização dos Sistemas de Telecomunicações; 
- Ampliação da liberalização de fluxos financeiros;

- Inserção de empresas brasileiras no setor de software.

A Figura 10, a seguir, construída a partir dos dados do IBGE, mostra a evolução do PIB de serviços a preços correntes no Brasil desde 1995.

Figura 10: Valor do PIB de serviços a preços correntes (em R \$ trilhões)

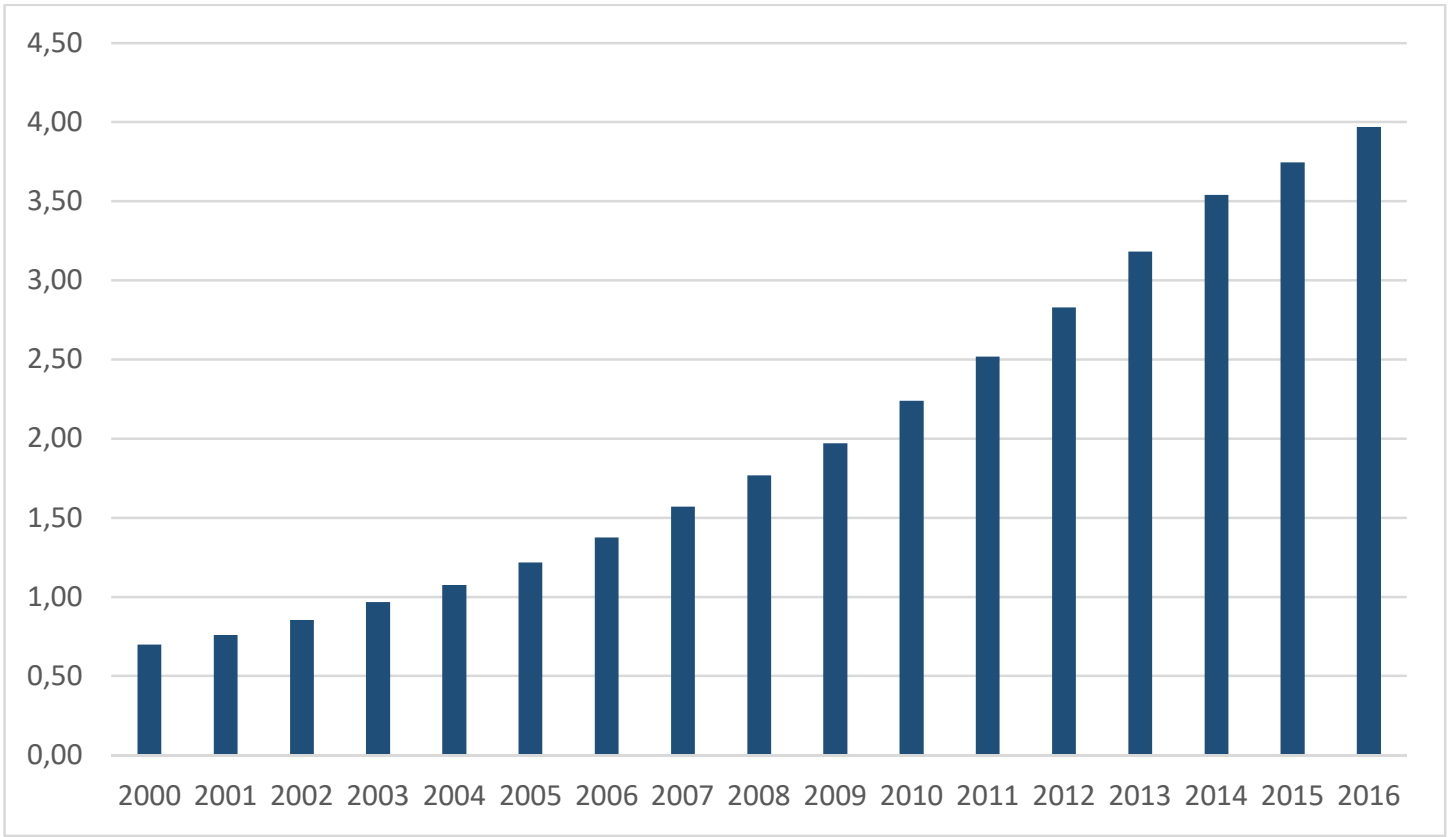

Fonte: Contas Nacionais Trimestrais (IBGE, s.d.)

Percebe-se na Figura 10 que o PIB de serviços cresce continuamente nos vinte anos reportados pelo IBGE, saindo de um patamar abaixo de R \$ 0,5 trilhão em 1995 para próximo de R 3,5 trilhões em 2014, um crescimento de aproximadamente 600\% em um período de 20 anos.

\subsubsection{COMPETIÇÃO NO SETOR DE SERVIÇOS}

Em geral, empresas de serviços competem em um ambiente econômico muito difícil, pois, como apontam Fitzsimmons \& Fitzsimmons (2014), o ambiente de serviços convive com o seguinte cenário: 
- Barreiras de entrada relativamente fracas aos competidores: inovações em serviços não são patenteáveis. Assim, inovações podem ser copiadas pelos concorrentes;

- Oportunidades mínimas para economias de escala: a necessidade de deslocamento físico limita a área de mercado. Assim, o escoamento de serviços ocorre em pequena escala, e empresas com franquias ou que utilizam a internet para substituir o deslocamento conseguem minimizar esse efeito;

- Flutuações erráticas das vendas: a demanda de serviços flutua muito dependendo da hora e do dia da semana, sendo às vezes até sazonais;

- Desvantagem no tamanho para negociar com compradores e fornecedores: em geral empresas de serviço têm um porte pequeno e ficam em desvantagem na negociação com vendedores ou fornecedores. Obviamente existem exceções, como por exemplo o McDonald's comprar carne;

- Substituição de produtos: as empresas de serviços têm dois riscos nesse aspecto: além de seus concorrentes diretos, uma inovação no mercado pode tornar seu produto obsoleto;

- Fidelidade dos clientes: empresas estabelecidas buscam oferecer serviços personalizados de forma a fidelizar seus clientes;

- Barreiras à saída: algumas empresas de serviços mantêm a operação mesmo com lucros baixos ou inexistentes. Por exemplo, uma empresa familiar pode ter como objetivo empregar membros da família e não maximizar o lucro. Outras empresas como lojas de antiguidades podem estar funcionando apenas como hobby ou por valor sentimental de seus proprietários mesmo sem apresentar grandes lucros. Dessa forma tornam a competição maior nos setores onde estão inseridas.

A globalização e a inovação tecnológica (Bryson et al., 2013) fizeram aumentar a competição no setor. Rubalcaba \& Kox (2007), destacam que o setor de serviços, quando comparado com os outros, é mais suscetível à concorrência internacional, o que deixa a competição do setor mais acirrada.

\subsection{ESTRATÉGIA DE NEGÓCIOS}

De acordo com Ghemawat (2002), o termo estratégia vem da Grécia antiga, originalmente com conotação voltada à guerra. Essa influência é perceptível com o uso, pelas áreas de negócios, de expressões tipicamente militares como officer, headquarter, tropas, linha de frente (Kim \& 
Mauborgne, 2004). A utilização desse termo no ramo da Administração iniciou-se no século $\mathrm{XX}$, sendo que o uso massivo dos conceitos de estratégia se deram a partir da segunda metade do referido século, quando as universidades americanas passaram a adotar disciplinas para analisar a estratégia das empresas em relação ao ambiente competitivo (Ghemawat, 2002). O surgimento das consultorias de estratégia como BCG e McKinsey, no final dos anos 1960 e início dos anos 1970, trouxe grande impacto com a aplicação de pesquisa quantitativa em análises de negócios e estratégia corporativa. A partir de meados da década de 1980 as empresas aprenderam a analisar o ambiente competitivo, definir sua posição de mercado, desenvolver vantagens competitivas e corporativas e entender como sustentar suas vantagens em relação aos seus competidores (Casadesus-Masanell \& Ricart, 2010).

Camargos \& Dias (2003) afirmam que não existe um conceito único, definitivo de estratégia. $\mathrm{O}$ vocábulo teve vários significados, diferentes em sua amplitude e complexidade, no decorrer do desenvolvimento da Administração Estratégica.

Na definição de Porter (1996, p.68): "Estratégia é a criação de uma posição única e valiosa, envolvendo um conjunto diferente de atividades; a essência da estratégia é fazer as atividades de forma diferente dos rivais". A posição estratégica emerge de três diferentes fontes:

- Servir algumas necessidades de muitos clientes;

- Servir muitas necessidades de poucos clientes;

- Servir muitas necessidades de muitos clientes em um mercado específico.

Porter (1980) também define que existem três estratégias genéricas que podem ser utilizadas sozinhas ou em combinação: liderança em custos, diferenciação e foco.

Liderança em custos significa dar ao cliente um produto similar ao concorrente com um valor inferior (Porter, 1980). Esta estratégia resulta de inovações no processo, economias de escala, redesenho de produtos, redução no tempo de produção, redução de custos e reengenharia atividades (Allen, Helms, Takeda, White, \& White, 2006). Em geral, é uma estratégia mais adequada para grandes empresas (Lechner \& Gudmundsson, 2012).

A estratégia de diferenciação requer que a companhia tenha um produto ou serviço que seja único aos olhos do cliente (Salavou, 2015). Esse diferencial pode ser buscado de várias maneiras, não existindo um critério único para seu atingimento. O diferencial pode ser tanto quanto à percepção como quanto à utilização (Brenes, Montoya, \& Ciravegna, 2014). O diferencial em relação à percepção aparece quando a diferenciação se dá nas seguintes 
variáveis: preço, imagem da marca, tempo de mercado, qualidade de embalagem, experiência da empresa. O diferencial em relação ao uso aparece quando a empresa se destaca em: qualidade do produto, tecnologia utilizada, atendimento ao cliente, tempo de entrega, rede de distribuição. Foco é uma estratégia que se baseia em diferenciação, redução de custos ou ambos (Salavou, 2015). Essa estratégia visa aumentar a participação de mercado operando em mercados de nicho ou mercados não atrativos para grandes competidores (Allen et al., 2006). Esses nichos podem surgir por: geografia, características do consumidor, especificações do produto ou requerimentos.

Na visão de Casadesus-Masanell \& Ricart (2010), estratégia é o plano de ação desenhado para atingir determinado objetivo. Wright, Kroll, \& Parnell (1998) têm uma definição na mesma linha, apontando estratégia como planos da alta administração para alcançar resultados consistentes com a missão e objetivos gerais da organização. Verma (2007) resume estratégia como sendo a declaração de como a empresa pretende atingir o sucesso empresarial.

Mintzberg (1987) postula que a definição de estratégia não é um conceito simples e único; adotou, então, cinco definições de estratégia, os chamados 5 P's da estratégia:

- Estratégia como plano (plan): A estratégia é um plano unificado, abrangente e integrado com os objetivos que a empresa deseja alcançar. Dessa forma, as estratégias possuem duas características principais: são preparadas previamente às ações para as quais se aplicam e são desenvolvidas de forma consciente e proposital. A estratégia como plano define o que a empresa é e onde quer chegar (Iqbal \& Nieves, 2011);

- Estratégia como pretexto (ploy): Nesse caso, a estratégia é uma tática com o intuito de ludibriar o concorrente. A empresa sinaliza um movimento que não pretende realizar com a finalidade de confundir, iludir ou comunicar uma mensagem falsa aos competidores;

- Estratégia como padrão (pattern): Aqui a estratégia é uma sucessão de comportamentos padrão. Em outras palavras, não basta a elaboração do plano, necessita-se de uma definição baseada no fluxo de ações. Planos estão relacionados com a intenção estratégica da entidade, enquanto padrões estão ligados à estratégia adotada;

- Estratégia como posição (position): O quarto "P" diz respeito à localização da empresa no seu ambiente externo (clientes, fornecedores, concorrentes, governo, sindicatos etc.) e interno (empregados, acionistas, administradores etc.). Nessa concepção a estratégia 
permite definir onde a empresa vai concentrar os seus recursos, visando manter ou melhorar sua posição;

- Estratégia como perspectiva (perspective): A última definição vem de dentro da organização. Não diz respeito apenas à posição de mercado, mas também à forma de ver o mundo; o conjunto de normas, intenções, valores, ideologias e comportamentos difundidos e compartilhados sobre uma marca comum.

Na concepção de Iqbal \& Nieves (2011, p.85): “Tudo em estratégia é muito simples, mas isso não significa que o todo é muito fácil”. Os autores apontam que passar do planejamento à ação da estratégia é uma tarefa difícil pelas seguintes razões:

- Um certo nível de conforto é necessário para lidar com a complexidade, incerteza e conflitos entre a zona de conforto e a realidade;

- É preciso identificar padrões, tendências do projeto e estimar probabilidades;

- Deve-se considerar todos os fatores envolvidos e a interação entre eles;

- É importante o entendimento dos princípios e, muitas vezes, é necessário voltar à teoria básica para buscar a compreensão.

Os autores continuam, afirmando que, por vezes, a teoria é desconsiderada por ser impraticável e/ou muito abstrata. Na verdade, a teoria é a base para a boa prática; administradores devem manter seus modelos mentais de estratégia para alinhar seus objetivos.

Kaplan \& Norton (2008) propõem cinco passos para a estratégia da companhia ser operacionalizada com sucesso.

Inicialmente, o desenvolvimento da estratégia deve estar ligado à missão, visão e valores da empresa. Missão é uma descrição breve que define por qual razão a instituição existe e o que ela oferece para seus clientes. Visão é uma aspiração de futuro, onde a empresa quer estar no futuro (usualmente de 3 a 10 anos). Os valores descrevem quais as atitudes e comportamentos desejáveis pela organização; ao mesmo tempo, descrevem quais atos são intoleráveis. Além do alinhamento com esses três pontos, a estratégia deve abordar os pontos fortes e fracos da instituição e o ambiente de negócios onde está inserida. Uma boa definição de estratégia atrai investidores, fideliza empregados e conquista clientes (Gadiesh \& Gilbert, 2001).

O segundo passo é traduzir a estratégia em objetivos mensuráveis e transmití-los a todas as unidades de negócios e funcionários. Os autores propõem a criação de mapas de estratégia, nos quais o objetivo final é segmentado em pequenas atividades que podem ser medidas. A estratégia em algumas empresas é um conceito abstrato; sem um direcionamento claro do 
objetivo da companhia, os menores níveis da companhia não podem colocar em prática planos executáveis (Mankins \& Steele, 2005).

A seguir vem a fase de planejar as operações: uma vez que foram definidas as métricas, atividades e objetivos, o passo seguinte é definir o plano operacional para colocar em prática as ações para atingir os objetivos estratégicos. Esse estágio começa com a definição dos processos prioritários seguida da avaliação do plano de vendas, análise da capacidade da empresa e definição de orçamentos. Os executivos têm milhares de ações para seguir; entretanto, nem todas são prioritárias, nem há dinheiro para executar todas. Cabe ao líder ter o discernimento de qual caminho é o mais certo a ser seguido (Mankins \& Steele, 2005).

O seguinte passo é monitorar e aprender: após a implementação da estratégia e do plano operacional, cabe aos gestores acompanhar resultados e buscar aprendizados da operação. Aqui os relatórios gerenciais são de crucial importância. De acordo com Neilson, Martin, \& Powers (2008), um dos segredos da execução estratégica de sucesso é que o fluxo de informações dentro da empresa seja rápido e atinja muitas pessoas. Nessa fase são feitos dois tipos de acompanhamento: revisão operacional, em que se busca entender se o que foi planejado está sendo executado de forma correta; e revisão estratégica, na qual é mensurado se os resultados alcançados estão de acordo com o que houvera sido previamente planejado.

Finalmente, o quinto passo é testar e adaptar a estratégia: de tempos em tempos a alta gerência descobrirá que algumas estratégias anteriormente desenhadas ficaram obsoletas. Quando isso acontece, cabe à alta direção decidir se é possível uma correção de rota com a estratégia vigente ou se é necessária uma nova e transformadora estratégia. Nenhuma estratégia é eterna. Alguns fatores como novas necessidades dos clientes, redução de custos ou mudança no cenário econômico podem trazer mudanças na estratégia. Em geral, a estratégia deve ser revista trimestralmente e atualizada anualmente (Gadiesh \& Gilbert, 2001).

Porter (2008) propõe a análise das cinco forças competitivas (Figura 11) para a definição da estratégia de uma empresa. De acordo com o autor, essa análise varia em conformidade com o segmento na qual a instituição está incluída. 
Figura 11: Cinco Forças Competitivas

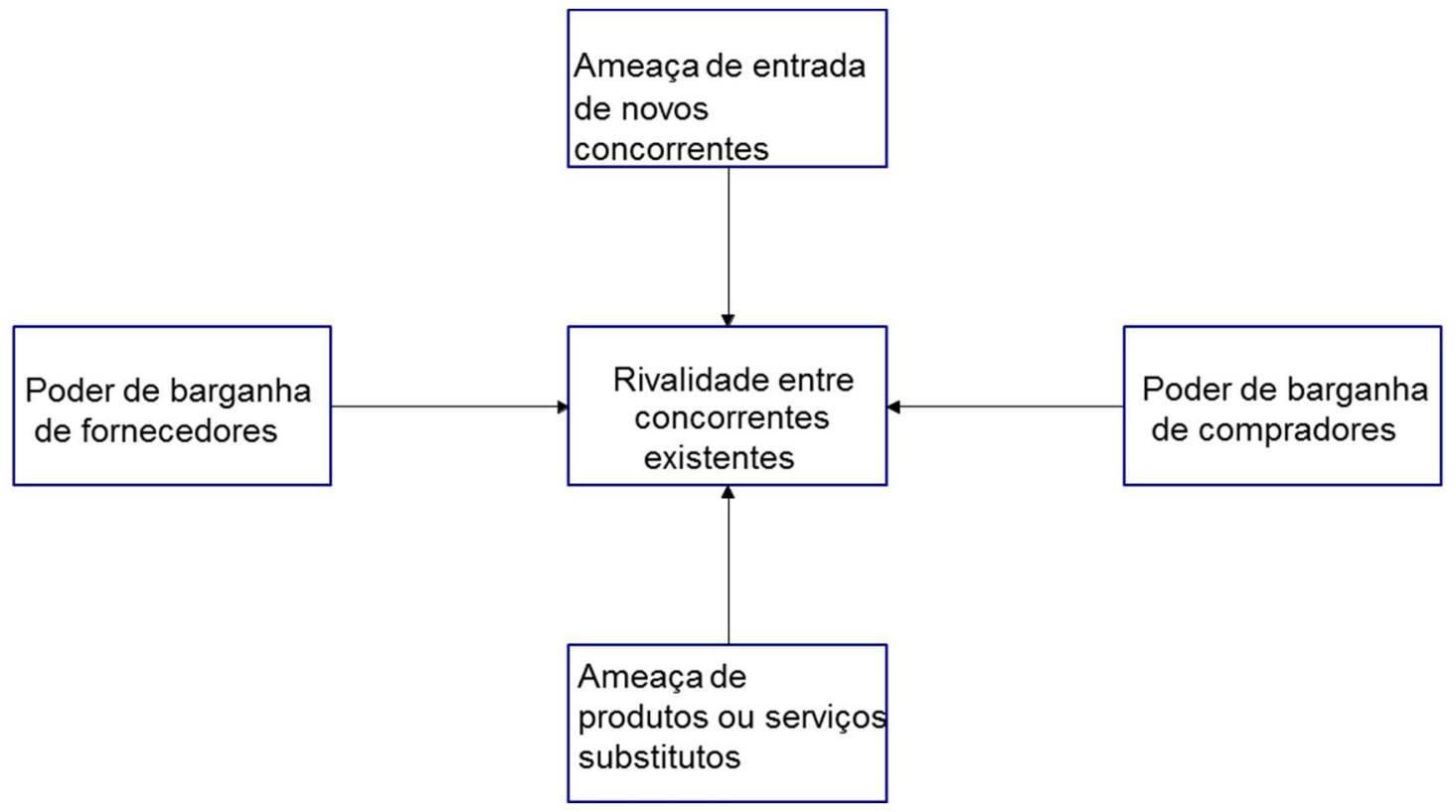

Fonte: Porter (2008)

A ameaça de novos entrantes traz novos competidores ao mercado, que fazem pressão nos preços, custos e no investimento necessário para a operação. São especialmente perigosos quando vêm de outros mercados. São grandes empresas e buscam uma diversificação nos seus negócios, como a Coca-Cola quando entrou no mercado de águas ou a Apple quando ingressou no mercado de música. A entrada de um novo competidor depende das barreiras de entrada do mercado.

$\underline{\mathrm{O} \text { poder dos fornecedores }}$ se faz presente quando praticam preços altos, apresentam baixa qualidade de serviços ou repassam seus custos. Esse cenário se apresenta quando existem poucos fornecedores no mercado ou a substituição do fornecedor é difícil ou o comprador não é importante para o fornecedor. Um exemplo seria a Microsoft aumentar o preço do seu produto sistema operacional.

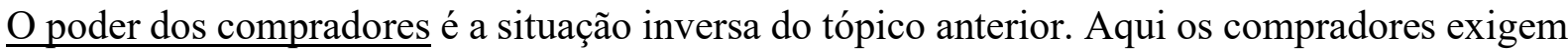
baixos preços e alta qualidade nos serviços. Esse cenário se apresenta quando existem poucos compradores, a empresa é muito dependente do cliente, o comprador pode facilmente trocar de vendedor. 
A ameaça de substitutos acontece quando um produto faz a função de outro, mesmo não sendo similar. Videoconferência substitui viagens, plástico substitui alumínio. Quando a ameaça de substituição é grande, os lucros das indústrias caem. Substitutos são muito perigosos quando apresentam um bom custo-benefício e/ou o custo de substituição é baixo.

A rivalidade entre competidores existentes aparece de várias formas: descontos, introdução de novos produtos, campanhas publicitárias ou melhorias no serviço. A competição restringe os lucros. A rivalidade é mais intensa quando existem muitos competidores de tamanho e poder similar. O crescimento do mercado é pequeno, barreiras de saída são elevadas.

Dada a importância do setor de serviços na economia de um país, torna-se fundamental a definição de estratégias eficientes e viáveis para o setor. $\mathrm{O}$ conceito de estratégia no contexto de serviços será discutido na próxima seção, visando maior entendimento de sua complexidade.

\subsubsection{ESTRATÉGIA EM SERVIÇOS}

Iqbal \& Nieves (2011) apontam que organizações interessadas em colocar a estratégia no contexto de serviços têm duas perspectivas distintas, porém relacionadas para operar. $\mathrm{Na}$ primeira perspectiva, estratégias são desenvolvidas para os serviços oferecidos e, na segunda perspectiva, os serviços são oferecidos de acordo com a estratégia do negócio.

Na primeira visão, chamada pelos autores de estratégias para serviços, a instituição parte dos serviços oferecidos para desenhar sua estratégia. Na segunda, os serviços são desenhados ou ofertados ao cliente como parte da estratégia de negócios. Esta visão está mais relacionada com o entendimento das necessidades dos clientes.

Fitzsimmons \& Fitzsimmons (2014) descrevem, com exemplos, como seriam as estratégias genéricas propostas por Porter (1980) sob a ótica de serviços.

Liderança global em custos: Esse tipo de estratégia requer eficiência em escala, rígido controle de custos e despesas. Uma estratégia de liderança em custos às vezes pode revolucionar o setor, como fizeram Fedex, McDonald's e Wal Mart. Para seguir essa estratégia, as empresas podem usar métodos variados:

Procura por clientes de baixo custo - $\mathrm{O}$ atendimento de alguns clientes tem um custo menor que os outros, e eles podem ser o alvo de prestadores de serviços. Existem empresas americanas especializadas em fazer seguro de automóveis de militares. $\mathrm{O}$ 
atendimento costuma ser barato, pois seus membros, relativamente nômades, estão acostumados a fazer negócios por telefone, correio ou internet.

Padronização de serviço personalizado - A palavra aqui é rotina. Um exemplo são cursos in company oferecidos por empresas de treinamento. Embora o perfil dos clientes seja diferente, o conteúdo do curso pode ser próximo. No entanto, a substituição do produto é uma constante ameaça.

Redução da interação na prestação dos serviços - A estratégia, potencialmente arriscada, é diminuir o contato pessoal com cliente, desde que este aceite. Os bancos utilizam muito essa estratégia fomentando a utilização de caixas automáticos, internet e smartphones para acesso às contas.

Redução dos custos de rede - Empresas de serviços que necessitam de uma rede para unir os serviços com os consumidores têm um custo elevado (por exemplo, fornecedoras de serviço de energia elétrica). A Federal Express concebeu uma abordagem diferenciada para reduzir seus custos de rede. Utilizando Memphis como centro, ela faz com que todas as entregas passem por essa cidade, evitando rotas diretas entre outros pontos e reduzindo, assim, o custo de rede. O mesmo raciocínio se aplica para companhias aéreas que adotam algumas cidades como base em um país.

Serviços off-line - Alguns serviços por sua natureza são on-line pois só podem ser realizados com o cliente presente, transporte, por exemplo. Serviços que não necessitam da presença do cliente podem ser executados off-line, permitindo ganhos de escala. Por exemplo, um serviço de consertos de calçados pode ter vários postos de coleta e retirada e o serviço é prestado posteriormente.

Diferenciação: A essência dessa estratégia é conceber cada serviço como único. Não significa ignorar custos. Contudo, o objetivo aqui é conquistar a lealdade do cliente, oferecer o produto que satisfaz o cliente pelo preço que ele está disposto a pagar. Os métodos são:

Tornando tangível o intangível - Serviços, pela sua própria natureza, são quase sempre intangíveis e não oferecem lembranças materiais da compra. Tentando contornar essa questão, muitos hotéis oferecem artigos de toalete com a logomarca do hotel para reforçar a experiência na memória do cliente.

Personalizando o produto padrão - Proporcionar um toque customizado aproxima os clientes das empresas a um custo muito baixo. Chamar o cliente pelo nome, enviar 
cumprimentos no aniversário, oferecer uma bebida em uma barbearia, são exemplos que podem aproximar os clientes.

Redução do risco percebido - A falta de informação sobre a compra de um serviço cria sensação de risco para muitos potenciais clientes. No serviço de manutenção de veículos, por vezes o cliente aceita pagar mais a um fornecedor com instalações limpas e organizadas que dê referências e garantias do trabalho.

Valorização do treinamento pessoal- Empresas que investem em treinamento de seus funcionários têm uma melhora na qualidade dos serviços e dificilmente podem ser copiadas. Em alguns casos as empresas estabelecem centros de treinamento similares à faculdade, como, por exemplo, a universidade Telefonica em Barcelona.

Controle de qualidade - Manter a qualidade dos serviços em vários locais é um desafio significativo. As empresas tentam padronizar ao máximo para reduzir a variabilidade.

Foco: Essa estratégia é construída na ideia de servir muito bem um mercado em particular. A essência aqui é servir esse mercado de forma mais eficaz e eficiente que seus concorrentes. Como resultado a empresa conhece melhor as necessidades desse mercado. Essa estratégia é como aplicar diferenciação e/ou liderança em custos para um mercado específico. Um exemplo desse segmento são empresas que fabricam carros de alto luxo e focam apenas em clientes com alto potencial financeiro.

Heskett, Sasser, \& Schlesinger (1997) propõem um modelo de estratégia em serviços postulando que a visão estratégica em serviços começa com avaliação do sistema de entrega do serviço, da estratégia operacional, do conceito do serviço e dos segmentos alvos de mercado.

Sistema de entrega do serviço compreende toda a estrutura necessária para a entrega: sistemas de informação, equipamentos que permitam a operação. Estratégia operacional diz respeito à organização, controles, políticas, processos que permitam que o consumidor perceba valor maior do produto em relação ao custo que a empresa tem. Quando se fala de conceito de serviço, os autores apontam que se refere ao posicionamento do serviço oferecido pela companhia em relação às necessidades do cliente e aos serviços ofertados pela concorrência. Os segmentos alvos de mercado estão relacionados à psicografia (como o cliente pensa e age) e à demografia (quem são os clientes, como vivem, qual seu nível de educação).

Os autores concluem que o objetivo da adoção deste modelo de visão é a obtenção de clientes mais fiéis e empresas com foco na estratégia são mais lucrativas. 
A Figura 12, a seguir, sintetiza os elementos da visão estratégica em serviços. Dentro de cada quadro aparecem questões para auxiliar no desenvolvimento da categoria. Entre as categorias uma questão é formulada para avaliar a efetividade de as categorias se apoiarem.

Figura 12: Elementos da Visão Estratégica de Serviços

\begin{tabular}{|c|c|c|c|c|c|c|}
\hline $\begin{array}{c}\text { Sistema de } \\
\text { Entrega de } \\
\text { Serviço }\end{array}$ & & $\begin{array}{c}\text { Estratégia } \\
\text { Operacional }\end{array}$ & & $\begin{array}{l}\text { Conceito de } \\
\text { Serviço }\end{array}$ & & $\begin{array}{c}\text { Segmento alvo } \\
\text { de mercado }\end{array}$ \\
\hline $\begin{array}{l}\text { Quais são funções } \\
\text { importantes no sistema } \\
\text { de prestação de serviço, } \\
\text { incluindo: } \\
\text { O papel das pessoas } \\
\text { Tecnologia } \\
\text { Equipamento } \\
\text { Layout } \\
\text { Procedimentos } \\
\text { Qual sua capacidade? } \\
\text { Normal? } \\
\text { Nos picos? } \\
\text { Até que ponto este } \\
\text { sistema: } \\
\text { Ajuda a garantir padrões } \\
\text { de qualidade? } \\
\text { Diferencia-se da } \\
\text { competição? de entrada } \\
\text { Cria barreira de } \\
\text { para os competidores? }\end{array}$ & $\begin{array}{l}\longleftarrow \\
\text { O sistema de } \\
\text { entrega de } \\
\text { serviço } \\
\text { permite a } \\
\text { execução da } \\
\text { estratégia } \\
\text { operacional? }\end{array}$ & $\begin{array}{l}\text { Quais são os elementos } \\
\text { importantes da estratégia } \\
\text { Operações? } \\
\text { Finanças? } \\
\text { Marketing? } \\
\text { Organização? } \\
\text { Recursos Humanos? } \\
\text { Controle? } \\
\text { Em quais elementos a } \\
\text { maior parte dos esforços } \\
\text { vai ser concentrada? } \\
\text { Onde serão feitos } \\
\text { investimentos? } \\
\text { Como a qualidade e custo } \\
\text { serão controlados? } \\
\text { Medições? } \\
\text { Incentivos? } \\
\text { Recompensas? } \\
\text { Que resultados serão } \\
\text { esperados diante da } \\
\text { competição em termos } \\
\text { de: } \\
\text { Qualidade de serviço? } \\
\text { Perfilde Custo? } \\
\text { Produtividade? } \\
\text { Moral/Lealdade dos } \\
\text { atendentes }\end{array}$ & $\begin{array}{l}\text { Até que ponto } \\
\text { o valor dos } \\
\text { resultados e a } \\
\text { qualidade do } \\
\text { processo para } \\
\text { os clientes são } \\
\text { alavancados } \\
\text { sobre o custo } \\
\text { para o } \\
\text { fornecedor do } \\
\text { serviço? }\end{array}$ & 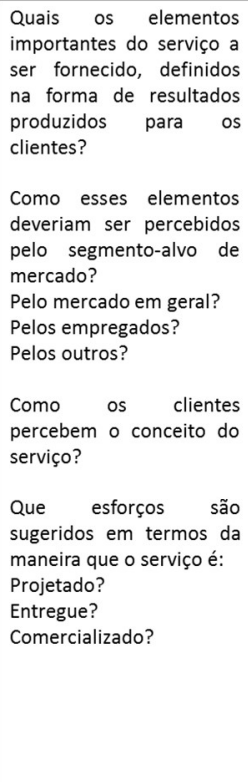 & $\begin{array}{l}\longleftrightarrow \\
\text { Qual é a } \\
\text { posição do } \\
\text { conceito de } \\
\text { serviço em } \\
\text { relação às } \\
\text { necessidades } \\
\text { dos clientes e } \\
\text { oferta dos } \\
\text { competidores? }\end{array}$ & $\begin{array}{l}\text { Quais são as } \\
\text { características comuns } \\
\text { dos segmentos de } \\
\text { mercado importantes? } \\
\text { Quais dimensões podem } \\
\text { ser usadas para } \\
\text { segmentar o mercado? } \\
\text { Demográficas? } \\
\text { Psicográficas? } \\
\text { Qual é a importância dos } \\
\text { vários segmentos? } \\
\text { Quais as necessidades de } \\
\text { cada um? } \\
\text { Quão bem essas } \\
\text { necessidades } \\
\text { atendidas? são } \\
\text { De que maneira? } \\
\text { Por quem? }\end{array}$ \\
\hline
\end{tabular}

Fonte: Fitzsimmons \& Fitzsimmons (2014) baseado em (Heskett, Sasser, \& Schlesinger, 1997)

Por sua vez, Johnston, Clark, \& Shulver (2012) definem um modelo com cinco elementos considerados críticos pelos autores para uma estratégia de serviços: objetivos corporativos, ambiente, conceito de serviço, objetivos de desempenho e operação (Figura 13).

Objetivos corporativos são aqueles que definem as metas para a estratégia. Se a estratégia é um conjunto de planos ou políticas para alcançar os objetivos, essas necessidades devem estar contempladas no objetivo da empresa. Na essência os objetivos definem os parâmetros para mudança.

Ambiente se relaciona ao contexto no qual a companhia está inserida. As necessidades do ambiente devem ser compreendidas não apenas como oportunidades para empresa, mas também a resposta dos clientes e outras organizações. 
Conceito de serviço identifica a proposta de serviço da empresa, o serviço que a empresa deseja criar. O conceito de serviço auxilia a organização a focar no valor que ela oferece aos consumidores.

Objetivos de desempenho oferecem as mensurações nas quais a estratégia pode ser traduzida em operação. Ajudam a definir as tarefas da operação.

Operação diz respeito às pessoas, processos, estrutura do sistema de mensuração de performance, cadeia de suprimentos que devem ser desenvolvidos e modificados para implementar a estratégia. A operação ainda fornece o ímpeto para mudanças no potencial e capacitação das operações.

Figura 13: Modelo de Estratégia de Johnston, Clark e Shulver

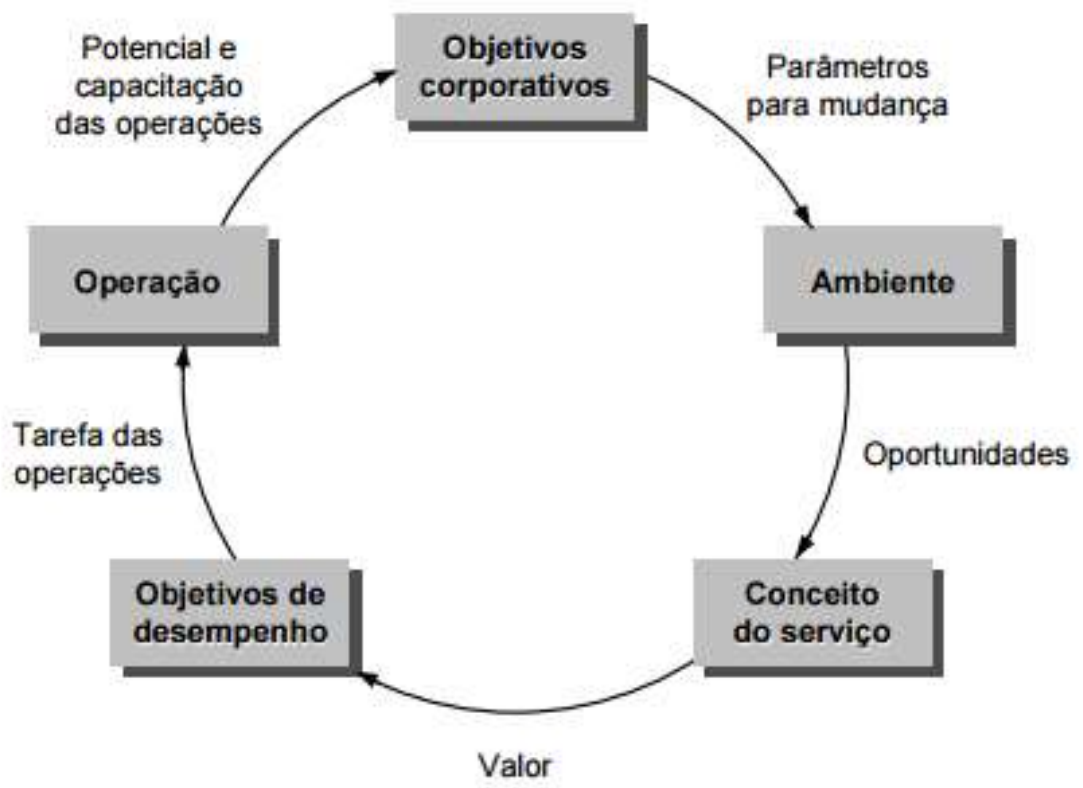

Fonte: Johnston, Clark, \& Shulver (2012)

Na opinião dos autores, o processo de estratégia deve ser interativo e contínuo. Por essa razão o modelo se retroalimenta e há a necessidade de certo grau de flexibilidade no planejamento.

Kellogg \& Nie (1995) propõem a matriz SP/SP (service process/service package) que apresenta as estratégias de acordo com a estrutura do processo de serviço e a estrutura de pacote de serviço. 
A dimensão do processo de serviços geralmente está relacionada com questões operacionais como localização, escolhas tecnológicas e capacidade. As autoras identificam três níveis para essa dimensão, de acordo com a influência que o cliente tem no processo de serviços. Dessa forma, os três níveis são:

- Serviço Especializado: no qual a influência do cliente é alta, o cliente ajuda a criar e definir o serviço; como, por exemplo, serviços de consultoria.

- Loja de Serviços: aqui a influência do cliente é definida como média. Ele define os requisitos e pode customizar parte do serviço, como acontece no ramo da educação.

- Fábrica de Serviços: nesse nível a influência do cliente é baixa, os serviços já são padronizados e pré-definidos, como acontece em um restaurante fast food.

A outra dimensão é o pacote de serviços. De acordo com Fitzsimmons \& Fitzsimmons (2014), o pacote de serviços é o conjunto de produtos e serviços oferecidos em um ambiente. É composto por cinco características: instalações de apoio, bens facilitadores, serviços implícitos, serviços explícitos e informação. Instalações de apoio são os recursos físicos necessários para se oferecer um serviço. Bens facilitadores referem-se ao material usado ou consumido pelo cliente. Serviços explícitos são os benefícios prontamente percebidos pelo cliente. Serviços implícitos são percebidos vagamente pelo cliente, uma característica extrínseca do serviço. A informação disponibilizada pelo cliente ou fornecedor, permite um serviço eficiente e customizado. Na matriz SP/SP a dimensão de pacote de serviços é dividida pelo nível de customização:

- Pacote de serviço único: Totalmente customizado, o cliente define o "que", "como" e "onde" do serviço.

- Pacote de serviço seletivo: Consideravelmente customizado. Embora algumas partes sejam padronizadas, a maior parte do serviço é customizada pelo cliente.

- Pacote de serviço restrito: a customização é limitada. A maior parte do serviço é padronizada e o cliente seleciona em um número limitado de opções.

- Pacote de serviço genérico: pouca ou nenhuma customização. O serviço é padrão.

A matriz SP/SP é destacada na Figura 14, a seguir. 
Figura 14: Matriz SP/SP

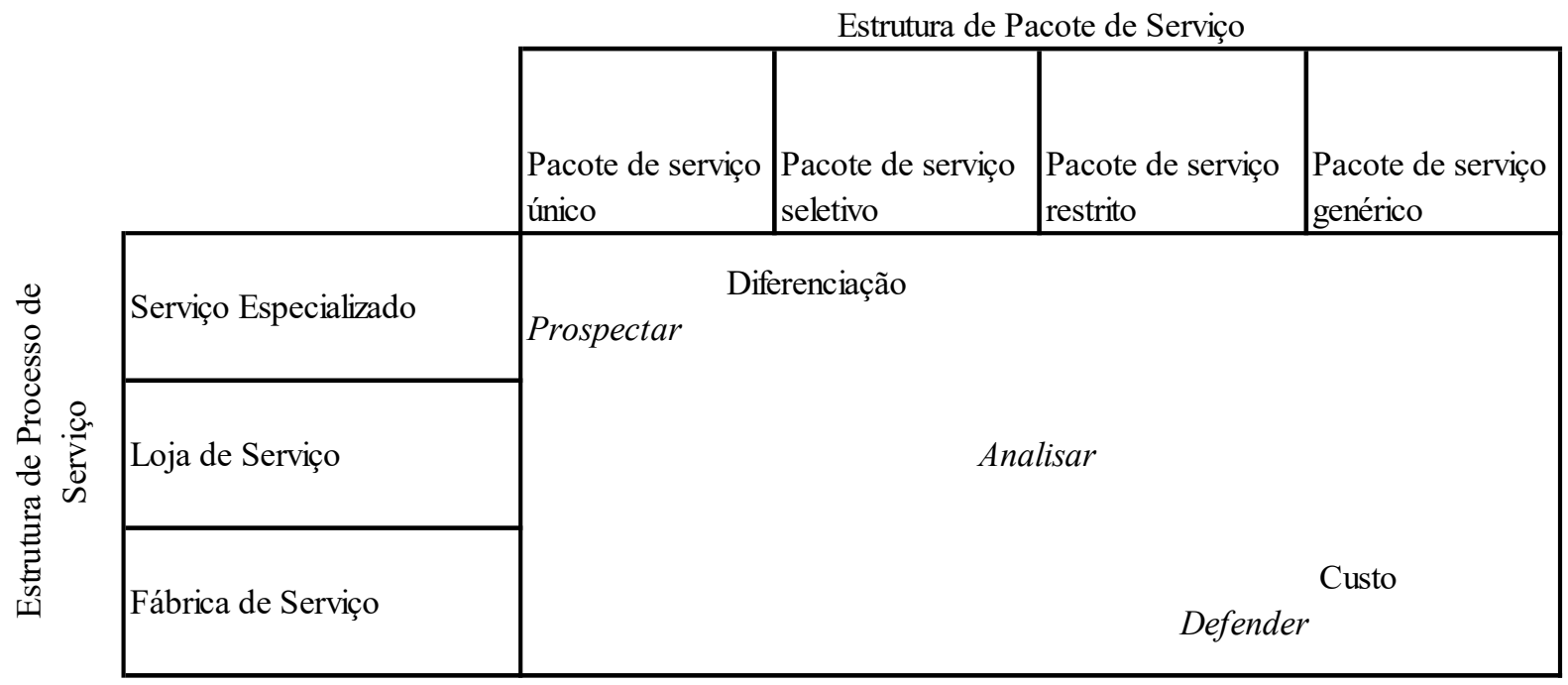

Fonte: Adaptado pelo autor de Kellogg \& Nie (1995)

As autoras apontam quais estratégias mais adequadas de acordo com a localização na matriz SP/SP. As estratégias genéricas de Porter, diferenciação e custo, localizam-se em extremos opostos da matriz. Diferenciação em casos de pacote de serviços bastante customizados e estrutura de processo de serviços especializados, ao passo que custo está mais próximo de pacote de serviços genérico e fábrica de serviços. Também são apresentadas na matriz (Figura 14) as estratégias genéricas propostas por Miles, Snow, Meyer, \& Coleman Jr., (1978), a saber:

- Estratégia Defensiva: organizações muito eficientes em seu mercado e raramente necessitam de grandes ajustes em sua tecnologia, estrutura ou método de operação.

- Estratégia Prospectora: Instituições que continuamente procuram por oportunidades no mercado, inovação de produtos e processos.

- Estratégia Analítica. Empresas que estão em uma posição intermediária entre os prospectores e os defensores, sofrem com o dilema de buscar uma mudança, mas também têm um produto ou mercado relativamente estável.

- Estratégia Reativa: As outras três estratégias são proativas. Nessa última a organização busca se ajustar num ambiente de mudança e incerteza. Necessitam desenvolver novas competências de maneira rápida sob o risco de naufragarem. Essa estratégia não aparece na Figura 14, pois ela pode ser necessária em qualquer cenário, independente da Estrutura de Pacote de Serviço ou Estrutura de Processo de Serviço. 
A estratégia para serviços deve ter foco (Lovelock et al., 2014). O foco da estratégia deve ser definido de acordo com a gama de produtos oferecidos pela empresa e a quantidade de mercados atendidos (Figura 15).

Figura 15: Focos Básicos para a Estratégia de Serviços

Número de produtos oferecidos

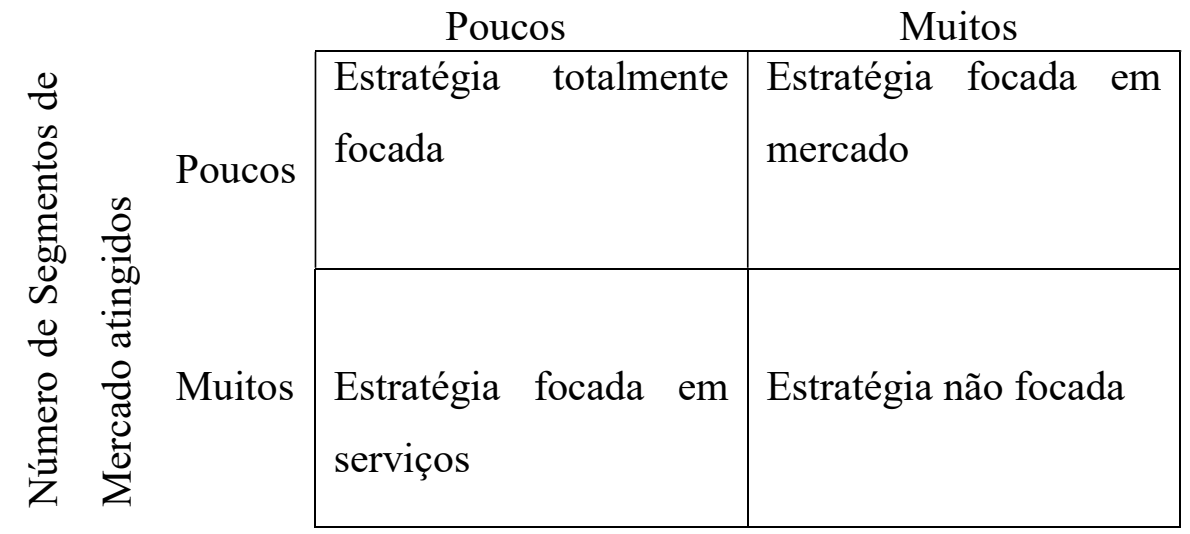

Fonte: Lovelock, Patterson, \& Wirtz (2014)

Estratégia totalmente focada está presente quando a companhia tem poucos produtos (ou até mesmo apenas um produto) e atua num segmento específico. Isso força a empresa a ter uma excelente qualidade. Um exemplo é o hospital Shouldice nos Estados Unidos que oferece apenas cirurgia de hérnia, em geral para homens de 40 a 60 anos.

Estratégia focada no mercado aparece quando a empresa tem muitos produtos e atende um segmento de mercado específico, como por exemplo, seguradoras focadas em aposentados.

Estratégia focada em serviços são empresas com poucos produtos que atendem vários mercados. Cada vez que um novo mercado é atingido, a empresa necessita desenvolver aptidões para entender esse novo segmento. Os autores citam como exemplo clínicas de cirurgia ortopédica.

Estratégia não focada acontece quando as empresas possuem uma grande gama de produtos e amplos mercados; por exemplo, nos hipermercados.

\subsubsection{DIRECIONADORES DA ESTRATÉGIA}

De acordo com Hakala (2011), independente da estratégia adotada pela empresa, há um direcionador que a motiva. Esses princípios influenciam diretamente as atividades da 
companhia, a cultura da empresa e os resultados. Conforme Gatignon \& Xuereb (1997), existem três principais direcionadores para as empresas: mercado, competidores e tecnologia. Importante ressaltar que não são orientações excludentes; elas podem coexistir, embora, em geral, uma delas é predominante em uma empresa (Cadogan, 2012; Mu \& Di Benedetto, 2011).

Empresas cuja estratégia é direcionada pelo mercado buscam satisfazer os anseios dos clientes, seguem a filosofia "o consumidor em primeiro lugar" (Zhou, Kin, Yim, \& Tse, 2005). A habilidade desse tipo de empresa deve ser identificar, analisar, entender e responder às necessidades do cliente (Gatignon \& Xuereb, 1997). Nesse tipo de direcionamento, a empresa é mais próxima do cliente e pode compensar sua possível falta de inovações (mais comum em uma estratégia direcionada pela tecnologia) com a criação de produtos e serviços que proporcionem benefícios específicos para seus clientes (Deutscher, Zapkau, Schwens, Baum, \& Kabst, 2016).

Em uma empresa onde a estratégia é motivada pelos competidores, o direcionador é aprender com a concorrência: quem são, como atuam, que tecnologia adotam, quais clientes atingem, quais seus pontos fortes e fracos (Gebauer et al., 2011). Essa análise de competidores deve servir de base para a empresa desenvolver produtos e definir seu posicionamento (Gatignon \& Xuereb, 1997).

Estratégia direcionada pela tecnologia refere-se a, de maneira proativa, desenvolver e integrar tecnologias no desenvolvimento de produtos e serviços (Hao \& Song, 2016). Empresas que adotam esse tipo de orientação têm inclinação a utilizar ou desenvolver novas tecnologias para atender seus clientes (Hakala, 2011). Essas companhias "criam" a necessidade no consumidor com produtos/tecnologias inovadores (Hakala \& Kohtamäki, 2011), sendo que sua competição se baseia em diferenciação (Gatignon \& Xuereb, 1997).

\subsection{CONSIDERAÇÕES FINAIS}

Para o alcance dos objetivos deste estudo, a revisão da literatura compreendeu inicialmente uma síntese dos principais conceitos relacionados à Business Intelligence e Big Data, destacando suas particularidades. A seguir, para delinear o contexto em que o estudo foi abordado, discutiram-se aspectos do setor de serviços e as estratégias adotadas nesse segmento. O próximo capítulo versará sobre os modelos utilizados para entender os fatores que influenciam a utilização de tecnologia nas empresas, que será o suporte para responder às perguntas elaboradas neste trabalho. 


\section{MODELOS DE ACEITAÇÃO DE TECNOLOGIA}

Com a massificação no uso dos computadores nos últimos vinte e cinco anos do século $\mathrm{XX}$, o uso da tecnologia passou a ser um diferencial nas empresas (Venkatesh, Morris, Davis, \& Davis, 2003), e esta deve ser aceita pelos empregados para obtenção de melhores resultados. O campo de estudo de aceitação de tecnologia evoluiu a partir do fim dos anos 1980 com a proposta do modelo TAM - Technology Acceptance Model - apresentado por Davis et al. (1989). De acordo com Han et al. (2016), um modelo de aceitação de tecnologia visa modelar como o cérebro humano trabalha em relação à continuidade de uso de determinada tecnologia.

Modelos de aceitação foram inicialmente desenvolvidos para utilização em psicologia e sociologia (Viswanath Venkatesh, Thong, \& Xu, 2012) e se baseiam em três conceitos (Oei, 2014): Reações individuais ao uso da tecnologia da informação, Intenção de uso da tecnologia da informação e Uso da tecnologia da informação, conforme apresentado na Figura 16.

Figura 16: Conceitos Básicos de Modelos de Aceitação de Tecnologia

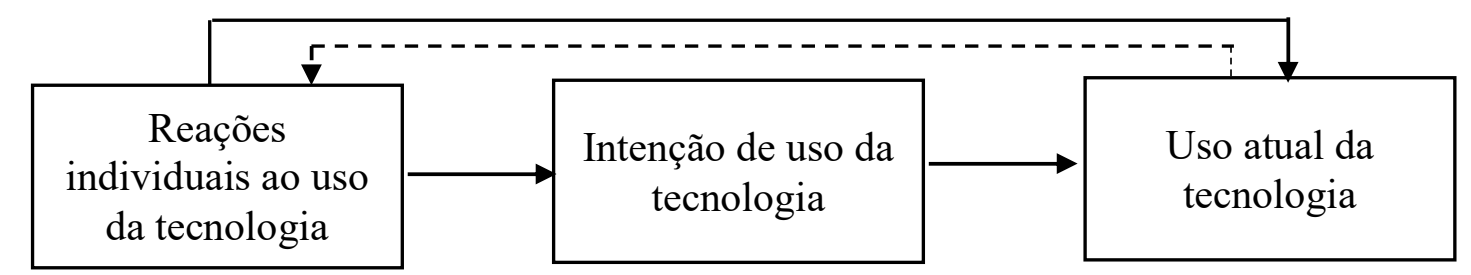

Fonte: Venkatesh et al. (2003)

Nos próximos tópicos serão apresentados alguns modelos de aceitação de tecnologia, evidenciando a evolução das pesquisas até se chegar no modelo ECT -Modificado, foco deste trabalho.

\subsection{MODELO TRA - THEORY OF REASONED ACTION}

O modelo TRA é uma das mais fundamentais e influentes teorias sobre comportamento humano (Venkatesh et al., 2003). Esse modelo foi inicialmente concebido por Fishbein \& Ajzen (1975). Originalmente foi criado para utilização em psicologia e sociologia e aplicado por Davis et al. (1989) para investigar a aceitação da tecnologia. Na TRA, considera-se que as pessoas se comportam de forma racional, avaliando o que têm a perder e a ganhar, via manifestação de suas atitudes (Gutman, Joia, \& Moreno Jr, 2014). Dessa maneira, suas ideias, metas pessoais, valores, crenças e atitudes influenciam seu comportamento e a intenção de comportar-se de 
determinada forma também é influenciada pelas normas subjetivas existentes, ou seja, a percepção do indivíduo de que pessoas importantes para ele acreditem que ele deva comportarse daquela forma. A Figura 17 mostra um esquema de relacionamento entre os constructos dessa teoria.

Figura 17: THEORY OF REASONED ACTION - TRA

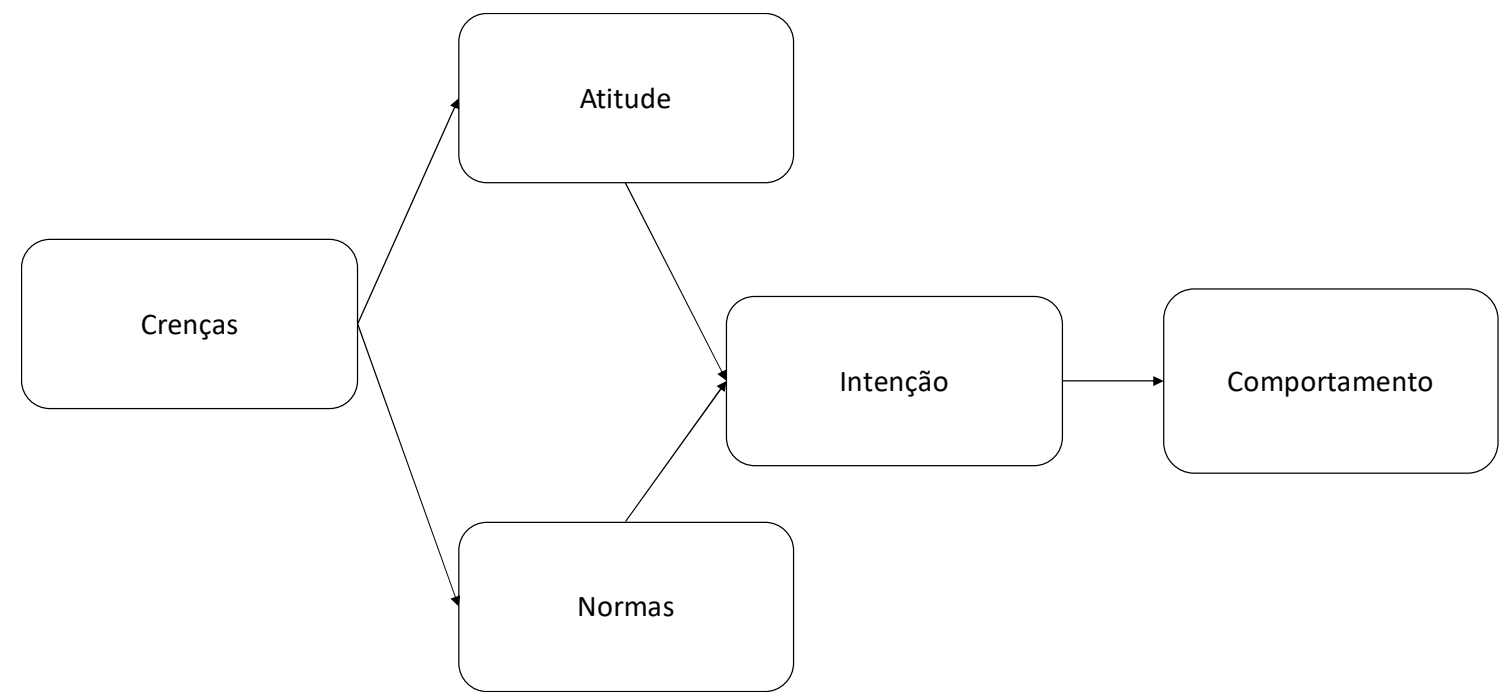

Fonte: Fishbein \& Ajzen (1975)

Na Figura 17 percebe-se a relação do modelo TRA: as crenças do indivíduo influenciam suas atitudes e a percepção sobre as normas existentes. Atitudes e Normas influenciam diretamente a sua intenção de comportamento que, por sua vez, afeta o comportamento.

\subsection{MODELO TPB - THEORY OF PLANNED BEHAVIOUR}

O modelo TPB, proposto por Ajzen (1991), surge como um complemento do modelo TRA, incluindo o conceito de controle percebido do comportamento ao modelo mencionado na seção 3.1. Dessa maneira, a intenção de comportamento nesse modelo tem três determinantes: atitude em relação ao comportamento, norma subjetiva e controle comportamental percebido (Cheon, Lee, Crooks, \& Song, 2012).

O constructo de controle comportamental percebido é a confiança que o indivíduo tem na sua capacidade de desempenhar determinado comportamento (Ajzen, 1991). Dessa forma, aqueles que se percebem como capazes de executar um comportamento são mais propensos a desempenhar determinado comportamento. A Figura 18 mostra o framework desse modelo. 
Figura 18: THEORY OF PLANNED BEHAVIOUR - TPB

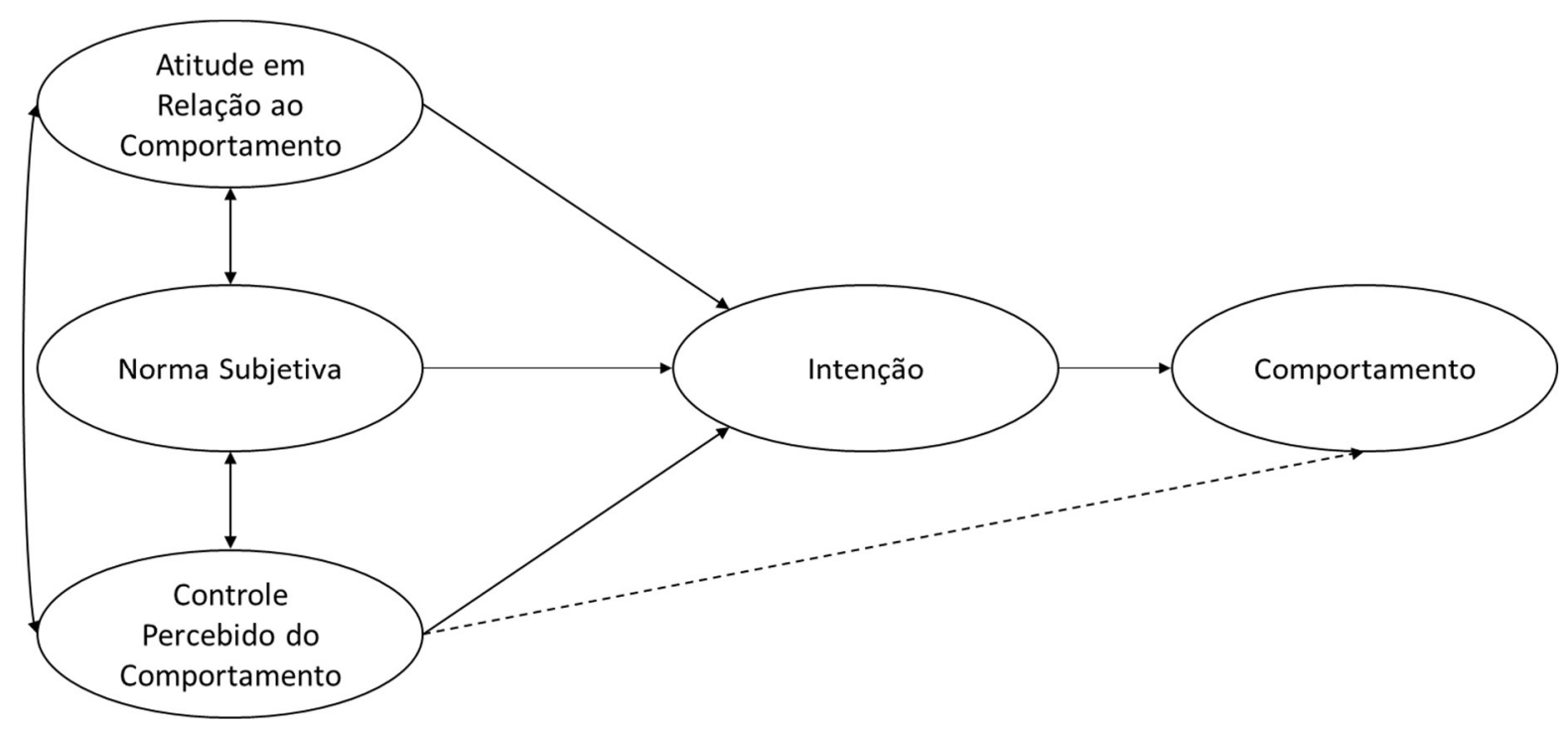

Fonte: Ajzen (1991)

Nota-se no framework a introdução do constructo de Controle Percebido do Comportamento, o qual é o único desse modelo que tem interação direta com todos os demais constructos.

\subsection{MODELOS TAM E TAM2 - TECNOLOGY ACCEPTANCE MODEL}

O TAM é o modelo mais largamente utilizado para avaliar aceitação de tecnologia da informação (Benbasat \& Barki, 2007), introduzido por Davis et al. (1989) como uma evolução do modelo TRA (Chakraborty, Hu, \& Cui, 2008).

A ideia central do TAM é prover uma base para traçar o impacto de variáveis ligadas a crenças internas e atitudes sobre intenções. O TAM teoriza que uma intenção comportamental do indivíduo para usar um sistema é determinada por duas crenças: Facilidade Percebida de Uso e Utilidade Percebida (Venkatesh \& Davis, 2000). No framework, os efeitos das Variáveis Externas (características do sistema) na Intenção de Uso são mediados por Utilidade e Facilidade Percebidas, conforme ilustra a Figura 19. 
Figura 19: TECNOLOGY ACCEPTANCE MODEL - TAM

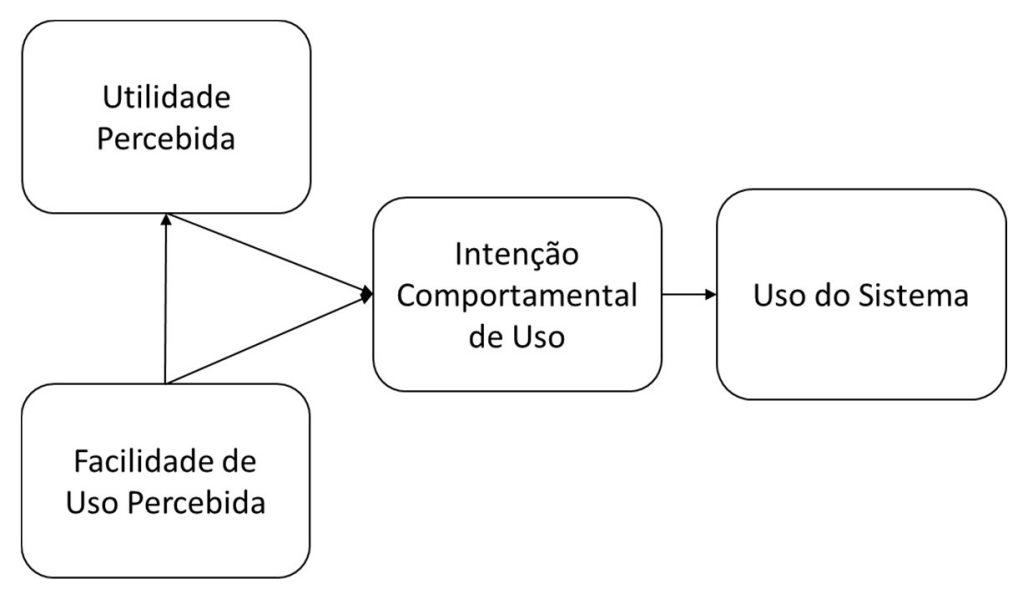

Fonte: Davis et al. (1989)

O modelo TAM2 surgiu como uma extensão do modelo TAM, tal como proposto por Venkatesh \& Davis (2000). No intuito de decompor a utilidade percebida, os autores propõem a incorporação, ao modelo original, de constructos de influência social (normas subjetivas, voluntariedade e imagem) e processos cognitivos (relevância do trabalho, qualidade do resultado e demonstrabilidade do resultado). Na Figura 20, a seguir, são apresentadas as relações entre os constructos.

Figura 20: TECNOLOGY ACCEPTANCE MODEL2 - TAM2

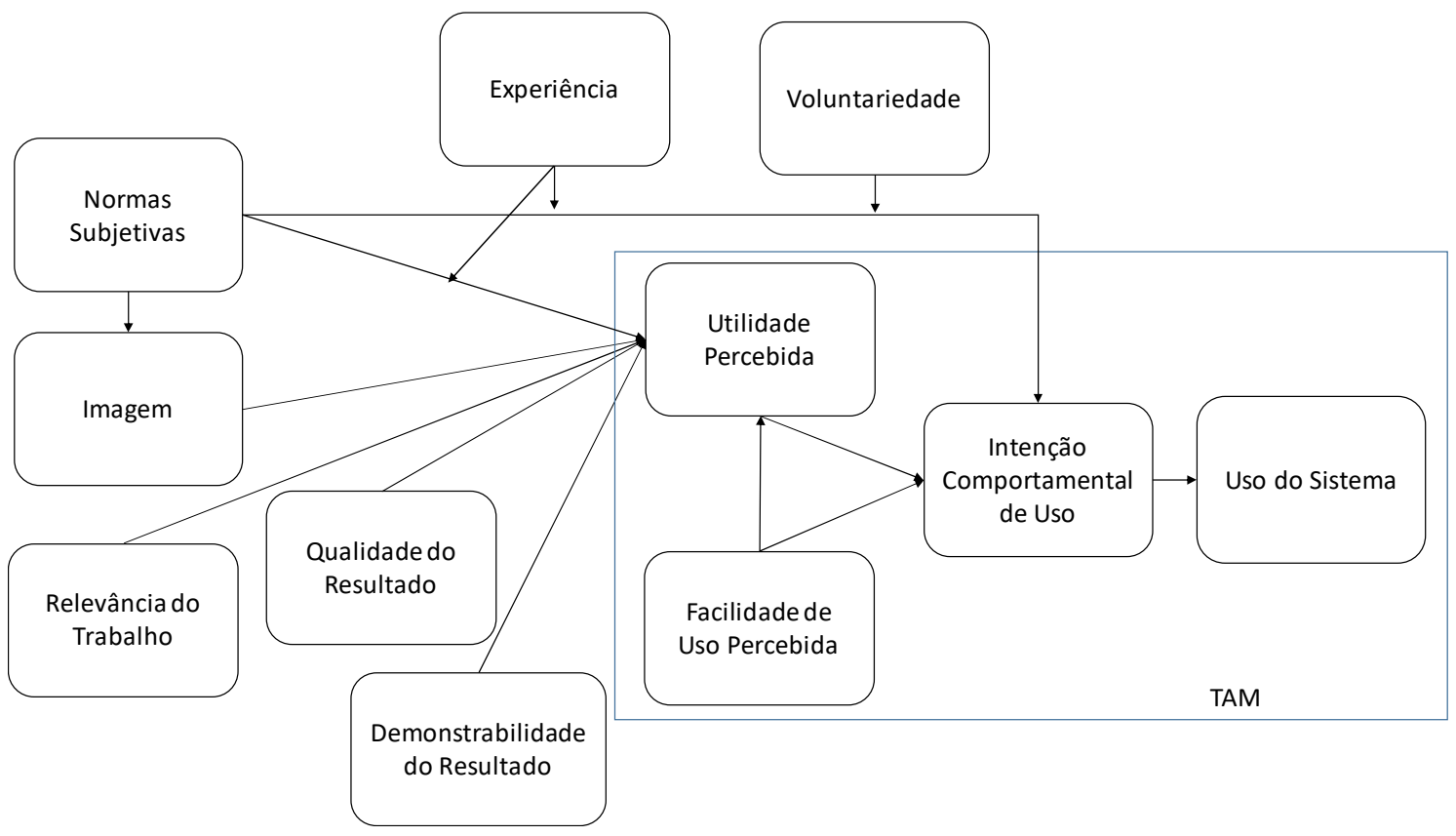

Fonte: Venkatesh \& Davis (2000) 


\subsection{MODELO MPCU - MODEL OF PC UTILIZATION}

O modelo MPCU foi proposto por Thompson, Higgins, \& Howell (1991) com o intuito de investigar a relação entre atitudes e uso do computador, uma área de estudo carente até então (Thompson et al., 1991). Esse modelo foi uma adaptação do trabalho de Triandis (1971), que preconiza que o comportamento pode ser explicado por quatro pilares: atitude, fatores sociais, hábito e consequências percebidas.

No modelo MPCU, os fatores que afetam a utilização do computador (PC) incluem consequências percebidas, afeto, fatores sociais e condições facilitadoras (Jen, Lu, \& Liu, 2009). Consequências percebidas são divididas em três constructos: complexidade, adequação à função e consequências de longo prazo do uso (Thompson et al., 1991). Os autores não incluíram o hábito, uma vez que esse constructo está diretamente ligado ao constructo final em avaliação, uso do PC. O modelo pode ser visualizado na Figura 21, a seguir.

Figura 21: MODEL OF PC UTILIZATION - MPCU

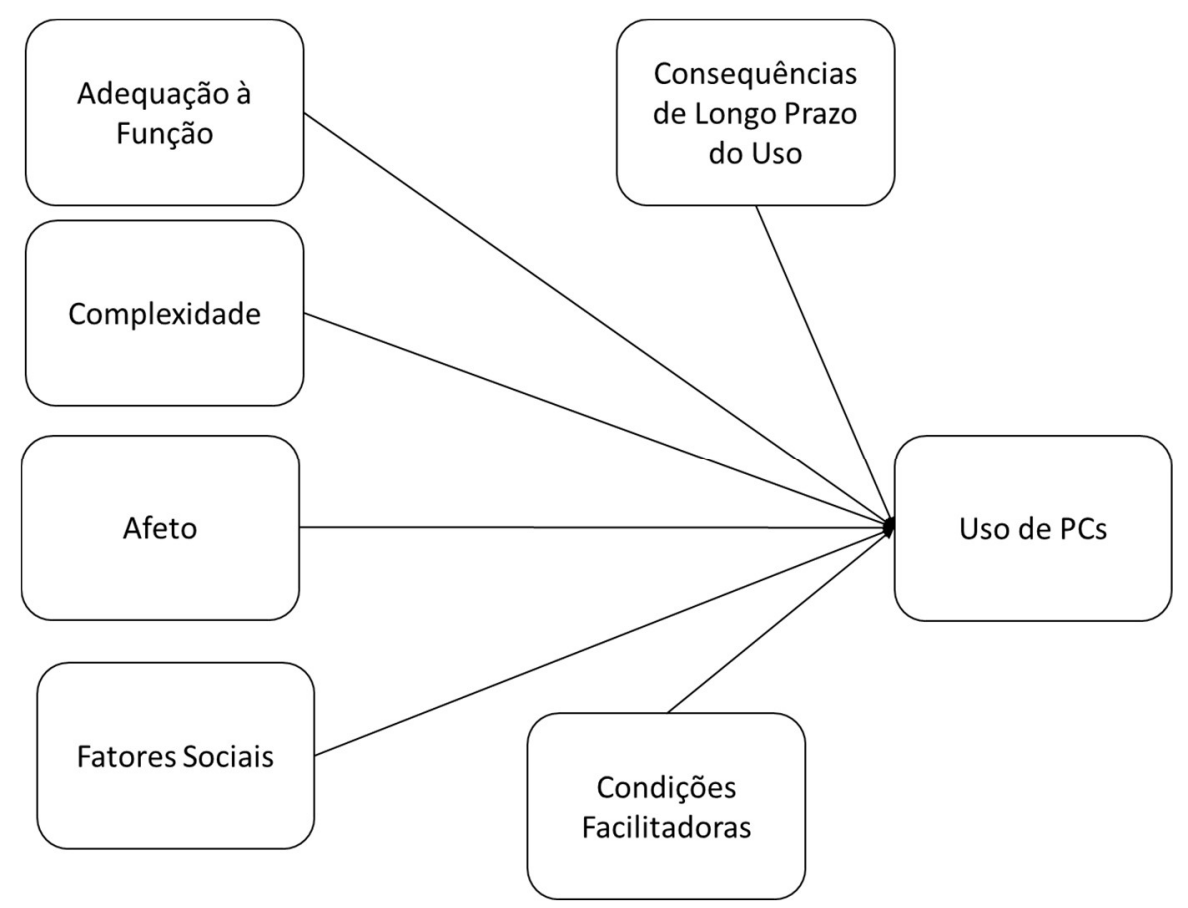

Fonte: Thompson et al. (1991)

\subsection{MODELO IDT - INNOVATION DIFFUSION THEORY}

Rogers (2003) apresentou o modelo IDT, utilizado para analisar como as percepções individuais podem prever ou explicar adoção de inovações tecnológicas e sua posterior difusão (Gutman et 
al., 2014). Inovação é uma ideia, prática ou objeto percebido como novo por um indivíduo. Difusão é o processo pelo qual a inovação é comunicada por meio de determinados canais, ao longo do tempo, para os membros de um sistema social (Rogers, 2003). O modelo é representado na Figura 22.

Figura 22: INNOVATION DIFFUSION THEORY - IDT

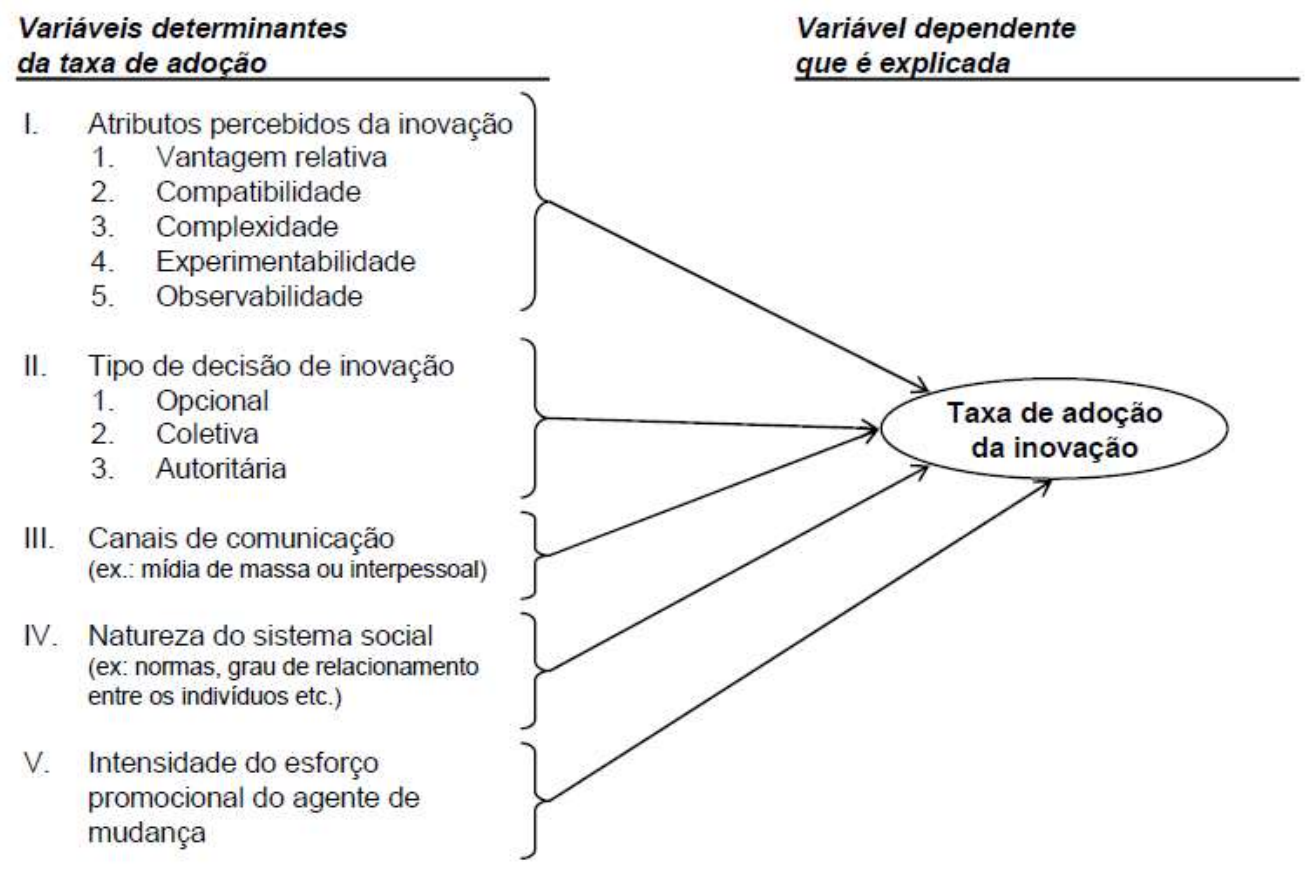

Fonte: Rogers (2003)

No modelo de Rogers (2003) a taxa de adoção da inovação é explicada por cinco variáveis determinantes: Atributos percebidos da inovação, Tipo de decisão de inovação, Canais de comunicação, Natureza do Sistema Social e Intensidade do esforço promocional do agente da mudança.

\subsection{MODELO DTPB - DECOMPOSED THEORY OF PLANNED BEHAVIOR}

O modelo DTPB é uma combinação dos modelos TAM e TPB anteriormente apresentados, idealizado por Taylor \& Todd (1995). Esses autores concluíram que o modelo TAM falha ao não incluir fatores sociais e de controle, que afetam o comportamento; como consequência, propõem a inclusão da norma subjetiva e do comportamento percebido como preditores do modelo (Jen et al., 2009), propondo as junções dos modelos TAM e TPB, conforme Figura 23. 
Figura 23: DECOMPOSED THEORY OF PLANNED BEHAVIOR - DTPB

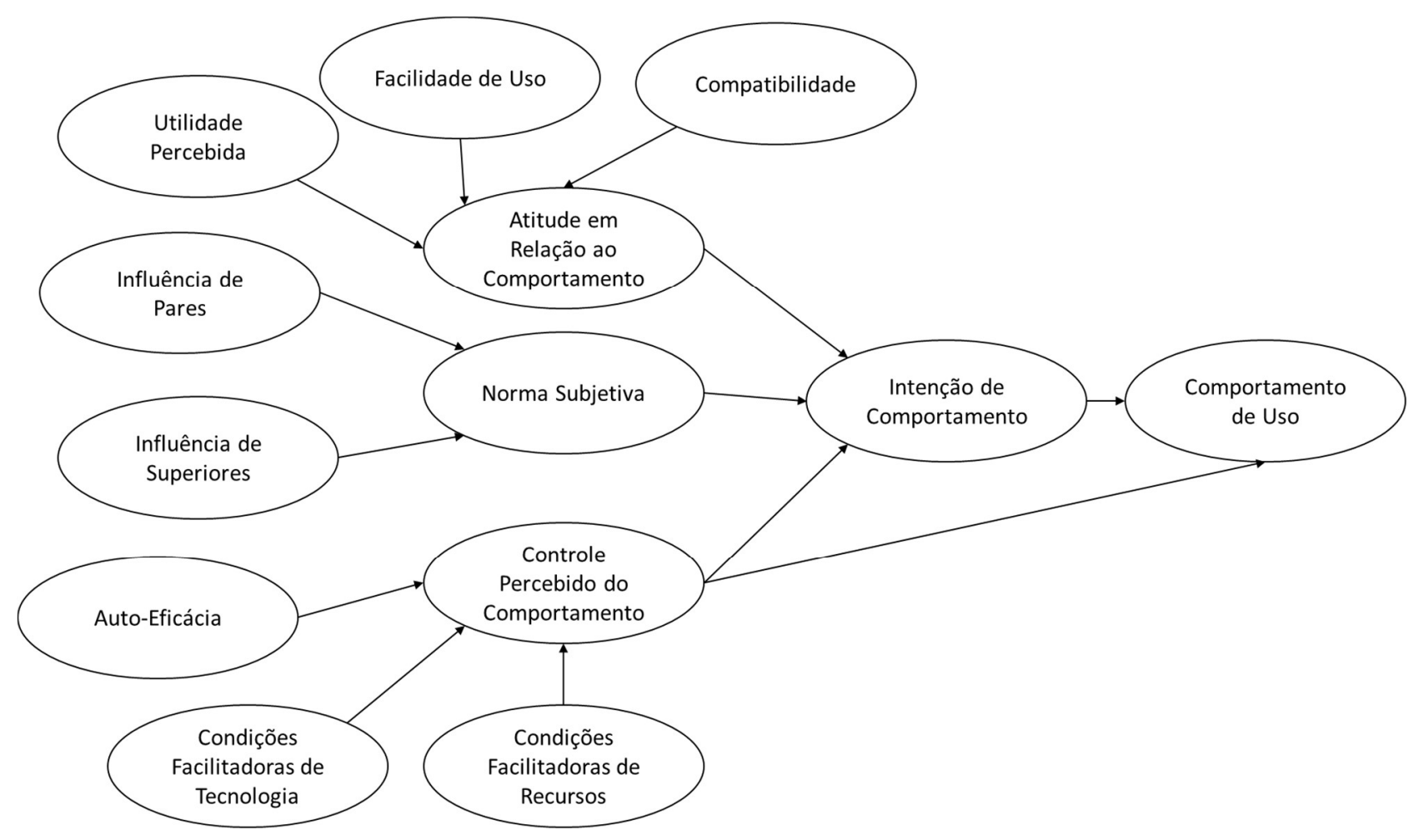

Fonte: Taylor \& Todd (1995)

\subsection{MODELO MM - MOTIVATIONAL MODEL}

Baseado na premissa que a motivação é o processo que empurra o indivíduo para atingir seus objetivos desejados, Davis, Bagozzi, \& Warshaw (1992) propuseram o modelo MM que inclui a motivação no modelo de aceitação da tecnologia. De acordo com os autores essa motivação pode ser extrínseca ou intrínseca.

Motivação intrínseca se refere à motivação do usuário em executar a tarefa, ao passo que a motivação extrínseca está ligada às recompensas esperadas ao se executar a tarefa, como reconhecimento, pagamento ou promoção (Jen et al., 2009). Utilidade percebida é o motor da motivação extrínseca, enquanto prazer é a palavra-chave da motivação intrínseca (Davis et al., 1992). Na sequência, a Figura 24 apresenta o modelo. 
Figura 24: MOTIVATIONAL MODEL - MM

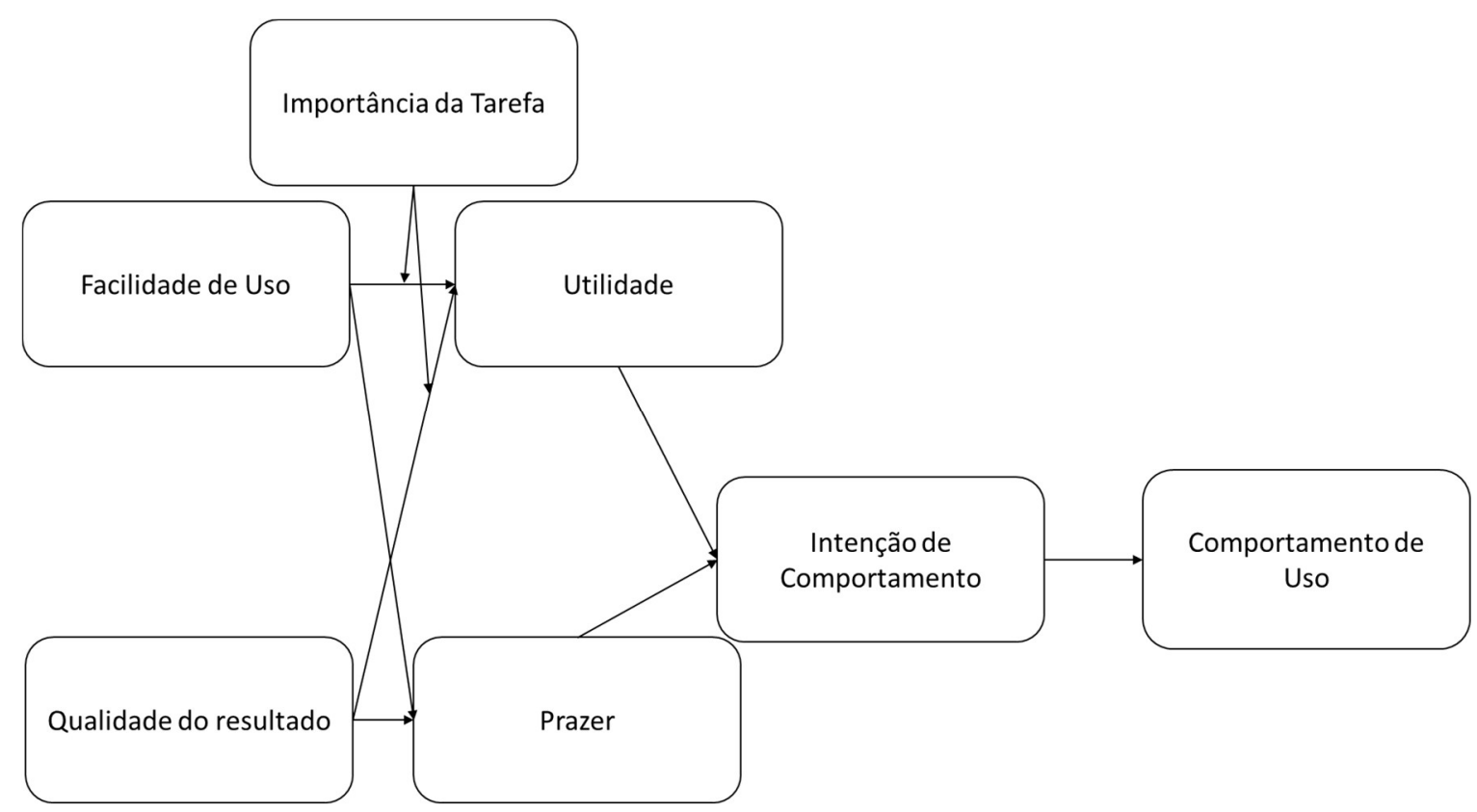

Fonte: Davis et al. (1992)

A Figura 24 mostra que as motivações extrínseca (Utilidade) e intrínseca (Prazer) são mediadores da intenção de comportamento, que, por sua vez, media o comportamento de uso.

\subsection{MODELO SCT - SOCIAL COGNITIVE THEORY}

O modelo SCT foi proposto por Bandura (1986), integrando as ideias de comportamento e aprendizado social. Uma década depois, Compeau \& Higgins (1995) adaptaram o modelo para a aceitação de tecnologia (Jen et al., 2009).

SCT é um modelo baseado na suposição que o comportamento de uso é influenciado pela motivação humana, seus pensamentos e inspirações, combinando-os com fatores do ambiente (Shu, Tu, \& Wang, 2011). Essa característica é chamada de determinismo recíproco (Compeau \& Higgins, 1995). O indivíduo cria e modifica o ambiente e as modificações que ele introduz afetam a ele próprio e, por sua vez, o seu comportamento e sua vida futura. O modelo pode ser visualizado na Figura 25. 
Figura 25: SOCIAL COGNITIVE THEORY - SCT

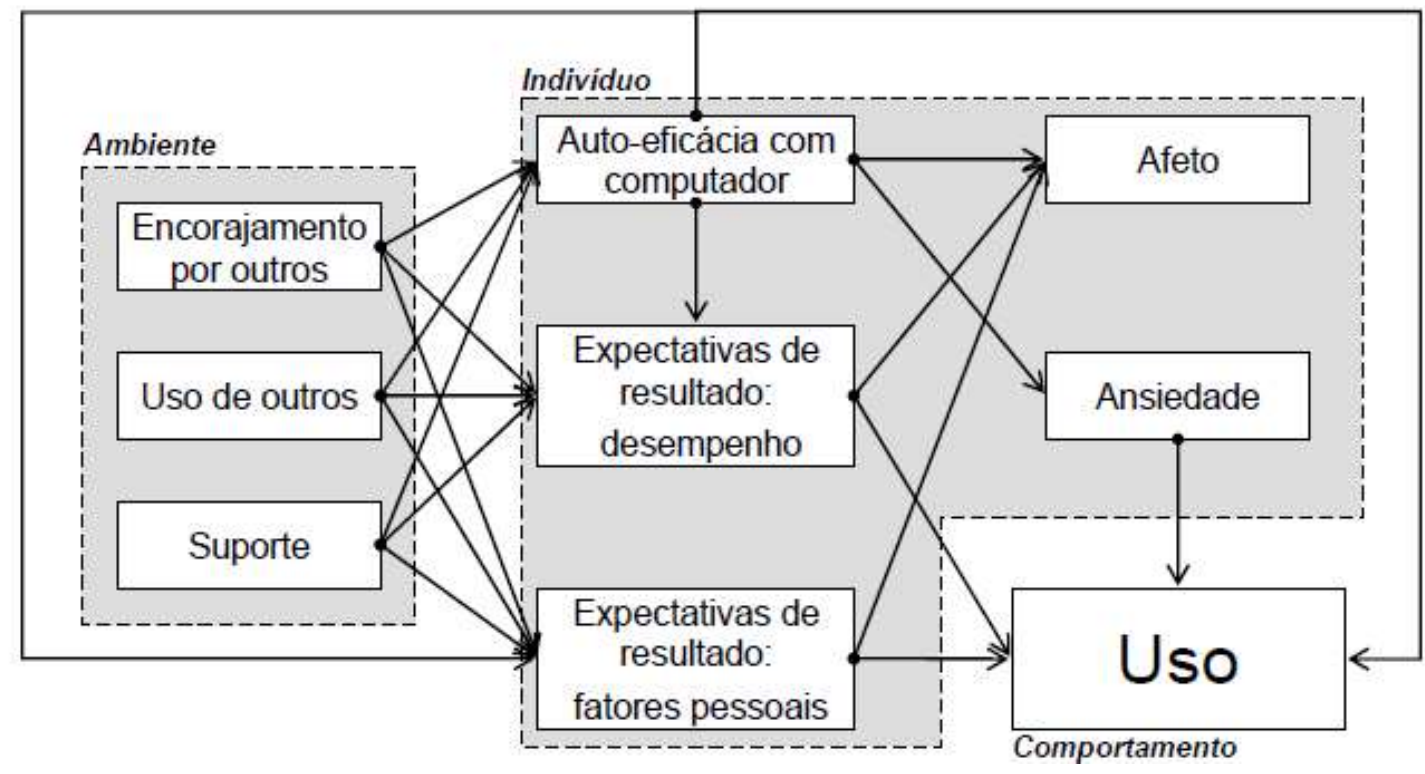

Fonte: Sá (2007) adaptado de Compeau \& Higgins (1995)

A Figura 25 indica como os fatores ambientais afetam o indivíduo, cujas reações afetam o comportamento de uso.

\subsection{MODELO UTAUT - UNIFIED THEORY OF ACCEPTANCE AND USE OF TECHNOLOGY}

O modelo UTAUT surgiu como uma evolução dos oito modelos citados nas seções anteriores (TRA, TPB, TAM/TAM2, MPCU, DTPB, IDT, MM e SCT). De acordo com Venkatesh et al. (2003), o UTAUT surgiu da convergência desses oito modelos. Li \& Kishore (2006) apontam que o modelo UTAUT é um dos mais completos para avaliação da aceitação de tecnologia. O modelo unificado apresenta quatro constructos determinantes diretos da intenção e comportamento de uso: Expectativa de desempenho, Expectativa de Esforço, Influência Social e Condições Facilitadoras (Williams, Rana, \& Dwivedi, 2015). As variáveis gênero, idade, experiência e voluntariedade (diz respeito à utilização da ferramenta de forma espontânea) são moderadoras das relações entre os constructos antecedentes (expectativa de desempenho, expectativa de esforço, influência social e condições facilitadoras) e os consequentes (intenção de uso e comportamento de uso). 
A Figura 26 mostra a estrutura do modelo. A seguir serão explicados os constructos.

Figura 26: UNIFIED THEORY OF ACCEPTANCE AND USE OF TECHNOLOGY UTAUT

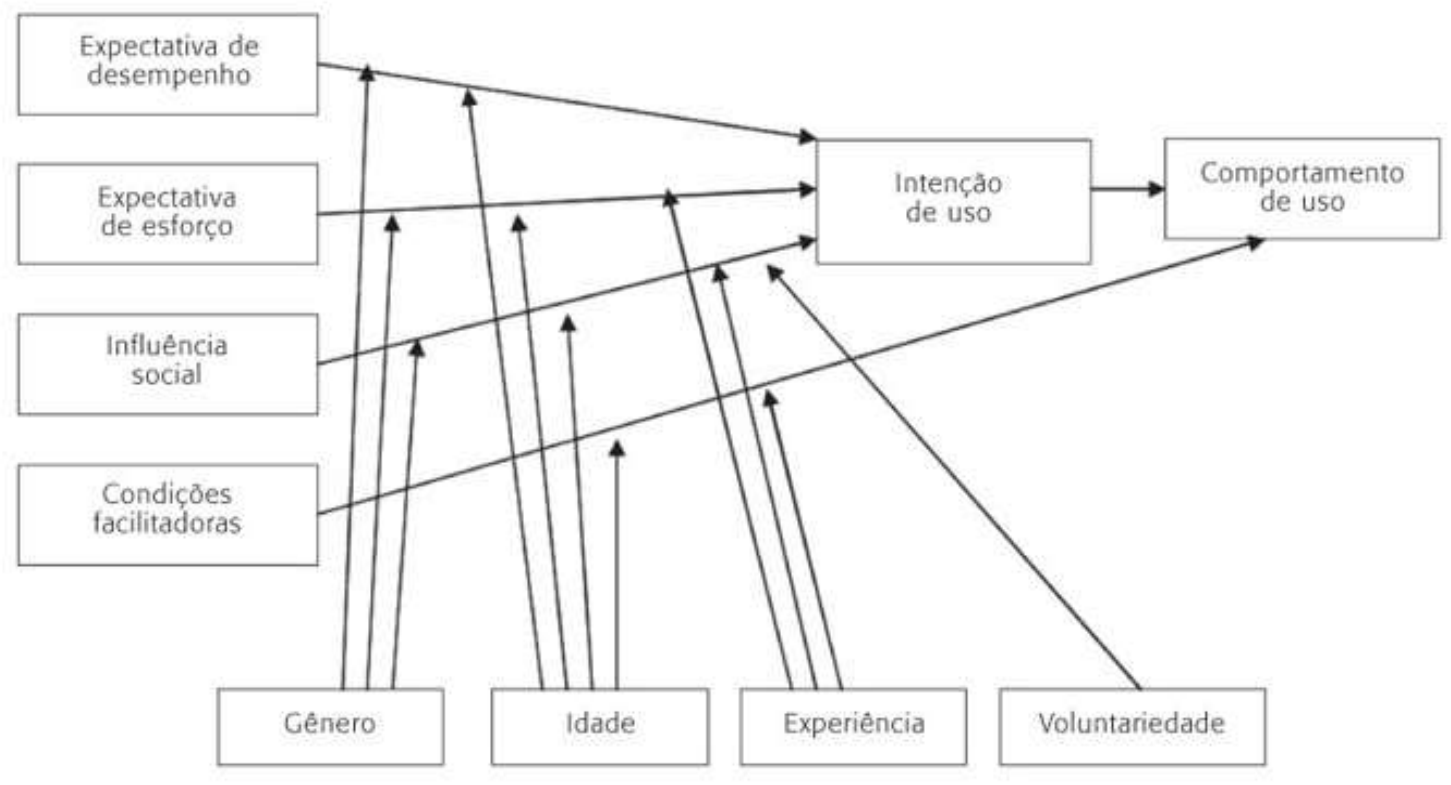

Fonte: Venkatesh et al. (2003)

Expectativa de desempenho é definida como o grau em que o indivíduo acredita que a utilização do sistema vai colaborar para atingir seus objetivos.

Expectativa de esforço diz respeito ao nível de facilidade para utilização do sistema.

Influência Social foca o grau em que o indivíduo percebe que pessoas importantes acreditem que ele deve utilizar o sistema.

Condições Facilitadoras aborda o grau em que o indivíduo acredita que existe uma infraestrutura organizacional e técnica para suportar o uso do sistema.

A Figura 27, retirada de Sá (2007), baseado em Venkatesh et al. (2003), aponta a origem de cada constructo do modelo UTAUT. 
Figura 27: Fatores Principais do Modelo UTAUT

\begin{tabular}{|c|c|c|c|}
\hline Construto & Definiça & Origem & \\
\hline $\begin{array}{l}\text { 1. Expectativa d } \\
\text { desempenho }\end{array}$ & $\begin{array}{l}\text { "Grau em que un individuo acredita } \\
\text { que o uso do sistema vai ajudá-lo a } \\
\text { atingir ganhos no resultado do trabalho" }\end{array}$ & 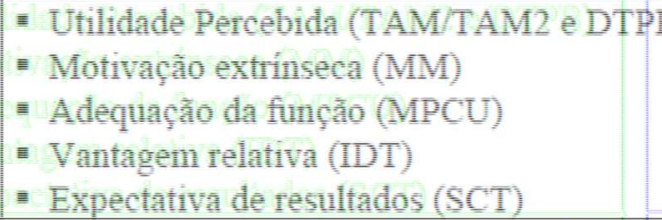 & B) \\
\hline $\begin{array}{l}\text { 2. Expectativa d } \\
\text { esforgstethat }\end{array}$ & \begin{tabular}{|l} 
"Grau de facilidade associada ao uso do \\
sistema" \\
w Fachilidadext \\
\end{tabular} & 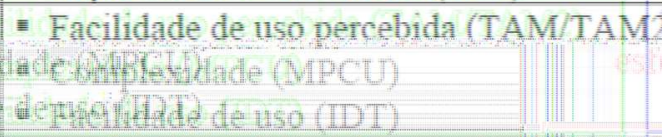 & \\
\hline 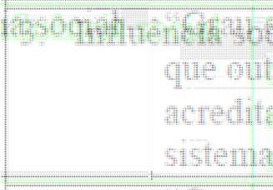 & 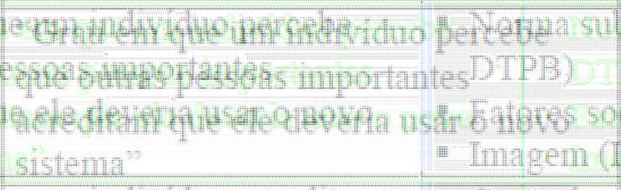 & 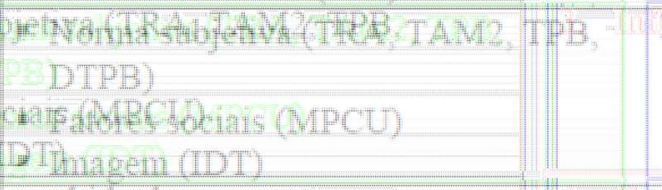 & 3 \\
\hline 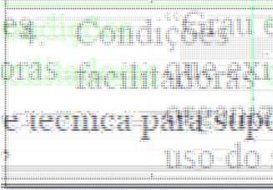 & 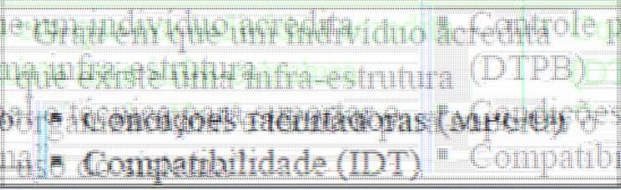 & 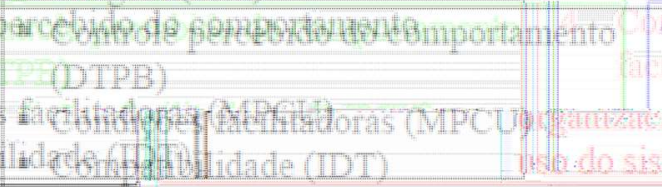 & \\
\hline
\end{tabular}

Fonte: Sá (2007)

\subsection{MODELO ECT - EXPECTATION-CONFIRMATION THEORY}

O modelo ECT foi apresentado a partir de dois artigos de Oliver (Oliver, 1977, 1980) e propõe que a expectativa do cliente e a performance do produto impactam a satisfação. Originalmente trata-se de uma teoria aplicada a marketing, que avalia a satisfação e o comportamento de uso dos consumidores (Hsu, Chang, \& Lin, 2013).

Bhattacherjee incorporou o constructo de utilidade percebida do modelo TAM para refletir a expectativa do usuário de TI (Bhattacherjee, 2001a, 2001b; Bhattacherjee \& Premkumar, 2004).

A Figura 28, a seguir, mostra a estrutura desse modelo.

Figura 28: EXPECTATION-CONFIRMATION THEORY - ECT

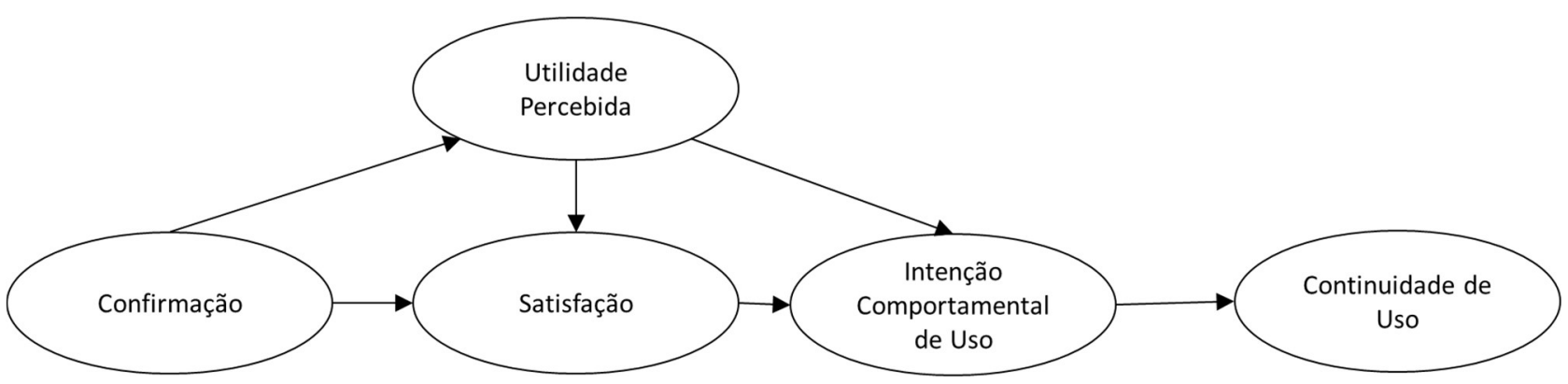

Fonte: Bhattacherjee (2001a, 2001b) 


\subsection{MODELO ADOTADO NESTE ESTUDO}

O modelo adotado neste estudo é uma combinação do modelo ECT incluindo um constructo de hábito retirado de Limayem, Hirt, \& Cheung (2007), influenciando a continuidade de uso e sendo influenciado pela satisfação, conforme proposto por Han et al. (2016). Além disso, foram incluídos dois constructos que suportam a Utilidade Percebida, conforme proposto por Pejić Bach et al. (2016), que propõem a utilização de um modelo TAM modificado em seu trabalho.

De acordo com Han et al. (2016), a inclusão do hábito tem um papel de combinar o consciente com o inconsciente uma vez que os respondentes tendem a responder de acordo com o ambiente, e não apenas com suas intenções pessoais. Já na visão de Pejić Bach et al., (2016), a inclusão do constructo de estratégia direcionada pela tecnologia se justifica, pois, estudos anteriores mostram que empresas que adotam este tipo de direcionador de estratégia têm melhor desenvolvimento no campo de ferramentas internas de tecnologia da informação. Os mesmos autores propõem a adoção do constructo de qualidade da informação baseados num estudo de Kuo \& Lee (2009), cuja pesquisa aborda a importância da qualidade da informação na utilidade percebida de um sistema de tomada de decisão.

A Figura 29, a seguir, apresenta o modelo utilizado neste estudo.

Figura 29: Modelo adotado neste estudo

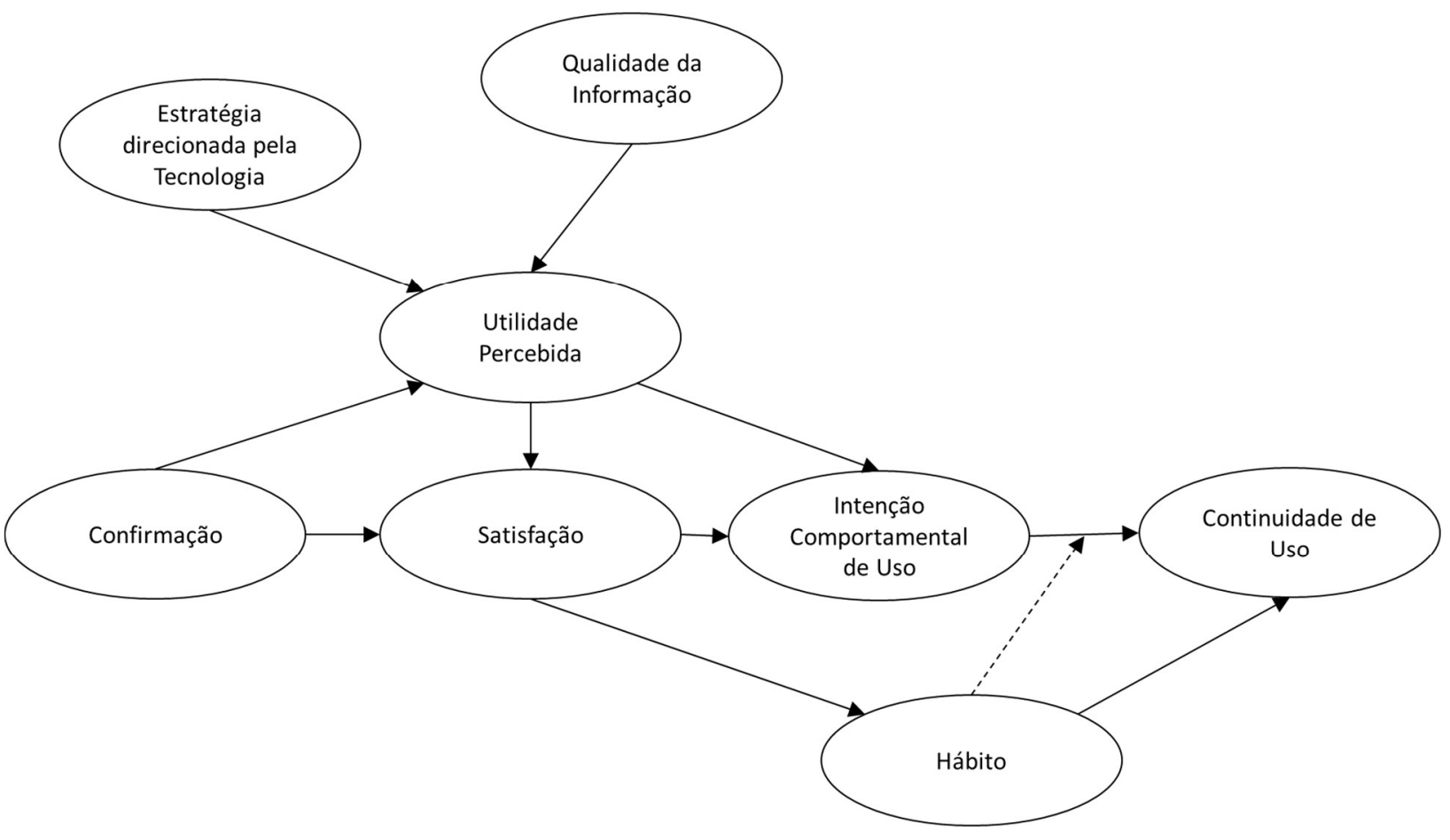

Fonte: $\mathrm{O}$ autor 
Os constructos que serão analisados no modelo são:

- Estratégia Direcionada pela Tecnologia é definida por Gatignon \& Xuereb (1997) como desenvolvimento, integração e uso de novas tecnologias em novos produtos e tecnologias. Estudos recentes (Pejić Bach et al., 2016) mostram que a estratégia direcionada pela tecnologia tem forte impacto no uso de TI.

- Qualidade da Informação afeta diretamente a satisfação do usuário com o uso da tecnologia e consequentemente as crenças sobre sua utilização (Wixom \& Todd, 2005).

- Confirmação define-se como a percepção do usuário em relação às suas expectativas prévias de uso do sistema de informação e seu desempenho real (Bhattacherjee, 2001b).

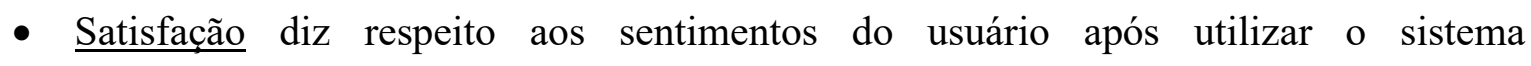
(Bhattacherjee, 2001b).

- Utilidade Percebida está relacionada com a crença que a pessoa tem de quanto a utilização da ferramenta será útil para a execução do seu trabalho.(Davis, 1989).

- Hábito refere-se à propensão de a pessoa utilizar automaticamente determinado sistema de informação quando se depara com uma situação específica (Limayem et al., 2007).

- Intenção Comportamental de Uso: diz respeito à disposição do usuário em utilizar o sistema de informação (Davis, 1989).

- Continuidade de Uso está ligada à recorrência com que o usuário utiliza a ferramenta (Bhattacherjee, 2001b).

Intenção e Continuidade são dois constructos que se diferenciam na relação temporal. Enquanto continuidade refere-se ao uso do sistema no passado (recente), no caso desta tese, nos últimos sete dias; intenção é um constructo mais ligado ao futuro, verifica a disposição de o respondente permanecer utilizando.

Esse modelo foi selecionado por se mostrar mais adequado para responder às perguntas apresentadas nesta tese, uma vez que identifica fatores que facilitam a utilização do sistema de $\mathrm{BI}$ e, ao mesmo tempo, considera o constructo da tecnologia como propulsora da estratégia e o impacto do mesmo na utilidade percebida da ferramenta.

No próximo capítulo são apresentados os aspectos metodológicos que nortearam o desenvolvimento deste estudo. 


\section{ASPECTOS METODOLÓGICOS}

O capítulo versa sobre os aspectos metodológicos que permitiram chegar aos resultados desta tese. Os tópicos abordados são:

- População e Amostra

- Instrumento de Coleta

- Hipóteses Testadas

- Técnicas Utilizadas

O Modelagem de Equações Estruturais

\subsection{POPULAÇÃO E AMOSTRA}

Como delimitação da população, foram selecionados funcionários que atuam em empresas de serviços que operam no Brasil. Nesse público foi selecionada uma amostra de empregados, independente do cargo, que utilizem sistemas de BI, para responder uma pesquisa quantitativa de corte transversal único.

A amostra foi realizada por conveniência do tipo bola de neve. O método bola de neve, proposto por Goodman (1961), significa que o pesquisador seleciona alguns respondentes e, para cada um deles, é solicitado que repasse o questionário para sua rede de contatos, que tenham perfil adequado para a pesquisa, gerando assim a bola de neve (Vieira, 2010). De acordo com Salganik \& Heckathorn (2004), bola de neve é uma técnica adequada para ser utilizada quando o pesquisador não conhece toda a população e é uma tarefa impraticável conhecê-la em virtude de tempo e custo. Por outro lado, Biernacki \& Waldorf(1981) apontam as limitações da técnica: o pesquisador não tem controle da amostra. Por ser um método não probabilístico não se podem extrapolar os resultados para a população e há um viés de seleção, dado que pessoas com uma rede de contatos maior têm maior probabilidade de serem indicadas para responder a pesquisa. 


\subsection{INSTRUMENTO DE COLETA}

Os Sistemas de Business Intelligence e Analytics são cada vez mais utilizados nas corporações, principalmente naquelas que participam de um ambiente muito competitivo (Grublješič \& Jaklič, 2014). Pesquisa de Bronzo, Resende, Oliveira, McCormack, Sousa, \& Ferreira (2013) aponta que o alinhamento do processo de BI com os objetivos da empresa tem efeito positivo nos resultados da organização. Os sistemas de BI\&A são importantes não somente para guardar informações e velocidade de processamento, mas, principalmente, pela capacidade de transformar dados em informações (Popovič et al., 2012). A questão-chave é uma vez implantado, avaliar a aceitação dos usuários e tirar proveito de toda a capacidade da ferramenta (Grubljesic \& Jaklic, 2015).

O questionário foi criado a partir da proposta dos trabalhos de Han et al. (2016) e Pejić Bach et al. (2016). Para os constructos continuidade de uso, intenção comportamental de uso, satisfação, confirmação, utilidade percebida, qualidade da informação, estratégia direcionada pela tecnologia e hábito, as assertivas foram propostas para serem respondidas em uma escala de 10 pontos. As questões demográficas foram aplicadas como questões de múltipla escolha, com a opção de o respondente preencher a resposta caso a mesma não estivesse entre as opções de resposta.

Constructo Continuidade de Uso:

- Nos últimos 7 dias, eu utilizei frequentemente o sistema de Business Intelligence.

- Nos últimos 7 dias, a cada vez que eu utilizei o sistema de Business Intelligence, eu gastei bastante tempo.

- Nos últimos 7 dias, eu utilizei o sistema de Business Intelligence várias vezes no mesmo dia.

Constructo Intenção Comportamental de Uso:

- Eu pretendo continuar utilizando o sistema de Business Intelligence enquanto a empresa tiver essa ferramenta.

- Minha intenção é utilizar o sistema de Business Intellingence ao invés de outras alternativas.

- Se eu puder eu gostaria de permanecer utilizando o sistema de Business Intelligence. 


\section{Constructo Satisfação:}

- Eu estou satisfeito com a performance do sistema de Business Intelligence.

- Considero sábia minha decisão de utilizar sistemas de Business Intelligence.

- Considero satisfatória minha experiência utilizando sistemas de Business Intelligence.

Constructo Confirmação:

- Minha experiência utilizando o sistema de Business Intelligence é melhor do que eu esperava.

- A qualidade do serviço do sistema de Business Intelligence é melhor do que eu esperava.

- No geral, minhas expectativas de uso do sistema de Business Intelligence foram confirmadas.

Constructo Utilidade Percebida:

- Utilizar sistemas de Business Intelligence melhora minha performance no trabalho.

- Utilizar sistemas de Business Intelligence melhora minha produtividade no trabalho.

- Utilizar sistemas de Business Intelligence melhora minha efetividade no trabalho.

- Em geral, o sistema de Business Intelligence é útil no trabalho.

Constructo Qualidade da Informação:

- As informações contidas no sistema de Business Intelligence estão organizadas de forma clara.

- A informação contida no sistema de Business Intelligence está disponível quando necessária.

- A informação contida no sistema de Business Intelligence é importante.

- A informação contida no sistema de Business Intelligence é significativa.

Constructo Estratégia Direcionada pela Tecnologia:

- Nossa companhia sabe o que "é melhor" para o cliente.

- Nossa companhia desenvolve produtos baseados em tecnologia.

- Nossos produtos têm qualidade superior.

Constructo Hábito:

- Usar o sistema de Business Intelligence é automático para mim.

- Usar o sistema de Business Intelligence é natural para mim.

- Quando tenho uma tarefa a realizar, utilizar o sistema de Business Intelligence é a minha escolha óbvia.

Questões demográficas: 
- Ramo de atividade da empresa

- Departamento em que o funcionário trabalha

- Escolaridade

- Sexo

- Idade

- Cargo

- Experiência: Anos como usuário de sistemas de BI.

\subsection{HIPÓTESES TESTADAS}

Com base no framework proposto no capítulo 3, as seguintes hipóteses foram testadas no modelo seguindo a mesma linha adotada pelos trabalhos de Han et al.(2016) e Pejić Bach et al. (2016), conforme mostrado na Figura 30.

Figura 30: Hipóteses testadas no modelo proposto

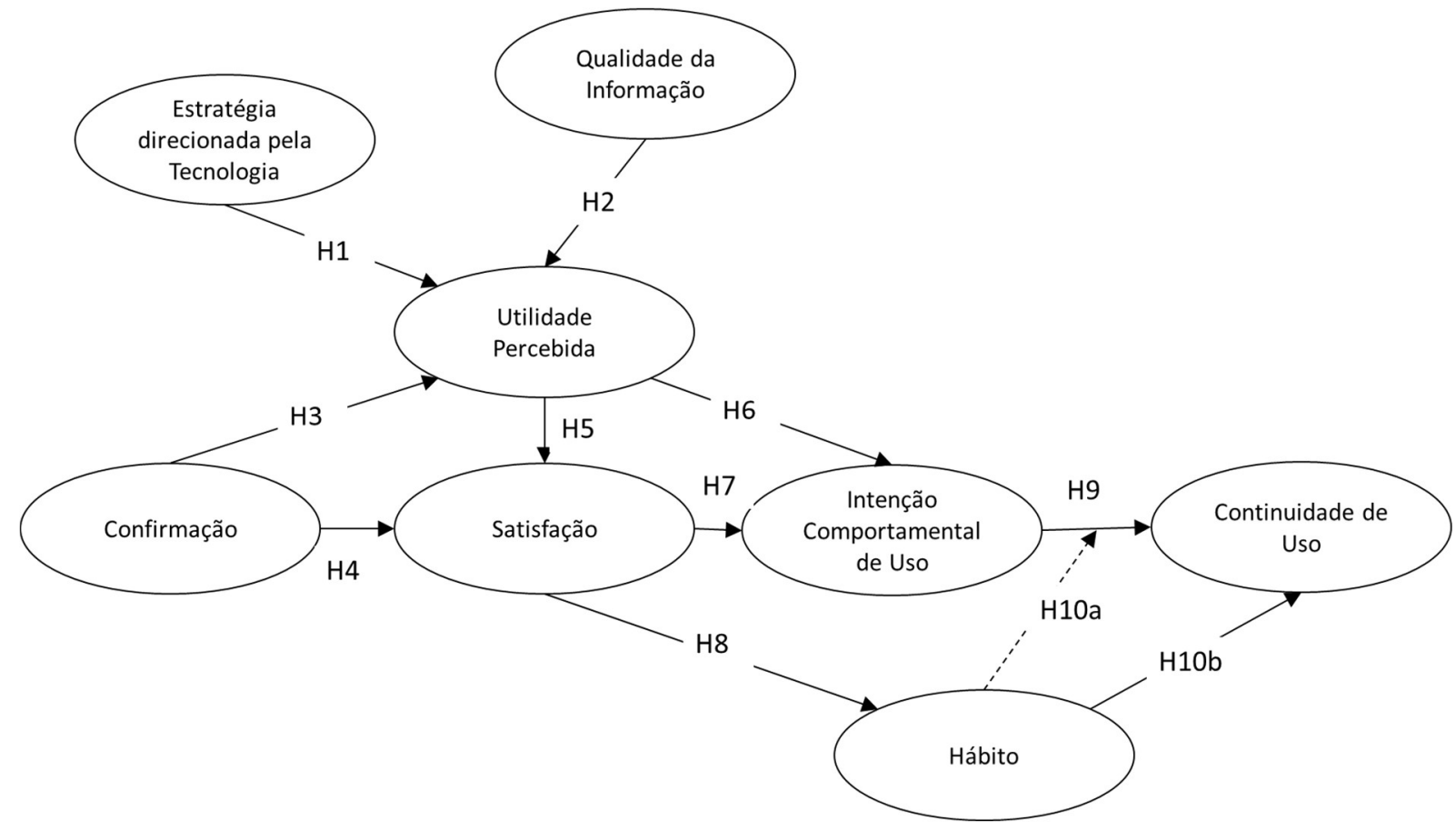

Fonte: $\mathrm{O}$ autor

H1: A Estratégia direcionada pela Tecnologia influencia de forma positiva a Utilidade Percebida.

H2: A Qualidade da Informação influencia de forma positiva a Utilidade Percebida. 
H3: Confirmação afeta de forma positiva a Utilidade Percebida.

H4: Confirmação afeta de forma positiva a Satisfação.

H5: A Utilidade Percebida tem efeito positivo na Satisfação.

H6: A Utilidade Percebida impacta de forma positiva a Intenção Comportamental de Uso.

H7: Satisfação tem impacto positivo na Intenção Comportamental de Uso.

H8: Satisfação influencia de forma positiva o Hábito.

H9: A Intenção Comportamental de Uso afeta de forma positiva a Continuidade de Uso.

H10a: O Hábito tem efeito moderador na relação entre Intenção Comportamental de Uso e Continuidade de Uso.

H10b: O Hábito tem efeito positivo na Continuidade de Uso.

\subsection{TÉCNICAS UTILIZADAS}

Para o alcance dos objetivos propostos neste trabalho foram analisados os dados obtidos na pesquisa quantitativa com o uso de técnicas estatísticas uni, bi e multivariadas, utilizando-se os softwares SPSS 21 e SmartPLS 3.2.1. Na seção 4.4.1 será detalhada a técnica multivariada Modelagem de Equações Estruturais que permitirá testar a adequação do modelo adotado neste estudo.

\subsubsection{MODELAGEM DE EQUAÇÕES ESTRUTURAIS}

Kaplan (2008) aponta que a modelagem de equações estruturais é uma técnica de análise de dados que se origina por métodos estatísticos tradicionalmente utilizados em três ciências: psicologia, econometria e genética. A tradição de trabalhar com análise fatorial é advinda da psicologia, já a modelagem de equações múltiplas é largamente utilizada em econometria, embora sua origem esteja na genética. De acordo com Sarstedt, Ringle, Smith, Reams, \& Hair (2014), um modelo de equações estruturais (MEE) é um método que permite aos pesquisadores modelar, simultaneamente estimando e testando teorias complexas com dados. As estruturas de relações entre as variáveis são expressas em um conjunto de equações similares à uma série de regressões múltiplas (Hair, Black, Babin \& Anderson, 2010). Dessa maneira, a técnica utiliza 
de princípios teóricos e lógicos dos modelos de análise fatorial com a lógica de teste das regressões múltiplas.

Para melhor entendimento da técnica é importante ressaltar que existem quatro principais tipos de relações causais entre as variáveis, de acordo com Silveira (2006). São eles:

a) Relações causais diretas, em que uma variável tem efeito direto em outra, o que também pode ocorrer de forma recíproca.

b) Relações causais indiretas em que uma variável causa efeito na outra por meio de uma terceira variável.

c) Relações espúrias, em que duas variáveis tem uma variável comum que exerce efeito em ambas.

d) Associação sem correlação, em que duas variáveis têm uma variável comum, mas não é possível determinar se a variável comum contribui para a covariação entre as duas variáveis em virtude de relações espúrias ou indiretas.

A Figura 31, a seguir, extraída de Silveira (2006), mostra graficamente os quatro tipos de relações causais (as setas indicam caminho ou relação de causa entre duas variáveis e um efeito direto entre elas).

Figura 31: Tipos de Relações Causais

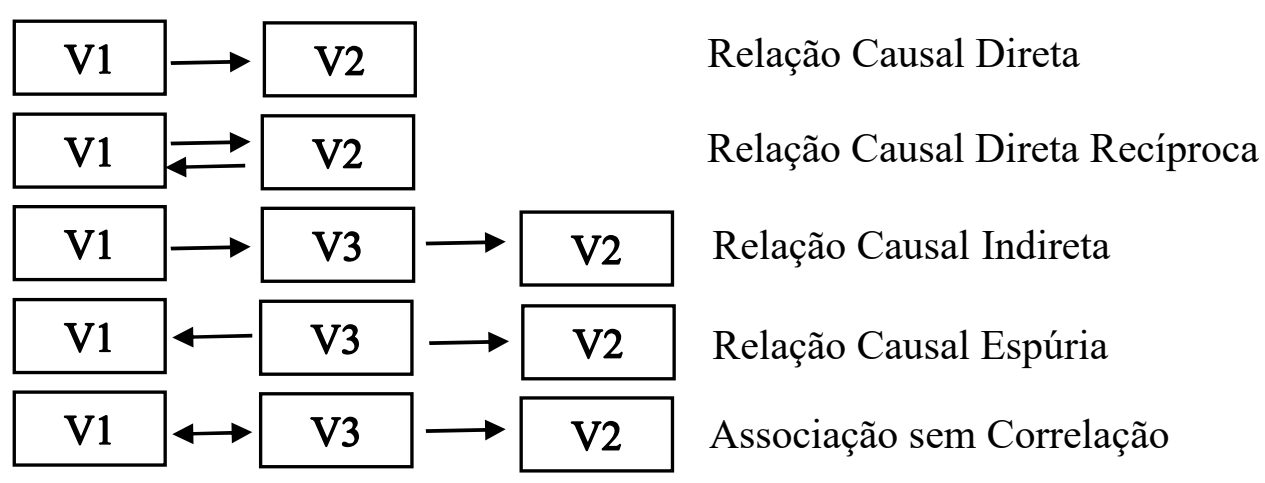

Fonte: Adaptado pelo autor a partir de Silveira (2006)

Na aplicação da técnica de modelagem de equações estruturais existem seis principais passos a serem seguidos (Iriondo, Albert, \& Escudero, 2003), conforme apresentados a seguir:

I. Especificação do Modelo: Essa primeira fase consiste em transformar as hipóteses em uma série de equações representadas na forma de uma análise de caminhos (path analysis). Análise de caminhos é a técnica estatística utilizada para mostrar a relação causal de duas ou mais variáveis (Silveira, 2006). Ela deve ser embasada por um 
conhecimento a priori entre a relação dessas variáveis, quer seja por experiências anteriores ou conhecimento teórico (Iriondo et al., 2003).

II. Identificação do Modelo: Consiste na definição de como será a estimação (única) de cada parâmetro para o modelo proposto com base nos dados utilizados. Essa estimativa vai depender da metodologia adotada para a construção do modelo, sendo baseada em variância e covariâncias (Stoelting, 2002).

III. Coleta de Dados: Dados de todas as variáveis utilizadas no modelo devem ser coletados na população de interesse. Uma estratégia de amostragem deve ser traçada de forma a alcançar as conclusões apropriadas (Iriondo et al., 2003).

IV. Estimativas do Modelo: A proposta nessa fase é estimar o valor dos parâmetros desconhecidos (Stoelting, 2002). O objetivo da estimativa é produzir parâmetros, de forma que a matriz de covariâncias convirja e a matriz de erros seja minimizada. Vários métodos podem ser utilizados para gerar as estimativas dos parâmetros. A escolha do método guia as características necessárias dos dados incluindo tamanho da amostra e sua distribuição.

V. Teste do Ajuste do Modelo: Nesse passo, o intuito é verificar se o modelo estimado se adequa aos dados. Nesse momento é avaliado o índice de adequação do modelo (GoF Goodness of Fit), no qual a covariância dos dados estimados é comparada com a estimativa do modelo (Iriondo et al., 2003). O diagnóstico do modelo não se limita apenas ao índice de adequação do modelo. Como será visto no próximo capítulo, existem diversos indicadores que atestam a qualidade do modelo.

VI. Readequação do Modelo: Em geral, modelos são rejeitados nos testes de ajustes em virtude de sua complexidade e grande número de restrições (Iriondo et al., 2003). Nesse estágio, o modelo necessita ser modificado para melhorar seus indicadores de ajuste e/ou aumentar sua simplicidade (Ringle, Da Silva, \& Bido, 2014) para melhorar os indicadores estatísticos. Para ajustar o modelo, novos caminhos serão criados ou caminhos existentes serão excluídos (Stoelting, 2002).

A classificação dos tipos de variáveis de um MEE pode ser feita sob diversos prismas. Quanto ao aspecto de serem mensuráveis ou não, elas podem ser classificadas em latentes ou observadas (Pilati \& Laros, 2007). Variáveis observadas (VO), também chamadas de indicadores ou variáveis medidas, são aquelas mensuradas diretamente pelo pesquisador. Já as variáveis latentes (VL), também chamadas de constructos, não são medidas diretamente, mas representadas por uma ou mais variáveis observadas (Malaeb, Summers, \& Pugesek, 2000). De 
acordo com Silveira (2006), para medir variáveis latentes utilizam-se de escalas multi-itens, nas quais são apresentados dois ou mais itens destinados a serem indicadores do mesmo constructo. Os escores de cada item são compostos de forma a compor um escore para o constructo (Koufteros, 1999).

Outro tipo de classificação pode ser feito quanto à influência que uma variável exerce sobre as outras. Nessa visão, as variáveis podem ser exógenas ou endógenas (Kaplan, 2008). Variáveis exógenas são aquelas que não são influenciadas ou não sofrem efeitos de outras, também chamadas de variáveis independentes (Silveira, 2006). São variáveis que no modelo "enviam" setas. Por outro lado, as variáveis endógenas ou dependentes são aquelas que recebem influência de outras variáveis presentes no modelo. São variáveis que no modelo "recebem" setas. Pela natureza dos MEE é possível uma variável ser endógena e exógena ao mesmo tempo, ou seja, comportar-se como variável dependente e independente (Pilati \& Laros, 2007).

Outro aspecto a ser considerado pelo pesquisador na construção de um MEE é que o modelo pode ser subdividido em dois momentos (Pilati \& Laros, 2007). O primeiro relativo ao estágio de mensuração, que diz respeito à qualidade das medidas utilizadas para aferir as variáveis latentes. Nesta fase, o pesquisador deve submeter as medidas à análise fatorial confirmatória (AFC) por meio da MEE e testar a qualidade das medidas a partir dos índices de adequação do modelo de mensuração, entre outros indicadores. O segundo momento é relacionado ao modelo estrutural e definem-se as relações de determinação e covariâncias que as variáveis latentes terão entre si.

Conforme Nakagawa (2008), a modelagem de equações estruturais apresenta métodos distintos de estimação dos parâmetros e mensuração dos modelos, sendo os mais utilizados o Modelo de Equações Estruturais Baseado em Covariâncias (MEEBC) e o Modelo de Equações Estruturais Partial Least Squares (MEEPLS). Zwicker, Souza, \& Bido (2008) apontaram as principais diferenças entre essas duas metodologias, conforme apresentado na Figura 32, a seguir. 
Figura 32: Diferenças entre MEEPLS e MEEBC

\begin{tabular}{|c|c|c|}
\hline Aspecto & MEEPLS (soff modeling) & MEEBC (hard modeling) \\
\hline Objetivo & Predição & $\begin{array}{l}\text { Explicação: modelos causais, teste de } \\
\text { teoria }\end{array}$ \\
\hline Abordagem & Baseado na variância & Baseado na covariância \\
\hline Precisão & $\begin{array}{l}\text { Consistente conforme aumentam o } \\
\text { tamanho da amostra (consistency) e a } \\
\text { quantidade de indicadores (consistency } \\
\text { at large) }\end{array}$ & Ótimo para amostras grandes \\
\hline Variáveis latentes (VI) & $\begin{array}{l}\text { Combina ções lineares dos indicadores; } \\
\text { escores fatoriais são estimados } \\
\text { explicitamente }\end{array}$ & $\begin{array}{l}\text { Indeterminância fatorial: diversos } \\
\text { modelos podem reproduzir a matriz de } \\
\text { covariâncias }\end{array}$ \\
\hline Modelo de mensuração & $\begin{array}{l}\text { Pode haver indicadores formativos ou } \\
\text { reflexivos }\end{array}$ & Apenas indicadores reflexivos \\
\hline Requisitos quanto à teoria & $\begin{array}{l}\text { Mais flexivel, contexto mais } \\
\text { exploratório }\end{array}$ & Fortemente dependente da teoria \\
\hline Distribuição dos dados & $\begin{array}{l}\text { Nà̀ há suposições, por isso, se diz que é } \\
\text { soft }\end{array}$ & $\begin{array}{l}\text { Dependendo do método de estimação, as } \\
\text { variáveis devem apresentar distribuição } \\
\text { normal multivariada }\end{array}$ \\
\hline Tamanho da amostra & $\begin{array}{l}\text { Análise do poder estatístico com a } \\
\text { porção do modelo que possui o maior } \\
\text { número de preditores ou } 10 \text { vezes o } \\
\text { maior numero de preditores (indicadores } \\
\text { formativos ou setas estruturais chegando } \\
\text { até a VL, o que for maior). O minimo } \\
\text { recomendado é de } 30 \text { a } 100 \text { casos }\end{array}$ & $\begin{array}{l}\text { Idealmente baseado na análise do poder } \\
\text { estatistico, sendo o minimo recomendado } \\
\text { da ordem de } 200 \text { casos }\end{array}$ \\
\hline $\begin{array}{l}\text { Identificação } \\
\text { (estimação única dos } \\
\text { parâmetros) }\end{array}$ & $\begin{array}{l}\text { Para modelos recursivos é sempre } \\
\text { identificado }\end{array}$ & $\begin{array}{l}\text { Depende do modelo e deve ter pelo menos } \\
\text { de } 3 \text { a } 4 \text { indicadores por VL. Necessário } \\
\text { impor restrições aos parâmetros. Três } \\
\text { problemas: às vezes o modelo não } \\
\text { converge, soluções impróprias e } \\
\text { indeterminância fatorial }\end{array}$ \\
\hline $\begin{array}{l}\text { Significância dos } \\
\text { Parâmetros }\end{array}$ & $\begin{array}{l}\text { Estimada por métodos não-paramétricos, } \\
\text { por exemplo, bootstrapping }\end{array}$ & $\begin{array}{l}\text { Geralmente, estimada por métodos } \\
\text { paraméuricos, mas bootstrapping é uma } \\
\text { opção. } 3\end{array}$ \\
\hline Compleridade & $\begin{array}{l}\text { Capaz de lidar com alta complexidade } \\
\text { (100 constructos e } 1000 \text { indicadores) }\end{array}$ & $\begin{array}{l}\text { Complexidade de média a moderada } \\
\text { (menos de } 100 \text { indicadores). }\end{array}$ \\
\hline $\begin{array}{l}\text { Inclusão de restrições nos } \\
\text { parâmetros do modelo }\end{array}$ & $\begin{array}{l}\text { Mesmo que não haja seta entre as VI, } \\
\text { supõe-se que elas tenham correlação } \\
\text { entre si. Não é possível impor restrições } \\
\text { aos parâmetros do modelo, como por } \\
\text { exemplo, fixando valores para } \\
\text { correlação entre duas VI }\end{array}$ & $\begin{array}{l}\text { Se não houver setas entre as VI, assume- } \\
\text { se que a correlação entre elas seja zero } \\
\text { (restrição implicita). É possível impor } \\
\text { restriçôes em qualquer parâmetro do } \\
\text { modelo, fixando-se valores ou relação } \\
\text { entre valores }\end{array}$ \\
\hline
\end{tabular}

Fonte: Adaptado de Zwicker, Souza, \& Bido (2008)

Nesta tese, o método de estimação utilizado foi o PLS em razão de sua maior simplicidade de aplicação e flexibilidade quanto à distribuição dos dados e ao tamanho amostral. 
${ }^{3}$ Bootstrapping é uma técnica de reamostragem, na qual, partindo-se da amostra original, sorteiam-se com reposição, várias amostras de igual tamanho com o intuito de estimar os parâmetros da população (Awang, Afthanorhan, \& Asri, 2015). 


\section{ANÁLISE DE DADOS}

A seguir, são apresentados os resultados das análises da pesquisa realizada, e o teste das hipóteses apresentadas neste trabalho.

\subsection{AMOSTRA OBTIDA}

O pré-teste foi feito com seis respondentes especialistas em sistemas de Business Intelligence entre os dias 27/04/2017 e 05/05/2017. A esses primeiros respondentes foi solicitado que preenchessem o questionário no link indicado e posteriormente foi feita uma entrevista pessoal com cada um deles para entender as dúvidas e dificuldades no preenchimento da pesquisa. Com base nas observações feitas uma questão foi modificada.

O questionário definitivo foi aplicado entre os dias 05/05/2017 e 22/09/2017, produzindo um total de 81 respondentes. Desses respondentes, um questionário foi extraído da amostra, pois o respondente não preenchia o requisito de atuar na área de serviços. O questionário foi aplicado com o auxílio da ferramenta SurveyMonkey (pt.surveymonkey.com). As assertivas eram apresentadas de forma aleatória ao respondente. Na construção do instrumento de pesquisa foi definido que o questionário só seria finalizado se todas as perguntas fossem respondidas. Dessa forma, nenhuma pergunta apresentou valores missing. Nas próximas seções serão apresentados os resultados obtidos.

\subsection{ANÁLISE UNIVARIADA}

Inicialmente foi aplicada análise univariada a cada assertiva que compõe os constructos. A Tabela 2, a seguir, mostra os resultados da análise univariada para cada assertiva. 
Tabela 2: Análise Univariada das Assertivas

\begin{tabular}{|c|c|c|c|c|c|c|c|c|c|}
\hline Constructo & Assertiva & $\mathrm{N}$ & Mínimo & Máximo & Média & $\begin{array}{l}\text { Desvio } \\
\text { padrão }\end{array}$ & \begin{tabular}{|l|} 
Coeficiente \\
de Variação
\end{tabular} & Mediana & Moda \\
\hline \multirow{3}{*}{$\begin{array}{c}\text { Continuidade de } \\
\text { uso }\end{array}$} & Nos últimos 7 dias, eu utilizei frequentemente o sistema de Business Intelligence. & 80 & $\overline{1}$ & 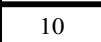 & 7,70 & 2,83 & 36,76 & 8 & 10 \\
\hline & Nos últimos 7 dias, a cada vez que eu utilizei sistema de Business Intelligence, eu gastei bastante tempo & 80 & 1 & 10 & 6,14 & 2,46 & 40,06 & 6 & 3 \\
\hline & Nos últimos 7 dias, eu utilizei o sistema de Business Intelligence várias vezes no mesmo dia. & 80 & 1 & 10 & 7,68 & 2,76 & 36,01 & 8 & 10 \\
\hline \multirow{3}{*}{$\begin{array}{c}\text { Intenção } \\
\text { Comportamental } \\
\text { de Uso }\end{array}$} & Eu pretendo continuar utilizando o sistema de Business Intelligence enquanto a empresa tiver essa ferramenta. & 80 & 1 & 10 & 8,83 & 1,72 & 19,48 & 10 & 10 \\
\hline & M inha intenção é utilizar o sistema de Business Intellingence ao invés de outras alternativas. & 80 & 1 & 10 & 7,49 & 2,16 & 28,90 & 8 & 8 \\
\hline & Se eu puder eu gostaria de permanecer utilizando o sistema de Business Intelligence. & 80 & 1 & 10 & 8,54 & 1,87 & 21,89 & 9 & 10 \\
\hline \multirow[t]{3}{*}{ Satisfação } & Eu estou satisfeito com a performance do sistema de Business Intelligence. & 80 & 1 & 10 & 7,01 & 2,10 & 29,89 & 8 & 8 \\
\hline & Considero satisfatória minha exp eriência utilizando sistemas de Business Intelligence & 80 & 1 & 10 & 7,56 & 1,85 & 24,43 & 8 & 8 \\
\hline & \begin{tabular}{|l} 
Considero sábia minha decisão de utilizar sistemas de Business Intelligence. \\
\end{tabular} & 80 & 5 & 10 & 8,61 & 1,57 & 18,24 & 9 & 10 \\
\hline \multirow[t]{3}{*}{ Confirmação } & M inha exp eriência utilizando o sistema de Business Intelligence é melhor do que eu esperava. & 80 & 1 & 10 & 7,21 & 2,20 & 30,46 & 8 & 8 \\
\hline & A qualidade do serviço do sistema de Business Intelligence é melhor do que eu esperava. & 80 & 1 & 10 & 6,84 & 2,20 & 32,11 & 7 & 8 \\
\hline & No geral, minhas exp ectativas de uso do sistema de Business Intelligence foram confirmadas. & 80 & 1 & 10 & 7,40 & 1,96 & 26,47 & 8 & 8 \\
\hline \multirow{4}{*}{$\begin{array}{l}\text { Utilidade } \\
\text { Percebida }\end{array}$} & Utilizar sistemas de Business Intelligence melhora minha performance no trabalho. & 80 & 1 & 10 & 8,49 & 1,71 & 20,10 & 9 & 10 \\
\hline & Utilizar sistemas de Business Intelligence melhora minha produtividade no trabalho. & 80 & 3 & 10 & 8,45 & 1,61 & 19,10 & 9 & 10 \\
\hline & Utilizar sistemas de Business Intelligence melhora minha efetividade no trabalho. & 80 & 1 & 10 & 8,41 & 1,64 & 19,54 & 9 & 10 \\
\hline & Em geral, o sistema de Business Intelligence é útil no trabalho. & 80 & 2 & 10 & 8,79 & 1,55 & 17,62 & 9 & 10 \\
\hline \multirow{4}{*}{$\begin{array}{l}\text { Qualidade da } \\
\text { Informação }\end{array}$} & As informações contidas no sistema de Business Intelligence estão organizadas de forma clara. & 80 & 1 & 10 & 6,84 & 2,17 & 31,69 & 7 & $7 \mathrm{e} 8$ \\
\hline & A informação contida no sistema de Business Intelligence está disp onível quando necessária. & 80 & 1 & 10 & 7,21 & 1,99 & 27,53 & 7 & 7 \\
\hline & A informação contida no sistema de Business Intelligence é imp ortante. & 80 & 3 & 10 & 9,01 & 1,41 & 15,64 & 10 & 10 \\
\hline & A informação contida no sistema de Business Intelligence é significativa & 80 & 1 & 10 & 8,39 & 1,78 & 21,17 & 9 & 10 \\
\hline \multirow{3}{*}{$\begin{array}{c}\text { Estratégia } \\
\text { direcionada pela } \\
\text { Tecnologia }\end{array}$} & Nossa companhia sabe o que "é melhor" para o cliente. & 80 & 1 & 10 & 7,06 & 2,12 & 30,09 & 7 & 7 \\
\hline & Nossa companhia desenvolve produtos baseados em tecnologia. & 80 & 1 & 10 & 7,96 & 1,92 & 24,10 & 8 & 10 \\
\hline & Nossos produtos têm qualidade sup erior. & 80 & 1 & 10 & 7,40 & 2,24 & 30,30 & 8 & 8 \\
\hline \multirow[t]{3}{*}{ Hábito } & Usar o sistema de Business Intelligence é automático p ara mim. & 80 & 1 & 10 & 7,76 & 2,15 & 27,75 & 8 & 10 \\
\hline & Usar o sistema de Business Intelligence é natural para mim. & 80 & 1 & 10 & 8,16 & 2,06 & 25,22 & 9 & 10 \\
\hline & Quando tenho uma tarefa a realizar, utilizar o sistema de Business Intelligence é a minha escolha óbvia. & 80 & 1 & 10 & 7,69 & 2,11 & 27,50 & 8 & 8 \\
\hline
\end{tabular}

Fonte: Dados coletados processados 
$\mathrm{Na}$ análise da Tabela 2, nota-se que todas as assertivas tiveram média maior que 6 , sendo que as menores médias foram das assertivas: "Nos últimos 7 dias, a cada vez que eu utilizei sistema de Business Intelligence, eu gastei bastante tempo" - $(6,14)$; "A qualidade do serviço do sistema de Business Intelligence é melhor do que eu esperava." - $(6,84)$; "As informações contidas no sistema de Business Intelligence estão organizadas de forma clara. " - $(6,84)$. Por outro lado, as assertivas que apresentaram maior concordância foram: “A informação contida no sistema de Business Intelligence é importante.” - (média 9,01; moda 10; mediana 10); "Eu pretendo continuar utilizando o sistema de Business Intelligence enquanto a empresa tiver essa ferramenta." - (média 8,83; moda 10; mediana 10); “Em geral, o sistema de Business Intelligence é útil no trabalho." - (média 8,79; moda 10; mediana 9).

As variáveis demográficas, que foram apresentadas no questionário como faixas, serão apresentadas na forma de tabelas de frequência na sequência. A Tabela 3 mostra as características da amostra em relação a gênero, idade e grau de instrução.

Tabela 3: Dados demográficos da amostra coletada

\begin{tabular}{cc|cc|cc}
\hline Gênero & $\%$ & Idade & $\%$ & Grau de Instrução & $\%$ \\
\hline Feminino & $15,0 \%$ & Menos de 30 anos & $16,2 \%$ & Sup erior Incompleto & $6,2 \%$ \\
\hline Masculino & $85,0 \%$ & 30 a 35 anos & $33,8 \%$ & Superior Completo & $27,5 \%$ \\
\hline & & 36 a 45 anos & $38,8 \%$ & Pós- Graduação & $57,5 \%$ \\
\hline & & Mais de 45 anos & $11,2 \%$ & Mestrado & $8,8 \%$ \\
\hline
\end{tabular}

Fonte: Dados coletados processados

Observa-se na Tabela 3 que a maior parte da amostra é do sexo masculino (85\%), a idade está concentrada entre 30 e 45 anos $(72,6 \%)$ e, merece destaque, a concentração de pósgraduados $(57,5 \%)$, quando se analisa o grau de instrução.

Na sequência é apresentada a Tabela 4, que demonstra as características profissionais dos respondentes da amostra. 
Tabela 4: Características profissionais dos respondentes

\begin{tabular}{|c|c|c|c|c|c|c|c|}
\hline Ramo da Empresa & $\%$ & Departamento & $\%$ & Cargo & $\%$ & Tempo de Experiência com BI & $\%$ \\
\hline Telecom & $50,0 \%$ & Financeiro & $40,0 \%$ & Analista/Consultor & $52,5 \%$ & Menos de 1 ano & $7,4 \%$ \\
\hline Bancário & $22,5 \%$ & Planejamento Estratégico & $18,8 \%$ & Coordenador/Supervisor & $16,3 \%$ & De 1 a 3 anos & $21,3 \%$ \\
\hline Consultoria & $16,3 \%$ & Tecnologia da Informação (TI) & $17,5 \%$ & Média Gerência & $20,0 \%$ & Mais de 3 anos & $71,3 \%$ \\
\hline Tecnologia & $6,3 \%$ & Marketing & $13,8 \%$ & Alta Gerência & $11,2 \%$ & & \\
\hline Outros & $4,9 \%$ & Outros & $9,9 \%$ & & & & \\
\hline
\end{tabular}

Fonte: Dados coletados processados

A maior concentração de respondentes (50\%) vem da área de Telecomunicações, o que é natural visto que a experiência profissional do autor deste trabalho é este segmento; a área de atuação do respondente é principalmente a Financeira (40\%), embora as áreas de Planejamento Estratégico, Tecnologia da Informação e Marketing também estejam bem representadas na amostra. Quanto ao cargo do respondente, a maior parcela foi representada por analistas/consultores (52,5\%); entretanto, a representação de cargos de gestão (coordenadores, supervisores, média e alta gerência) é bastante significativa (47,5\%). Finalmente, foi questionado o tempo de experiência do usuário com sistemas de $\mathrm{BI}$, e a grande parcela dos respondentes tem mais de 3 anos de experiência (71,3\%).

\subsection{ANÁLISE BIVARIADA}

Neste tópico serão comparadas as respostas dadas nas assertivas de acordo com as características demográficas e profissionais, apresentadas no tópico anterior; algumas categorias serão agrupadas em virtude do tamanho da amostra. A variável gênero não será objeto de comparação, visto que o número de mulheres respondentes foi pequeno. Utilizar-se-á o teste t para amostras independentes, onde foi considerado o nível de significância de 5\% para testar a hipótese de igualdade entre as médias.

De acordo com Pestana \& Gageiro (2008), os testes t permitem testar hipóteses sobre médias de uma variável quantitativa em um ou dois grupos, formados a partir de uma variável qualitativa. No teste t para duas amostras independentes, compara-se a média de uma variável num grupo com a média da mesma variável no segundo grupo; o teste é estimado baseando-se nas médias, variâncias e tamanho das amostras (Norusis, 2011). 


\subsubsection{COMPARAÇÃO EM RELAÇÃO À IDADE}

Para a análise em relação à idade, foi feito o agrupamento de duas faixas, Até 35 anos e Maior de 35 anos. A Tabela 5, a seguir, mostra os resultados para cada assertiva. Os resultados do nível significância foram todos acima de 0,05 , indicando que, para $95 \%$ de confiança, não houve diferença estatística significante entre as respostas dos maiores de 35 anos e dos respondentes com menos de 35 anos. Isso aponta que a idade do respondente não diferencia a percepção do usuário em relação ao sistema de BI. 
Tabela 5: Teste t para comparação das médias de cada assertiva em relação à faixa etária

\begin{tabular}{|c|c|c|c|c|c|c|c|c|c|}
\hline & & & $\mathrm{N}$ & Média & padrão & padrão & t & df & Sig \\
\hline \multirow{6}{*}{ Continuidade de uso } & \multirow{2}{*}{$\begin{array}{l}\text { Nos últimos } 7 \text { dias, eu utlizei frequentemente o sistema } \\
\text { de Business Intelligence. }\end{array}$} & Até 35 anos & 40 & 7,70 & 3,11 & 0,49 & \multirow{2}{*}{0,00} & \multirow{2}{*}{78} & \multirow{2}{*}{1,000} \\
\hline & & Mais de 35 anos & 40 & 7,70 & 2,56 & 0,41 & & & \\
\hline & \multirow{2}{*}{\begin{tabular}{|l|} 
Nos últimos 7 dias, a cada vez que eu utilizei sistema de \\
Business Intelligence, eu gastei bastante tempo
\end{tabular}} & Até 35 anos & 40 & 6,15 & 2,41 & 0,38 & \multirow{2}{*}{0,05} & \multirow{2}{*}{78} & \multirow{2}{*}{0,964} \\
\hline & & Mais de 35 anos & 40 & 6,13 & 2,53 & 0,40 & & & \\
\hline & \multirow{2}{*}{$\begin{array}{l}\text { Nos últimos } 7 \text { dias, eu utilizei o sistema de Business } \\
\text { Intelligence várias vezes no mesmo dia. }\end{array}$} & Até 35 anos & 40 & 7,65 & 2,83 & 0,45 & \multirow{2}{*}{$-0,08$} & \multirow{2}{*}{78} & \multirow{2}{*}{0,936} \\
\hline & & Mais de 35 anos & 40 & 7,70 & 2,73 & 0,43 & & & \\
\hline \multirow{6}{*}{$\begin{array}{c}\text { Intenção } \\
\text { Comportamental de } \\
\text { Uso }\end{array}$} & \multirow{2}{*}{$\begin{array}{l}\text { Eu pretendo continuar utilizando o sistema de Business } \\
\text { Intelligence enquanto a empresa tiver essa ferramenta. }\end{array}$} & Até 35 anos & 40 & 8,93 & 1,46 & 0,23 & \multirow{2}{*}{0,52} & \multirow{2}{*}{78} & \multirow{2}{*}{0,606} \\
\hline & & Mais de 35 anos & 40 & 8,73 & 1,96 & 0,31 & & & \\
\hline & Minha intenção é utilizar o sistema de Business & Até 35 anos & 40 & 7,45 & 2,37 & 0,38 & & & \\
\hline & Intelligence ao invés de outras alternativas. & Mais de 35 anos & 40 & 7,53 & 1,96 & 0,31 & $-0,15$ & 18 & 0,8/8 \\
\hline & Se eu puder eu gostaria de permanecer utilizando 0 & Até 35 anos & 40 & 8,43 & 1,68 & 0,27 & 054 & 78 & 0593 \\
\hline & sistema de Business Intelligence. & Mais de 35 anos & 40 & 8,65 & 2,06 & 0,33 & $-0,04$ & 18 & 0,593 \\
\hline & Eu estou satisfeito com a performance do sistema de & Até 35 anos & 40 & 7,15 & 2,07 & 0,33 & 0,58 & 78 & $056-10$ \\
\hline & Business Intelligence. & Mais de 35 anos & 40 & 6,88 & 2,14 & 0,34 & , & 10 & 0,001 \\
\hline & Considero satisfatória minha ex periência ứlizando & Até 35 anos & 40 & 7,43 & 1,75 & 0,28 & & & \\
\hline Satistaçao & sistemas de Business Intelligence & Mais de 35 anos & 40 & 7,70 & 1,95 & 0,31 & $-0,00$ & 10 & 0,009 \\
\hline & Considero sábia minha decisão de utilizar sistemas de & Até 35 anos & 40 & 8,48 & 1,58 & 0,25 & 070 & 170 & 0 \\
\hline & Business Intelligence. & Mais de 35 anos & 40 & 8,75 & 1,56 & 0,25 & $-0,18$ & 18 & 0,431 \\
\hline & Minha experiência utilizando o sistema de Business & Até 35 anos & 40 & 7,05 & 2,24 & 0,35 & & & \\
\hline & Intelligence é melhor do que eu esperava. & Mais de 35 anos & 40 & 7,38 & 2,17 & 0,34 & $-0,06$ & 10 & 0,5T2 \\
\hline & A qualidade do serviço do sistema de Business & Até 35 anos & 40 & 6,78 & 2,18 & 0,34 & & & \\
\hline Contirmação & Intelligence é melhor do que eu esperava. & Mais de 35 anos & 40 & 6,90 & 2,24 & 0,35 & $-0,25$ & 18 & 0,801 \\
\hline & No geral, minhas expectativas de uso do sistema de & Até 35 anos & 40 & 7,28 & 2,00 & 0,32 & & & \\
\hline & Business Intelligence foram confirmadas. & Mais de 35 anos & 40 & 7,53 & 1,93 & 0,31 & $-0,57$ & 78 & 0,572 \\
\hline & Utilizar sistemas de Business Intelligence melhora minha & Até 35 anos & 40 & 8,55 & 1,48 & 0,23 & & & \\
\hline & performance no trabalho. & Mais de 35 anos & 40 & 8,43 & 1,92 & 0,30 & 0,33 & 18 & 0,145 \\
\hline & Utilizar sistemas de Business Intelligence melhora minha & Até 35 anos & 40 & 8,43 & 1,74 & 0,27 & & & \\
\hline & produtividade no trabalho. & Mais de 35 anos & 40 & 8,48 & 1,50 & 0,24 & $-0,14$ & 18 & 0,891 \\
\hline Utiladae perceoida & Utilizar sistemas de Business Intelligence melhora minha & Até 35 anos & 40 & 8,30 & 1,47 & 0,23 & & & \\
\hline & efetividade no trabalho. & Mais de 35 anos & 40 & 8,53 & 1,81 & 0,29 & $-0,61$ & 18 & 0,544 \\
\hline & Em geral, o sistema de Business Intelligence é útil no & Até 35 anos & 40 & 8,93 & 1,29 & 0,20 & 70 & 70 & 0 \\
\hline & & Mais de 35 anos & 40 & 8,65 & 1,78 & 0,28 & 0,19 & 18 & 0,431 \\
\hline & As informaçōes contidas no sistema de Business & Até 35 anos & 40 & 6,95 & 2,17 & 0,34 & & & \\
\hline & Intelligence estão organizadas de forma clara. & Mais de 35 anos & 40 & 6,73 & 2,18 & 0,35 & 0,46 & 18 & 0,645 \\
\hline & A informação contida no sistema de Business & Até 35 anos & 40 & 7,23 & 1,97 & 0,31 & & & \\
\hline Qualidade da & Intelligence está disponível quando necessária. & Mais de 35 anos & 40 & 7,20 & 2,03 & 0,32 & 0,06 & 78 & 0,956 \\
\hline Informação & A informação contida no sistema de Business & Até 35 anos & 40 & 9,13 & 1,38 & 0,22 & 071 & 78 & 0.479 \\
\hline & Intelligence é importante. & Mais de 35 anos & 40 & 8,90 & 1,45 & 0,23 & $0, \pi 1$ & 18 & $0,4 / y$ \\
\hline & \begin{tabular}{|l|} 
A informação contida no sistema de Business \\
\end{tabular} & Até 35 anos & 40 & 8,63 & 1,29 & 0,20 & & & \\
\hline & Intelligence é significativa & Mais de 35 anos & 40 & 8,15 & 2,14 & 0,34 & 1,20 & 18 & 0,234 \\
\hline & Nossa companhia sabe o que "é melhor" para o cliente. & Até 35 anos & 40 & 6,98 & 2,08 & 0,33 & & & \\
\hline & & Mais de 35 anos & 40 & 7,15 & 2,19 & 0,35 & $-0,31$ & 18 & $0, / 15$ \\
\hline Estratégia Direcionada & Nossa companhia desenvolve produtos baseados em & Até 35 anos & 40 & 7,90 & 1,91 & 0,30 & 020 & 78 & 7721 \\
\hline pela Tecnologia & tecnologia. & Mais de 35 anos & 40 & 8,03 & 1,95 & 0,31 & $-0, \angle y$ & 10 & 0,173 \\
\hline & Nossos produtos têm qualidade superior. & Até 35 anos & 40 & 7,23 & 2,35 & 0,37 & 7070 & & 0,1001 \\
\hline & & Mais de 35 anos & 40 & 7,58 & 2,15 & 0,34 & $-0,10$ & 18 & 0,489 \\
\hline & Usar o sistema de Business Intelligence é automático & Até 35 anos & 40 & 7,30 & 2,54 & 0,40 & & & \\
\hline & para mim. & Mais de 35 anos & 40 & 8,23 & 1,58 & 0,25 & $-1,95$ & 18 & 0,054 \\
\hline & Usar o sistema de Business Intelligence é natural para & Até 35 anos & 40 & 7,78 & 2,28 & 0,36 & & & \\
\hline Hábito & mim. & Mais de 35 anos & 40 & 8,55 & 1,75 & 0,28 & $-1,70$ & 78 & 0,092 \\
\hline & Quando tenho uma tarefa a realizar, utilizar o sistema de & Até 35 anos & 40 & 7,63 & 2,32 & 0,37 & & & \\
\hline & Business Intelligence è a minha escolha óbvia. & Mais de 35 anos & 40 & 7,75 & 1,92 & 0,30 & $-0,26$ & 18 & 0,193 \\
\hline
\end{tabular}

Fonte: Dados Coletados Processados 


\subsubsection{COMPARAÇÃO EM RELAÇÃO AO GRAU DE INSTRUÇÃO}

Neste tópico, o agrupamento das duas faixas foi feito agregando os respondentes que possuem até nível superior (superior completo ou superior incompleto) e respondentes que possuem mais que o nível superior (pós-graduação ou mestrado). A Tabela 6, na sequência, mostra os resultados para estes grupos.

Os resultados do nível significância em apenas dois casos foram inferiores a 0,05 , indicando diferença de percepção entre os grupos. Nas assertivas, "Utilizar sistemas de Business Intelligence melhora minha performance no trabalho" - assertiva do constructo Utilidade Percebida e "Usar o sistema de Business Intelligence é automático para mim." - assertiva do constructo Hábito; as avaliações do grupo até superior completo foram maiores e esta diferença é estatisticamente significante para um nível de confiança de $95 \%$. 
Tabela 6: Teste t para comparação das médias de cada assertiva em relação ao grau de instrução

\begin{tabular}{|c|c|c|c|c|c|c|c|c|c|}
\hline & & & $\mathrm{N}$ & Média & padrão & padrão & $t$ & $\mathrm{df}$ & Sig \\
\hline \multirow{6}{*}{ Continuidade de uso } & \multirow{2}{*}{$\begin{array}{l}\text { Nos últimos } 7 \text { dias, eu utlizei frequentemente o sistema } \\
\text { de Business Intelligence. }\end{array}$} & Até Superior Completo & 27 & 8,37 & 2,53 & 0,49 & \multirow{2}{*}{1,52} & \multirow{2}{*}{78} & \multirow{2}{*}{0,131} \\
\hline & & Pós-Graduação & 53 & 7,36 & 2,94 & 0,40 & & & \\
\hline & \multirow{2}{*}{$\begin{array}{l}\text { Nos últimos } 7 \text { dias, a cada vez que eu ǘlizei sistema de } \\
\text { Business Intelligence, eu gastei bastante tempo }\end{array}$} & Até Superior Completo & 27 & 6,04 & 2,52 & 0,48 & \multirow{2}{*}{$-0,26$} & \multirow{2}{*}{78} & \multirow{2}{*}{0,796} \\
\hline & & Pós-Graduação & 53 & 6,19 & 2,45 & 0,34 & & & \\
\hline & \multirow{2}{*}{$\begin{array}{l}\text { Nos últimos } 7 \text { dias, eu utilizei o sistema de Business } \\
\text { Intelligence várias vezes no mesmo dia. }\end{array}$} & Até Superior Completo & 27 & 8,00 & 2,73 & 0,53 & \multirow{2}{*}{0,75} & \multirow{2}{*}{78} & \multirow{2}{*}{0,456} \\
\hline & & Pós-Graduação & 53 & 7,51 & 2,79 & 0,38 & & & \\
\hline \multirow{6}{*}{$\begin{array}{c}\text { Intenção } \\
\text { Comportamental de } \\
\text { Uso }\end{array}$} & \multirow{2}{*}{$\begin{array}{l}\text { Eu pretendo continuar ubilizando o sistema de Business } \\
\text { Intelligence enquanto a empresa tiver essa ferramenta. }\end{array}$} & Até Superior Completo & 27 & 8,89 & 1,53 & 0,29 & \multirow{2}{*}{0,24} & \multirow{2}{*}{78} & \multirow{2}{*}{0,814} \\
\hline & & Pós-Graduação & 53 & 8,79 & 1,82 & 0,25 & & & \\
\hline & Minha intenção é utilizar o sistema de Business & Até Superior Completo & 27 & 8,11 & 2,24 & 0,43 & 187 & 78 & $0 \cap 065$ \\
\hline & & Pós-Graduação & 53 & 7,17 & 2,07 & 0,28 & 1,01 & 10 & 0,000 \\
\hline & Se eu puder eu gostaria de permanecer utilizando 0 & Até Superior Completo & 27 & 8,85 & 1,61 & 0,31 & 07 & & \\
\hline & sistema de Business Intelligence. & Pós-Graduação & 53 & 8,38 & 1,98 & 0,27 & 1,07 & 18 & 0,280 \\
\hline & Eu estou satisfeito com a performance do sistema de & Até Superior Completo & 27 & 7,48 & 2,21 & 0,42 & & & \\
\hline & Business Intelligence. & Pós-Graduação & 53 & 6,77 & 2,02 & 0,28 & 1,44 & 18 & 0,154 \\
\hline Satisfacão & Considero satisfatória minha ex periência utilizando & Até Superior Completo & 27 & 7,59 & 1,87 & 0,36 & (10 & 78 & | 018 \\
\hline satsiaçau & sistemas de Business Intelligence & Pós-Graduação & 53 & 7,55 & 1,86 & 0,25 & 0,10 & 10 & 0,010 \\
\hline & Considero sábia minha decisão de utilizar sistemas de & Até Superior Completo & 27 & 8,96 & 1,34 & 0,26 & & 78 & \\
\hline & Business Intelligence. & Pós-Graduação & 53 & 8,43 & 1,66 & 0,23 & 1,43 & 18 & 0,150 \\
\hline & Minha ex periência utilizando o sistema de Business & Até Superior Completo & 27 & 7,63 & 2,20 & 0,42 & & & \\
\hline & Intelligence é melhor do que eu esperava. & Pós-Graduação & 53 & 7,00 & 2,18 & 0,30 & $1, \angle 2$ & 18 &,$\angle 28$ \\
\hline & A qualidade do serviço do sistema de Business & Até Superior Completo & 27 & 7,22 & 1,95 & 0,37 & & & \\
\hline Contirmação & Intelligence é melhor do que eu esperava. & Pós-Graduação & 53 & 6,64 & 2,30 & 0,32 & 1,12 & 18 & 0,266 \\
\hline & No geral, minhas expectativ as de uso do sistema de & Até Superior Completo & 27 & 7,56 & 2,10 & 0,40 & 050 & (78 & $\ln 615$ \\
\hline & Business Intelligence foram confirmadas. & Pós-Graduação & 53 & 7,32 & 1,90 & 0,26 & 0,00 & 10 & 0,010 \\
\hline & Utilizar sistemas de Business Intelligence melhora minha & Até Superior Completo & 27 & 9,07 & 1,44 & 0,28 & & & \\
\hline & performance no trabalho. & Pós-Graduação & 53 & 8,19 & 1,77 & 0,24 & 2,25 & 18 & 0,027 \\
\hline & Utilizar sistemas de Business Intelligence melhora minha & Até Superior Completo & 27 & 8,70 & 1,66 & 0,32 & & & \\
\hline & produtividade no trabalho. & Pós-Graduação & 53 & 8,32 & 1,59 & 0,22 & 1,00 & 18 & 0,319 \\
\hline Utilid & Utilizar sistemas de Business Intelligence melhora minha & Até Superior Completo & 27 & 8,81 & 1,42 & 0,27 & 158 & & I119 \\
\hline & efetividade no trabalho. & Pós-Graduação & 53 & 8,21 & 1,72 & 0,24 & 1,00 & 18 & 0,119 \\
\hline & Em geral, o sistema de Business Intelligence é útil no & Até Superior Completo & 27 & 9,11 & 1,74 & 0,33 & & & \\
\hline & trabalho. & Pós-Graduação & 53 & 8,62 & 1,43 & 0,20 & 1,34 & 18 & 0,184 \\
\hline & As informações contidas no sistema de Business & Até Superior Completo & 27 & 7,26 & 2,25 & 0,43 & & & \\
\hline & Intelligence estão organizadas de forma clara. & Pós-Graduação & 53 & 6,62 & 2,11 & 0,29 & 1,25 & 18 & 0,216 \\
\hline & A informação contida no sistema de Business & Até Superior Completo & 27 & 7,67 & 1,84 & 0,35 & & & \\
\hline Qualidade da & Intelligence está disponivel quando necessária. & Pós-Graduação & 53 & 6,98 & 2,03 & 0,28 & 1,47 & 18 & 0,145 \\
\hline Informação & A informação contida no sistema de Business & Até Superior Completo & 27 & 9,26 & 1,16 & 0,22 & 112 & 78 & 10266 \\
\hline & Intelligence é importante. & Pós-Graduação & 53 & 8,89 & 1,51 & 0,21 & 1,12 & 18 & 0,200 \\
\hline & A informação contida no sistema de Business & Até Superior Completo & 27 & 8,52 & 1,78 & 0,34 & 0.47 & (78 & 0641 \\
\hline & Intelligence é significativa & Pós-Graduação & 53 & 8,32 & 1,78 & 0,25 & 0,47 & 18 & 0,04 \\
\hline & Nossa companhia sabe o que "é melhor" para o cliente. & Até Superior Completo & 27 & 7,44 & 1,93 & 0,37 & 5 & & \\
\hline & & Pós-Graduação & 53 & 6,87 & 2,21 & 0,30 & 1,15 & 18 & 0,254 \\
\hline Estratégia Direcionada & Nossa companhia desenvolve produtos baseados em & Até Superior Completo & 27 & 8,30 & 2,16 & 0,42 & & & \\
\hline pela Tecnologia & tecnologia. & Pós-Graduação & 53 & 7,79 & 1,78 & 0,24 & 1,11 & 18 & 0,269 \\
\hline & Nossos produtos têm qualidade superior. & Até Superior Completo & 27 & 7,70 & 2,22 & 0,43 & 086 & & O 391 \\
\hline & & Pós-Graduação & 53 & 7,25 & 2,26 & 0,31 & 0,80 & 18 & 0,391 \\
\hline & Usar o sistema de Business Intelligence é automático & Até Superior Completo & 27 & 8,48 & 1,85 & 0,36 & 218 & & - \\
\hline & para mim. & Pós-Graduação & 53 & 7,40 & 2,22 & 0,31 & 2,18 & 18 & 0,032 \\
\hline & Usar o sistema de Business Intelligence é natural para & Até Superior Completo & 27 & 8,52 & 2,08 & 0,40 & 11 & & \\
\hline Habito & mim. & Pós-Graduação & 53 & 7,98 & 2,04 & 0,28 & 1,TT & 18 & 0,212 \\
\hline & Quando tenho uma tarefa a realizar, utilizar o sistema de & Até Superior Completo & 27 & 8,07 & 1,86 & 0,36 & 117 & 78 & 246 \\
\hline & Business Intelligence é a minha escolha óbvia. & Pós-Graduação & 53 & 7,49 & 2,22 & 0,31 & 1,17 & 10 & 0,240 \\
\hline
\end{tabular}

Fonte: Dados Coletados Processados 


\subsubsection{COMPARAÇÃO EM RELAÇÃO AO CARGO}

Para esta variável, o agrupamento mais natural é juntar todos os grupos que envolvem gestão (coordenadores e supervisores, média gerência e alta gerência) e separar do grupo de analistas/consultores. Os resultados são apresentados na Tabela 7.

Nesta comparação, a única assertiva que apresentou diferença significante foi "Usar o sistema de Business Intelligence é natural para mim.” - constructo Hábito, onde as notas revelam que para os ocupantes de cargos de gestão é mais natural utilizar o sistema de BI do que para os não gestores. Esse resultado é esperado, visto que a ferramenta é utilizada para gerar informações para tomada de decisão e gestores têm como função a tomada de decisão nas empresas. 
Tabela 7: Teste t para comparação das médias de cada assertiva em relação ao cargo

\begin{tabular}{|c|c|c|c|c|c|c|c|c|c|}
\hline & & & $\mathrm{N}$ & Média & padrão & padrão & $\mathrm{t}$ & df & Sig \\
\hline \multirow{6}{*}{ Continuidade de uso } & \multirow{2}{*}{$\begin{array}{l}\text { Nos últimos } 7 \text { dias, eu utilizei frequentemente o sistema } \\
\text { de Business Intelligence. }\end{array}$} & Analista/Consultor & 42 & 7,79 & 3,06 & 0,47 & \multirow{2}{*}{0,28} & \multirow{2}{*}{78} & \multirow{2}{*}{0,778} \\
\hline & & Gestão & 38 & 7,61 & 2,58 & 0,42 & & & \\
\hline & \multirow{2}{*}{$\begin{array}{l}\text { Nos últimos } 7 \text { dias, a cada vez que eu utilizei sistema de } \\
\text { Business Intelligence, eu gastei bastante tempo }\end{array}$} & Analista/Consultor & 42 & 6,36 & 2,60 & 0,40 & \multirow{2}{*}{0,84} & \multirow[b]{2}{*}{78} & \multirow{2}{*}{0,404} \\
\hline & & Gestão & 38 & 5,89 & 2,30 & 0,37 & & & \\
\hline & \multirow{2}{*}{$\begin{array}{l}\text { Nos últimos } 7 \text { dias, eu utilizei o sistema de Business } \\
\text { Intelligence várias vezes no mesmo dia. }\end{array}$} & Analista/Consultor & 42 & 8,00 & 2,85 & 0,44 & \multirow{2}{*}{1,11} & \multirow{2}{*}{78} & \multirow{2}{*}{0,272} \\
\hline & & Gestão & 38 & 7,32 & 2,66 & 0,43 & & & \\
\hline \multirow{6}{*}{$\begin{array}{c}\text { Intenção } \\
\text { Comportamental de } \\
\text { Uso }\end{array}$} & \multirow{2}{*}{$\begin{array}{l}\text { Eu pretendo continuar utilizando o sistema de Business } \\
\text { Intelligence enquanto a empresa tiver essa ferramenta. }\end{array}$} & Analista/Consultor & 42 & 8,60 & 1,93 & 0,30 & \multirow{2}{*}{$-1,26$} & \multirow{2}{*}{78} & \multirow{2}{*}{0,211} \\
\hline & & Gestão & 38 & 9,08 & 1,44 & 0,23 & & & \\
\hline & Minha intenção é utilizar o sistema de Business & Analista/Consultor & 42 & 7,26 & 2,51 & 0,39 & & & \\
\hline & Intelligence ao invés de outras alternativas. & Gestão & 38 & 7,74 & 1,70 & 0,28 & $-0,98$ & 18 & 0,330 \\
\hline & Se eu puder eu gostaria de permanecer utilizando o & Analista/Consultor & 42 & 8,38 & 2,14 & 0,33 & & & \\
\hline & sistema de Business Intelligence. & Gestão & 38 & 8,71 & 1,52 & 0,25 & $-0,79$ & 78 & 0,434 \\
\hline & Eu estou satisfeito com a performance do sistema de & Analista/Consultor & 42 & 7,02 & 2,08 & 0,32 & & & \\
\hline & Business Intelligence. & Gestão & 38 & 7,00 & 2,14 & 0,35 & 0,05 & 78 & 0,960 \\
\hline & Considero satisfatória minha experiência utilizando & Analista/Consultor & 42 & 7,52 & 1,98 & 0,31 & & & \\
\hline Satisłação & sistemas de Business Intelligence & Gestão & 38 & 7,61 & 1,72 & 0,28 & $-0,20$ & 18 & 0,845 \\
\hline & Considero sábia minha decisão de utilizar sistemas de & Analista/Consultor & 42 & 8,50 & 1,73 & 0,27 & & & \\
\hline & Business Intelligence. & Gestão & 38 & 8,74 & 1,39 & 0,23 & $-0,6 /$ & 18 & 0,504 \\
\hline & Minha experiência utilizando o sistema de Business & Analista/Consultor & 42 & 7,14 & 2,24 & 0,35 & & & \\
\hline & Intelligence é melhor do que eu esperava. & Gestão & 38 & 7,29 & 2,18 & 0,35 & $-0,30$ & 78 & 0,768 \\
\hline & A qualidade do serviço do sistema de Business & Analista/Consultor & 42 & 6,93 & 2,21 & 0,34 & & & \\
\hline Confirmação & Intelligence é melhor do que eu esperava. & Gestão & 38 & 6,74 & 2,20 & 0,36 & 0,39 & 78 & 0,699 \\
\hline & No geral, minhas expectativas de uso do sistema de & Analista/Consultor & 42 & 7,38 & 2,20 & 0,34 & & & \\
\hline & Business Intelligence foram confirmadas. & Gestão & 38 & 7,42 & 1,69 & 0,27 & $-0,09$ & 18 & 0,928 \\
\hline & Utilizar sistemas de Business Intelligence melhora minha & Analista/Consultor & 42 & 8,48 & 1,81 & 0,28 & & & \\
\hline & performance no trabalho. & Gestão & 38 & 8,50 & 1,61 & 0,26 & $-0,06$ & 18 & 0,951 \\
\hline & Utilizar sistemas de Business Intelligence melhora minha & Analista/Consultor & 42 & 8,43 & 1,76 & 0,27 & & & \\
\hline & produtividade no trabalho. & Gestão & 38 & 8,47 & 1,47 & 0,24 & $-0,12$ & 78 & 0,902 \\
\hline Utilidade & Utilizar sistemas de Business Intelligence melhora minha & Analista/Consultor & 42 & 8,29 & 1,83 & 0,28 & & & \\
\hline & efetividade no trabalho. & Gestão & 38 & 8,55 & 1,43 & 0,23 & $-0,72$ & 78 & 0,472 \\
\hline & Em geral, o sistema de Business Intelligence é útil no & Analista/Consultor & 42 & 8,83 & 1,45 & 0,22 & & & \\
\hline & trabalho. & Gestão & 38 & 8,74 & 1,67 & 0,27 & 0,28 & $1 / 8$ & 0,183 \\
\hline & As informações contidas no sistema de Business & Analista/Consultor & 42 & 6,83 & 2,23 & 0,34 & & & \\
\hline & Intelligence estão organizadas de forma clara. & Gestão & 38 & 6,84 & 2,12 & 0,34 & $-0,02$ & 78 & 0,986 \\
\hline & A informação contida no sistema de Business & Analista/Consultor & 42 & 7,19 & 2,16 & 0,33 & & & \\
\hline Qualidade da & Intelligence está disponível quando necessária. & Gestão & 38 & 7,24 & 1,81 & 0,29 & $-0,10$ & 78 & 0,918 \\
\hline Informação & A informação contida no sistema de Business & Analista/Consultor & 42 & 8,86 & 1,66 & 0,26 & & & \\
\hline & Intelligence é importante. & Gestão & 38 & 9,18 & 1,06 & 0,17 & $-1,04$ & 78 & 0,303 \\
\hline & A informação contida no sistema de Business & Analista/Consultor & 42 & 8,57 & 1,80 & 0,28 & & & \\
\hline & Intelligence é significativa & Gestão & 38 & 8,18 & 1,75 & 0,28 & 0,97 & 18 & 0,333 \\
\hline & Nossa companhia sabe o que "é melhor" para o cliente. & Analista/Consultor & 42 & 7,21 & 2,08 & 0,32 & & & \\
\hline & & Gestão & 38 & 6,89 & 2,19 & 0,36 & 0,67 & 78 & 0,505 \\
\hline Estratégia Direcionada & Nossa companhia desenvolve produtos baseados em & Analista/Consultor & 42 & 7,83 & 1,92 & 0,30 & & & \\
\hline pela Tecnologia & tecnologia. & Gestão & 38 & 8,11 & 1,93 & 0,31 & $-0,63$ & 78 & 0,530 \\
\hline & Nossos produtos têm qualidade superior. & Analista/Consultor & 42 & 7,31 & 2,28 & 0,35 & O 38 & & 0707 \\
\hline & & Gestão & 38 & 7,50 & 2,23 & 0,36 & $-0,38$ & 18 & $0,10 \pi$ \\
\hline & Usar o sistema de Business Intelligence é automático & Analista/Consultor & 42 & 7,43 & 2,44 & 0,38 & & & \\
\hline & para mim. & Gestão & 38 & 8,13 & 1,74 & 0,28 & $-1,47$ & 78 & 0,146 \\
\hline & Usar o sistema de Business Intelligence é natural para & Analista/Consultor & 42 & 7,60 & 2,41 & 0,37 & & & \\
\hline Hábito & mim. & Gestão & 38 & 8,79 & 1,36 & 0,22 & $-2,69$ & 18 & 0,009 \\
\hline & Quando tenho uma tarefa a realizar, utilizar o sistema de & Analista/Consultor & 42 & 7,62 & 2,45 & 0,38 & & & \\
\hline & Business Intelligence é a minha escolha óbvia. & Gestão & 38 & 7,76 & 1,70 & 0,28 & $-0,30$ & 78 & 0,763 \\
\hline
\end{tabular}

Fonte: Dados Coletados Processados 


\subsubsection{COMPARAÇÃO EM RELAÇÃO AO RAMO DA EMPRESA}

Como metade da amostra é proveniente do segmento de Telecomunicações, fez mais sentido agrupar os respondentes entre funcionários de empresa deste ramo e compará-los com os respondentes dos demais ramos. A Tabela 8 , a seguir, mostra os resultados de cada assertiva para o agrupamento em relação ao ramo de atuação.

Os resultados do nível de significância mostraram que não há diferença estatisticamente significante, em todas as assertivas exceto duas: "Minha intenção é utilizar o sistema de Business Intelligence ao invés de outras alternativas." - assertiva do constructo Intenção Comportamental de Uso e "Utilizar sistemas de Business Intelligence melhora minha efetividade no trabalho." - assertiva do constructo Utilidade Percebida; em ambas as assertivas os respondentes que atuam em empresa de telecomunicações têm uma avaliação inferior aos respondentes dos demais grupos. 
Tabela 8: Teste t para comparação das médias de cada assertiva em relação ao ramo da empresa

\begin{tabular}{|c|c|c|c|c|c|c|c|c|c|}
\hline & & & $\mathrm{N}$ & Média & padrão & padrão & $\mathrm{t}$ & df & Sig \\
\hline \multirow{6}{*}{ Continuidade de uso } & \multirow{2}{*}{$\begin{array}{l}\text { Nos sultimos } 7 \text { dias, eu uflizei frequentemente o sistema } \\
\text { de Business Intelligence. }\end{array}$} & Telecom & 40 & 7,78 & 2,84 & 0,45 & \multirow{2}{*}{0,24} & \multirow{2}{*}{78} & \multirow{2}{*}{0,814} \\
\hline & & Não Telecom & 40 & 7,63 & 2,85 & 0,45 & & & \\
\hline & \multirow{2}{*}{$\begin{array}{l}\text { Nos últimos } 7 \text { dias, a cada vez que eu utilizei sistema de } \\
\text { Business Intelligence, eu gastei bastante tempo }\end{array}$} & Telecom & 40 & 6,50 & 2,49 & 0,39 & \multirow{2}{*}{1,33} & \multirow{2}{*}{ |78| } & \multirow{2}{*}{0,189} \\
\hline & & Não Telecom & 40 & 5,78 & 2,40 & 0,38 & & & \\
\hline & \multirow{2}{*}{$\begin{array}{l}\text { Nos últimos } 7 \text { dias, eu utilizei o sistema de Business } \\
\text { Intelligence várias vezes no mesmo dia. }\end{array}$} & Telecom & 40 & 7,98 & 2,51 & 0,40 & \multirow{2}{*}{0,97} & \multirow{2}{*}{78} & \multirow{2}{*}{0,335} \\
\hline & & Não Telecom & 40 & 7,38 & 3,00 & 0,47 & & & \\
\hline \multirow{6}{*}{$\begin{array}{c}\text { Intenção } \\
\text { Comportamental de } \\
\text { Uso }\end{array}$} & \multirow{2}{*}{$\begin{array}{l}\text { Eu pretendo continuar utilizando o sistema de Business } \\
\text { Intelligence enquanto a empresa tiver essa ferramenta. }\end{array}$} & Telecom & 40 & 8,58 & 1,88 & 0,30 & \multirow{2}{*}{$-1,31$} & \multirow{2}{*}{78} & \multirow{2}{*}{0,195} \\
\hline & & $\sqrt{\text { Não Telecom }}$ & 40 & 9,08 & 1,53 & 0,24 & & & \\
\hline & Minha intenção é utilizar o sistema de Business & Telecom & 40 & 6,93 & 2,35 & 0,37 & & & \\
\hline & Intelligence ao invés de outras altemativas. & Não Telecom & 40 & 8,05 & 1,83 & 0,29 & $-2, \Delta Y$ & 10 & $|0,019|$ \\
\hline & Se eu puder eu gostaria de permanecer ufilizando o & Telecom & 40 & 8,40 & 2,07 & 0,33 & 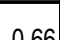 & 178 & \\
\hline & sistema de Business Intelligence. & Não Telecom & 40 & 8,68 & 1,65 & 0,26 & $-0,00$ & 10 & 0,0 \\
\hline & Eu estou satisfeito com a performance do sistema de & Telecom & 40 & 6,68 & 2,10 & 0,33 & & & \\
\hline & Business Intelligence. & Não Telecom & 40 & 7,35 & 2,06 & 0,33 & ${ }^{-1,45}$ & 18 & $|0,151|$ \\
\hline & Considero satisfatória minha ex periência utilizando & Telecom & 40 & 7,48 & 2,04 & 0,32 & & & \\
\hline Satusiaçao & sistemas de Business Intelligence & Não Telecom & 40 & 7,65 & 1,66 & 0,26 & $-0,4<$ & 10 & $|0,0 / 0|$ \\
\hline & Considero sábia minha decisão de utlizar sistemas de & Telecom & 40 & 8,43 & 1,66 & 0,26 & & & \\
\hline & Business Intelligence. & Não Telecom & 40 & 8,80 & 1,47 & 0,23 & $-1,0 /$ & 18 & 0,2 \\
\hline & Minha ex periência ufilizando o sistema de Business & Telecom & 40 & 7,05 & 2,32 & 0,37 & 0.66 & 178 & 105 \\
\hline & Intelligence è melhor do que eu esperava. & Não Telecom & 40 & 7,38 & 2,08 & 0,33 & $-0,00$ & 10 & $\mid 0,012$ \\
\hline & A qualidade do serviço do sistema de Business & Telecom & 40 & 6,38 & 2,50 & 0,39 & & & \\
\hline Confirmação & Intelligence é melhor do que eu esperava. & Não Telecom & 40 & 7,30 & 1,76 & 0,28 & $-1,92$ & 18 & 0,059 \\
\hline & No geral, minhas expectativas de uso do sistema de & Telecom & 40 & 7,33 & 2,23 & 0,35 & & 178 & 10.731 \\
\hline & Business Intelligence foram confirmadas. & Não Telecom & 40 & 7,48 & 1,66 & 0,26 & $-0,04$ & 10 & $|0,134|$ \\
\hline & Utilizar sistemas de Business Intelli: & Telecom & 40 & 8,28 & 1,92 & 0,30 & & 170 & \\
\hline & performance no trabalho. & $\begin{array}{l}\text { Não Telecom } \\
\end{array}$ & 40 & 8,70 & 1,45 & 0,23 & $\left.\right|^{-1,12}$ & 18 & $|0,200|$ \\
\hline & Utilizar sistemas de Business Intelligence melhora minha & Telecom & 40 & 8,18 & 1,47 & 0,23 & 151 小 15 & & \\
\hline & produtuvidade no tabalho. & Não Telecom & 40 & 8,73 & 1,72 & 0,27 & -1,04 & 10 & $|0,1<0|$ \\
\hline vindade perceona & Utilizar sistemas de Business Intelligence melhora minha & Telecom & 40 & 8,03 & 1,82 & 0,29 & & 178 & $\ln 021$ \\
\hline & efefividade no trabalho. & Não Telecom & 40 & 8,80 & 1,36 & 0,22 & $-2,10$ & 10 & $\mid 0,034$ \\
\hline & Em geral, o sistema de Business Intelligence é útil no & Telecom & 40 & 8,83 & 1,38 & 0,22 & $0 ? 2$ & 178 & I $R$ \\
\hline & trabalho. & Não Telecom & 40 & 8,75 & 1,72 & 0,27 & $\mid, \angle 2$ & 10 & {$[0,000$} \\
\hline & As informaçōes contidas no sistema de Business & Telecom & 40 & 6,68 & 2,15 & 0,34 & 67 & 178 & 10506 \\
\hline & |Intelligence estäo organizadas de forma clara. & Não Telecom & 40 & 7,00 & 2,20 & 0,35 & $-0,01$ & 10 & | \\
\hline & A informaçăo contida no sistema de Business & Telecom & 40 & 7,03 & 2,14 & 0,34 & & & \\
\hline Qualidade da & Intelligence está disponivel quando necessária. & Não Telecom & 40 & 7,40 & 1,82 & 0,29 & $-0,84$ & $1 / 8$ & $\mid 0,402$ \\
\hline Informação & A informaçäo contida no sistema de Business & Telecom & 40 & 8,83 & 1,63 & 0,26 & 110 & & I 8,0 \\
\hline & Intelligence è importante. & Não Telecom & 40 & 9,20 & 1,14 & 0,18 & -1, & 10 & $|0, \angle \Delta\rangle \mid$ \\
\hline & A informaçăo contida no sistema de Business & Telecom & 40 & 8,45 & 1,77 & 0,28 & 031 & & \\
\hline & Intelligence é significativa & Não Telecom & 40 & 8,33 & 1,80 & 0,29 & 0,31 & $1 / 8$ & $|0,155|$ \\
\hline & Nossa companhia sabe o que "é melhor" para o cliente. & Telecom & 40 & 6,90 & 2,26 & 0,36 & 16 & & $\ln 107$ \\
\hline & & Não Telecom & 40 & 7,23 & 1,99 & 0,32 & $-0,00$ & 10 & {$[0,401$} \\
\hline Estratégia Direcionada & Nossa companhia desenvolve produtos baseados em & Telecom & 40 & 8,25 & 1,82 & 0,29 & & & \\
\hline pela Tecnologia & tecnologia. & Não Telecom & 40 & 7,68 & 1,99 & 0,31 & 1,35 & 18 & {$[0,182]$} \\
\hline & Nossos produtos têm qualidade superior. & Telecom & 40 & 7,40 & 2,23 & 0,35 & 1 & & 11000 \\
\hline & & Não Telecom & 40 & 7,40 & 2,28 & 0,36 & $\mid, 00$ & 170 & 1,000 \\
\hline & Usar o sistema de Business Intelligence é automático & Telecom & 40 & 7,48 & 2,42 & 0,38 & & & 1023 \\
\hline & para mim. & $\sqrt{\text { Não Telecom }}$ & 40 & 8,05 & 1,84 & 0,29 & ${ }^{-1, Z U}$ & 18 & $|0, \angle 35|$ \\
\hline Hébito & Usar o sistema de Business Intelligence é natural para & Telecom & 40 & 7,88 & 2,30 & 0,36 & $1251-20$ & 178 & lo 211 \\
\hline Hadilo & |mim. & Não Telecom & 40 & 8,45 & 1,77 & 0,28 & $-1,20$ & 10 & $|0,214|$ \\
\hline & Quando tenho uma tareffa a realizar, utilizar o sistema de & Telecom & 40 & 7,38 & 2,50 & 0,39 & & & 10188 \\
\hline & Business Intelligence é a minha escolha óbvia. & Não Telecom & 40 & 8,00 & 1,62 & 0,26 & -1,30 & 10 & $|0,100|$ \\
\hline
\end{tabular}

Fonte: Dados Coletados Processados 


\subsubsection{COMPARAÇÃO EM RELAÇÃO AO DEPARTAMENTO DE ATUAÇÃO}

Nesta seção foram agrupados os departamentos de Finanças e Planejamento Estratégico, por serem áreas muito próximas, sendo que em muitas empresas estas ficam alocadas em uma mesma Vice-Presidência. Foi feita a comparação de suas médias com as das demais áreas. Os resultados são apresentados na Tabela 9.

Da mesma forma que a seção anterior, apenas duas assertivas apresentaram resultados com diferença estatisticamente significante, sendo que em ambas os respondentes que atuam em Finanças ou Planejamento Estratégico têm uma avaliação inferior aos respondentes de outras áreas: "Minha experiência utilizando o sistema de Business Intelligence é melhor do que eu esperava." - assertiva do constructo Confirmação e "Minha intenção é utilizar o sistema de Business Intelligence ao invés de outras alternativas." - assertiva do constructo Intenção Comportamental de Uso. 
Tabela 9: Teste $\mathrm{t}$ para comparação das médias de cada assertiva em relação ao departamento de atuação

\begin{tabular}{|c|c|c|c|c|c|c|c|c|c|}
\hline & & & $\mathrm{N}$ & Média & padrão & padrão & $\mathrm{t}$ & df & Sig \\
\hline \multirow{6}{*}{ Continuidade de uso } & \multirow{2}{*}{$\begin{array}{l}\text { Nos últimos } 7 \text { dias, eu ufilizei frequentemente o sistema } \\
\text { de Business Intelligence. }\end{array}$} & FinanceirolPlanejamento & 47 & 7,85 & 2,84 & 0,41 & \multirow{2}{*}{0,57} & \multirow{2}{*}{78} & \multirow{2}{*}{0,572} \\
\hline & & Outros & 33 & 7,48 & 2,84 & 0,49 & & & \\
\hline & \multirow{2}{*}{$\begin{array}{l}\text { Nos últimos } 7 \text { dias, a cada vez que eu utilizei sistema de } \\
\text { Business Intelligence, eu gastei bastante tempo }\end{array}$} & Financeiro/Planejamento & 47 & 6,04 & 2,42 & 0,35 & \multirow{2}{*}{$-0,41$} & \multirow[b]{2}{*}{78} & \multirow{2}{*}{0,683} \\
\hline & & Outros & 33 & 6,27 & 2,54 & 0,44 & & & \\
\hline & \multirow{2}{*}{$\begin{array}{l}\text { Nos últimos } 7 \text { dias, eu utilizei o sistema de Business } \\
\text { Intelligence várias vezes no mesmo dia. }\end{array}$} & FinanceirolPlanejamento & 47 & 7,70 & 2,66 & 0,39 & \multirow{2}{*}{0,10} & \multirow[b]{2}{*}{78} & \multirow{2}{*}{0,917} \\
\hline & & Outros & 33 & 7.64 & 2.95 & 0,51 & & & \\
\hline \multirow{6}{*}{$\begin{array}{c}\text { Intenção } \\
\text { Comportamental de } \\
\text { Uso }\end{array}$} & \multirow{2}{*}{$\begin{array}{l}\text { Eu pretendo continuar utilizando o sistema de Business } \\
\text { Intelligence enquanto a empresa tiver essa ferramenta. }\end{array}$} & Financeiro/Planejamento & 47 & 8,81 & 1,79 & 0,26 & \multirow{2}{*}{$-0,10$} & \multirow{2}{*}{ 78 } & \multirow{2}{*}{0,919} \\
\hline & & Outos & 33 & 8,85 & 1,64 & 0,29 & & & \\
\hline & Minha intenção é utilizar o sistema de Business & Financeiro/Planejamento & 47 & 7,00 & 2,34 & 0,34 & & & \\
\hline & Intelligence ao invés de outras alternativas. & Outros & 33 & 8,18 & 1,69 & 0,29 & $-2,48$ & 18 & 0,015 \\
\hline & Se eu puder eu gostaria de permanecer utilizando o & Financeiro/Planejamento & 47 & 8,49 & 1,99 & 0,29 & & & \\
\hline & sistema de Business Intelligence. & Outros & 33 & 8,61 & 1,71 & 0,30 & $-0,21$ & $1 / 8$ & 0,185 \\
\hline & Eu estou satisfietto com a performance do sistema de & Financeiro/Planejamento & 47 & 6,70 & 2,14 & 0,31 & & & \\
\hline & |Business Intelligence. & Outros & 33 & 7,45 & 1,99 & 0,35 & $-1,60$ & 18 & 0,114 \\
\hline & Considero satisfatória minha experiência ufilizando & Financeiro/Planejamento & 47 & 7,23 & 1,84 & 0,27 & & & \\
\hline Satisfação & sistemas de Business Intelligence & Outros & 33 & 8,03 & 1,78 & 0,31 & $-1,93$ & 18 & $0,05 /$ \\
\hline & \begin{tabular}{|l|} 
Considero sábia minha decisão de ufilizar sistemas de \\
\end{tabular} & Financeiro/Planejamento & 47 & 8,45 & 1,63 & 0,24 & & & \\
\hline & Business Intelligence. & Outros & 33 & 8,85 & 1,48 & 0,26 & $-1,13$ & 18 & 0,203 \\
\hline & Minha experiência utilizando o sistema de Business & Financeiro/Planejamento & 47 & 6,70 & 2,28 & 0,33 & & & \\
\hline & Intelligence é melhor do que eu esperava. & Outros & 33 & 7,94 & 1,87 & 0,33 & $-2,5 /$ & $1 / 8$ & 0,012 \\
\hline & A qualidade do serviço do sistema de Business & Financeiro/Planejamento & 47 & 6,47 & 2,45 & 0,36 & & & \\
\hline Confirmação & Intelligence é melhor do que eu esperava. & Outos & 33 & 7,36 & 1,67 & 0,29 & $-1,82$ & 18 & {$[0,0 / 2$} \\
\hline & No geral, minhas expectativas de uso do sistema de & Financeiro/Planejamento & 47 & 7,17 & 2,17 & 0,32 & & & \\
\hline & Business Intelligence foram confirmadas. & Outros & 33 & 7,73 & 1,59 & 0,28 & $-1,26$ & 18 & {$[0,213$} \\
\hline & Utilizar sistemas de Business Intelligence melhora minha & Financeiro/Planejamento & 47 & 8,40 & 1,84 & 0,27 & & & \\
\hline & performance no trabalho. & Outros & 33 & 8,61 & 1,52 & 0,26 & $-0,52$ & 18 & {$[0,600$} \\
\hline & Utilizar sistemas de Business Intelligence melhora minha & Financeiro/Planejamento & 47 & 8,45 & 1,57 & 0,23 & & & \\
\hline & produlividade no trabalho. & Outros & 33 & 8.45 & 1,70 & 0,30 & $-0,02$ & $1 / 8$ & 0,983 \\
\hline Utilidade Percebida & Utilizar sistemas de Business Intelligence melhora minha & Financeiro/Planejamento & 47 & 8,23 & 1,73 & 0,25 & & & \\
\hline & efétividade no trabalho. & Outros & 33 & 8,67 & 1,49 & 0,26 & $-1,10$ & 18 & 0,249 \\
\hline & Em geral, o sistema de Business Intelligence é útil no & Financeiro/Planejamento & 47 & 8,87 & 1,36 & 0,20 & & & \\
\hline & trabalho. & Outros & 33 & 8,67 & 1,80 & 0,31 & 0,58 & $/ 8$ & 0,562 \\
\hline & mações contidas no sistema de Business & Financeiro/Planejamento & 47 & 6,70 & 2,21 & 0,32 & 066 & 78 & $0-56$ \\
\hline & IItelligence estäo organizadas de forma clara. & Outros & 33 & 7,03 & 2,13 & 0,37 & $-0,06$ & 18 & 0,508 \\
\hline & A informação conida no sistema de Business & FinanceirolPlanejamento & 47 & 7,04 & 2,00 & 0,29 & 01 & 178 & $036-30$ \\
\hline Qualidade da & Intelligence está disponivel quando n & Outros & 33 & 7,45 & 1,97 & 0,34 & $-0,9 \mid$ & 10 & {$[0,004$} \\
\hline Informação & A informação contida no sistema de Business & Financeiro/Planejamento & 47 & 8,96 & 1,52 & 0,22 & & & 0680 \\
\hline & Intelligence é importante. & Outros & 33 & 9,09 & 1,26 & 0,22 & $-0,41$ & $1 / 8$ & 0,680 \\
\hline & \begin{tabular}{|l|} 
A informação contida no sistema de Business \\
\end{tabular} & Financeiro/Planejamento & 47 & 8,51 & 1,72 & 0,25 & 71 & & $\ln 10 ?$ \\
\hline & Intelligence é significaliva & Outros & 33 & 8,21 & 1,87 & 0,32 & 0,14 & 10 & {$[0,403$} \\
\hline & Nossa companhia sabe o que "é melhor" para o cliente. & Financeiro/Planejamento & 47 & 6,98 & 2,24 & 0,33 & 0.19 & & $\ln 677$ \\
\hline & & Outros & 33 & 7,18 & 1,98 & 0,34 & $-0,4<$ & 18 & {$[0,0 / 1$} \\
\hline Estratégia Direcionada & Nossa companhia desenvolve produtos baseados em & Financeiro/Planejamento & 47 & 7,96 & 1,82 & 0,27 & & & \\
\hline pela Tecnologia & tecnologia. & Outros & 33 & 7,97 & 2,08 & 0,36 & $-0,03$ & 10 & [0,9/8 \\
\hline & Nossos produtos têm qualidade superior. & Financeiro/Planejamento & 47 & 7,49 & 2,07 & 0,30 & 12 & 78 & 10673 \\
\hline & & Outos & 33 & 7,27 & 2,49 & 0,43 & 0,42 & 10 & {$[0,070$} \\
\hline & Usar o sistema de Business Intelligence é automáicco & FinanceirolPlanejamento & 47 & 7,53 & 2,20 & 0,32 & 111 & & \\
\hline & para mim. & Outos & 33 & 8,09 & 2,08 & 0,36 & $-1,14$ & $1 / 8$ & {$[0,256$} \\
\hline & Usar o sistema de Business Intelligence é natural para & Financeiro/Planejamento & 47 & 7,79 & 2,25 & 0,33 & 100 & 70 & lo 051 \\
\hline Habito & mim. & Outros & 33 & 8,70 & 1,65 & 0,29 & $-1,98$ & $1 / 8$ & {$[0,051$} \\
\hline & Quando tenho uma tarefa a realizar, ufilizar o sistema de & Financeiro/Planejamento & 47 & 7,40 & 2,36 & 0,34 & $1111+2+2$ & & 0151 \\
\hline & Business Intelligence é a minha escolha óbvia. & Outros & 33 & 8,09 & 1,67 & 0,29 & $-1,44$ & 18 & {$[0,154$} \\
\hline
\end{tabular}

Fonte: Dados Coletados Processados 


\subsubsection{COMPARAÇÃO EM RELAÇÃO AO TEMPO DE EXPERIÊNCIA COM BI}

Nesta seção foram separados os respondentes com até 3 anos de experiência com BI daqueles que possuem mais de três anos. Neste caso a diferença de respostas se deu em duas assertivas de Continuidade de Uso: "Nos últimos 7 dias, a cada vez que eu utilizei o sistema de Business Intelligence, eu gastei bastante tempo" e "Nos últimos 7 dias, eu utilizei frequentemente o sistema de Business Intelligence"; para as duas assertivas, aqueles que têm maior experiência em BI tendem a ser mais propensos a continuar utilizando, conforme pode ser visto na Tabela 10, a seguir. 
Tabela 10: Teste t para comparação das médias de cada assertiva em relação ao tempo de experiência com BI

\begin{tabular}{|c|c|c|c|c|c|c|c|c|c|}
\hline & & & $\mathrm{N}$ & Média & padrão & padrão & $\mathrm{t}$ & df & Sig \\
\hline \multirow{6}{*}{ Continuidade de uso } & \multirow{2}{*}{$\begin{array}{l}\text { Nos últimos } 7 \text { dias, eu ufilizei frequentemente o sistema } \\
\text { de Business Intelligence. }\end{array}$} & Atée 3 anos & 23 & 6,65 & 3,19 & 0,66 & \multirow[b]{2}{*}{$-2,15$} & \multirow[b]{2}{*}{78} & \multirow[b]{2}{*}{0,035} \\
\hline & & Mais de 3 anos & 57 & 8,12 & 2,58 & 0,34 & & & \\
\hline & \multirow{2}{*}{$\begin{array}{l}\text { Nos últimos } 7 \text { dias, a cada vez que eu udilizei sistema de } \\
\text { Business Intelligence, eu gastei bastante tempo }\end{array}$} & Até 3 anos & 23 & 5,09 & 2,39 & 0,50 & \multirow{2}{*}{$-2,51$} & \multirow{2}{*}{78} & \multirow{2}{*}{0,014} \\
\hline & & Mais de 3 anos & 57 & 6,56 & 2,38 & 0,31 & & & \\
\hline & \multirow{2}{*}{\begin{tabular}{|l}
$\begin{array}{l}\text { Nos últimos } 7 \text { dias, eu utilizei o sistema de Business } \\
\text { Intelligence várias vezes no mesmo dia. }\end{array}$ \\
\end{tabular}} & Atée 3 anos & 23 & 6,74 & 3,09 & 0,64 & \multirow{2}{*}{$-1,96$} & \multirow{2}{*}{78} & \multirow{2}{*}{0,054} \\
\hline & & Mais de 3 anos & 57 & 8,05 & 2,55 & 0,34 & & & \\
\hline \multirow{6}{*}{$\begin{array}{c}\text { Intenção } \\
\text { Comportamental de } \\
\text { Uso }\end{array}$} & \multirow{2}{*}{$\begin{array}{l}\text { Eu pretendo confinuar utilizando o sistema de Business } \\
\text { Intelligence enquanto a empresa tiver essa ferramenta. }\end{array}$} & Até 3 anos & 23 & 8,43 & 2,17 & 0,45 & \multirow{2}{*}{$-1,29$} & \multirow[b]{2}{*}{78} & \multirow[b]{2}{*}{0,1} \\
\hline & & Mais de 3 anos & 57 & 8,98 & 1,49 & 0,20 & & & \\
\hline & Minha intenção é ufilizar o sistema de Business & Atée 3 anos & 23 & 7,43 & 2,06 & 0,43 & & & \\
\hline & Intelligence ao invés de outras alternativas. & Mais de 3 anos & 57 & 7,51 & 2,22 & 0,29 & $-0,1$ & |c & \\
\hline & Se eu puder eu gostaria de permanecer utilizando o & Até 3 anos & 23 & 8,17 & 2,33 & 0,49 & & & \\
\hline & sistema de Business Intelligence. & Mais de 3 anos & 57 & 8,68 & 1,65 & 0,22 & $-1,1$ & 18 & \\
\hline & Eu estou satisfeito com a performance do sistema de & Atée 3 anos & 23 & 7,39 & 1,83 & 0,38 & & & \\
\hline & Business Intelligence. & Mais de 3 anos & 57 & 6,86 & 2,19 & 0,29 & 1,00 & $\left.\right|^{16}$ & \\
\hline & Considero satisfatória minha experiência utilizando & Atée 3 anos & 23 & 7,04 & 2,14 & 0,45 & & & \\
\hline Satisiaçao & sistemas de Business Intelligence & Mais de 3 anos & 57 & 7,77 & 1,69 & 0,22 & $-1,6$ & $\left.\right|^{16}$ & \\
\hline & Considero sábia minha decisão de utilizar sistemas de & Até 3 anos & 23 & 8,52 & 1,70 & 0,35 & & & \\
\hline & Business Intelligence. & Mais de 3 anos & 57 & 8,65 & 1,53 & 0,20 & $-0,3$ & 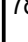 & \\
\hline & Minha experiência ufflizando o sistema de Business & Até 3 anos & 23 & 7,30 & 2,30 & 0,48 & 024 & & \\
\hline & Intelligence é melhor do que eu esperava. & Mais de 3 anos & 57 & 7,18 & 2,17 & 0,29 & $0, Z^{4}$ & $I^{\prime \prime}$ & \\
\hline & A qualidade do serviço do sistema de Business & Até 3 anos & 23 & 7,13 & 1,87 & 0,39 & & & \\
\hline Confırmaçao & Intelligence é melhor do que eu esperava. & Mais de 3 anos & 57 & 6,72 & 2,32 & 0,31 & 0,16 & 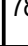 & \\
\hline & No geral, minhas expectativas de uso do $\mathrm{s}$ & Até 3 anos & 23 & 7,39 & 1,88 & 0,39 & & & \\
\hline & Business Intelligence foram confirmadas. & Mais de 3 anos & 57 & 7,40 & 2,01 & 0,27 & $-0,0$ & 18 & \\
\hline & Utilizar sistemas de Business Intelligence melhora minha & Atée 3 anos & 23 & 8,04 & 2,01 & 0,42 & & & \\
\hline & performance no trabalho. & Mais de 3 anos & 57 & 8,67 & 1,55 & 0,21 & $-1,4$ & $I^{\prime \prime}$ & \\
\hline & Utilizar sistemas de Business Intelligence melhora minha & Até 3 anos & 23 & 8,26 & 1,91 & 0,40 & & & \\
\hline & produtividade no trabalho. & Mais de 3 anos & 57 & 8,53 & 1,49 & 0,20 & $-0,0$ & $I^{\prime \prime}$ & 0,4 \\
\hline Utilidade Percebiaa & Utilizar sistemas de Business Intelligence melhora minha & Até 3 anos & 23 & 8,09 & 2,00 & 0,42 & & & \\
\hline & efetividade no trabalho. & Mais de 3 anos & 57 & 8,54 & 1,48 & 0,20 & $-1,1$ & 18 & \\
\hline & Em geral, o sistema de Business Intelligence é útil no & Até 3 anos & 23 & 8,96 & 1,43 & 0,30 & & & \\
\hline & trabalho. & Mais de 3 anos & 57 & 8,72 & 1,60 & 0,21 & $\mid, 0<$ & $l^{n}$ & {$[0,5$} \\
\hline & As informaçōes contidas no sistema de Business & Atée 3 anos & 23 & 7,00 & 2,13 & 0,44 & & & \\
\hline & Intelligence estão organizadas de forma clara. & Mais de 3 anos & 57 & 6,77 & 2,20 & 0,29 & $0,4<$ & $I^{\prime \prime}$ & {$[0,0$} \\
\hline & A informação contida no sistema de Business & Até 3 anos & 23 & 7,09 & 2,41 & 0,50 & & & \\
\hline Qualidade da & Intelligence está disponivel quando necessária. & Mais de 3 anos & 57 & 7,26 & 1,81 & 0,24 & $-0,0$ & 18 & 0,1 \\
\hline Informação & A informação contida no sistema de Business & Até 3 anos & 23 & 8,61 & 1,92 & 0,40 & & & \\
\hline & Intelligence é importante. & Mais de 3 anos & 57 & 9,18 & 1,12 & 0,15 & $-1,6$ & $I^{\prime}$ & \\
\hline & A informação contida no sistema de Business & Até 3 anos & 23 & 8,30 & 2,03 & 0,42 & R & & \\
\hline & Intelligence é significativa & Mais de 3 anos & 57 & 8,42 & 1,68 & 0,22 & $-0,2<$ & $I^{\prime \prime}$ & \\
\hline & Nossa companhia sabe o que "é melhor" para o cliente. & Atée 3 anos & 23 & 7,35 & 1,77 & 0,37 & & & \\
\hline & & Mais de 3 anos & 57 & 6,95 & 2,26 & 0,30 & $0, \pi$ & & \\
\hline Estratégia Direcionada & Nossa companhia desenvolve produtos baseados em & Atée 3 anos & 23 & 7,74 & 2,05 & 0,43 & & & \\
\hline pela Tecnologia & tecnologia. & Mais de 3 anos & 57 & 8,05 & 1,87 & 0,25 & $-0,6$ & $\pi$ & 0,5 \\
\hline & Nossos produtos têm qualidade superior. & Atée 3 anos & 23 & 7,57 & 1,97 & 0,41 & 047 & & \\
\hline & & Mais de 3 anos & 57 & 7,33 & 2,36 & 0,31 & {$[, 4<$} & $I^{\prime \prime}$ & $0,0\}$ \\
\hline & Usar o sistema de Business Intelligence é automático & Atée 3 anos & 23 & 7,17 & 2,19 & 0,46 & 5 & & \\
\hline & para mim. & Mais de 3 anos & 57 & 8,00 & 2,11 & 0,28 & $-1,0$ & $T^{\prime}$ & \\
\hline & Usar o sistema de Business Intelligence é natural para & Até 3 anos & 23 & 7,48 & 2,02 & 0,42 & & & \\
\hline Hábito & mim. & Mais de 3 anos & 57 & 8,44 & 2,03 & 0,27 & $-1, y$ & $T$ & {$[0,059$} \\
\hline & Quando tenho uma tarefa a realizar, udilizar o sistema de & Até 3 anos & 23 & 7,39 & 2,25 & 0,47 & 78 & & \\
\hline & Business Intelligence é a minha escolha óbvia. & Mais de 3 anos & 57 & 7,81 & 2,07 & 0,27 & $-0, T$ & 18 & \\
\hline
\end{tabular}

Fonte: Dados Coletados Processados 


\subsection{MODELO DE EQUAÇÕES ESTRUTURAIS}

Para estimar o tamanho mínimo da amostra que se deve usar pode-se utilizar o software G*Power 3.1.9.2 (http://www.gpower.hhu.de/en.html) (Faul, Erdfelder, Buchner, \& Lang, 2009). De acordo com Ringle et al. (2014) deve-se utilizar a variável latente com maior número de preditores (no caso deste trabalho são 3 preditores da Utilidade Percebida - vide Figura 29); deve-se ainda fornecer o poder do teste (Power $=1-\beta$ erro tipo II) e o tamanho do efeito $\left(\mathrm{f}^{2}\right)$. Hair, Hult, Ringle, \& Sarstedt (2014) sugerem que sejam adotados respectivamente 0,80 no poder e 0,15 para o tamanho do efeito. A amostra mínima calculada (Figura 33) é de 77 casos, de forma que a pesquisa de campo supera o requisito para adoção do modelo.

Figura 33: Tela do G*Power 3.1.9.2 com cálculo do tamanho da amostra

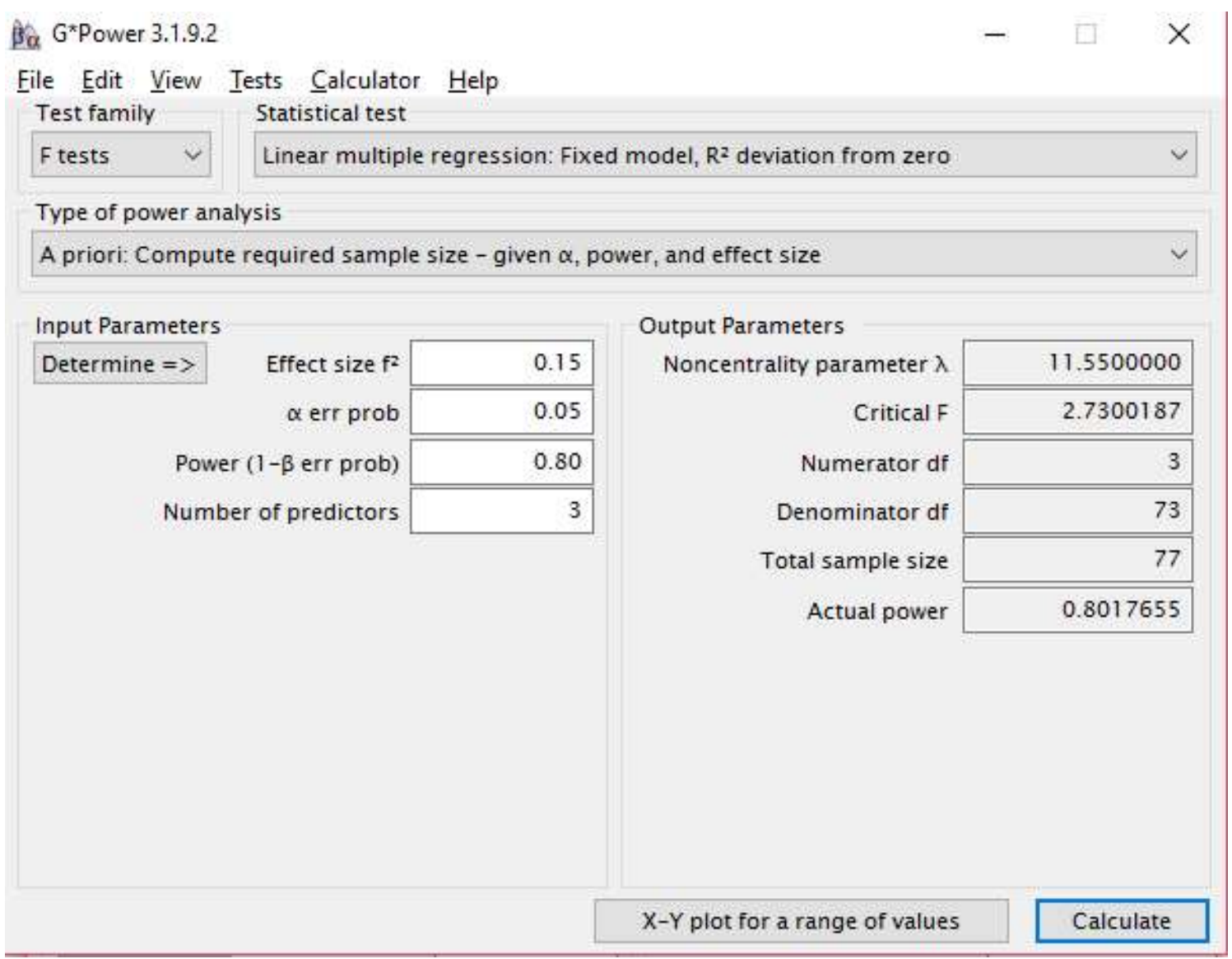

Fonte: G*Power 3.1.9.2

A técnica foi utilizada para teste do modelo apresentado na seção 3.11. Os resultados estão apresentados na Figura 34. 
Figura 34: Modelo ajustado por equações estruturais

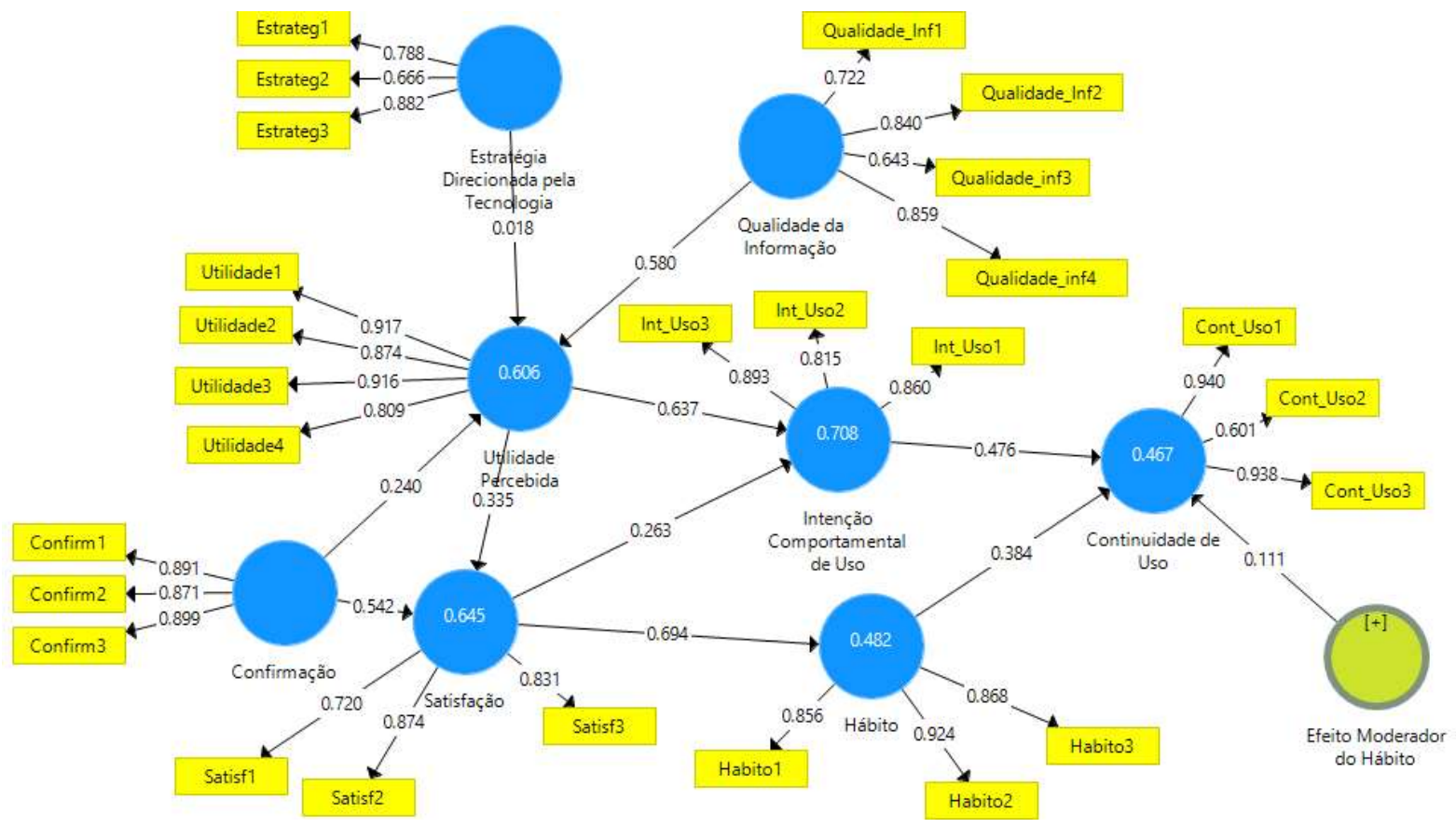

Fonte: Dados coletados processados

Uma vez que foi gerado o primeiro modelo, deve-se analisar as estatísticas para eventuais ajustes. Segundo Ringle et al. (2014), incialmente faz-se a avaliação do modelo de mensuração e, após os ajustes necessários neste, avalia-se o modelo estrutural. Os autores seguem apontando que as primeiras análises a serem feitas são as Validades Convergentes, obtidas pelas observações das Variâncias Médias Extraídas (Average Variance Extracted - AVEs). Henseler; Ringle. \& Sinkovic (2009) sugerem que os valores de AVE devem ser maiores que 0,50, pois a AVE é uma estatística que mostra a porção de dados explicada por cada um dos constructos, respectivos aos seus conjuntos de variáveis. Assim, quando as AVEs são maiores que 0,50 admite-se que o modelo converge a um resultado satisfatório (Fornell \& Larcker, 1981). A Tabela 11, a seguir, mostra que para todos os constructos analisados o valor de AVE é superior a 0,5. 
Tabela 11: Variância Média Extraída (AVE) de cada constructo

\begin{tabular}{|l|c|}
\hline Constructo & AVE \\
\hline Confirmação & 0,787 \\
\hline Continuidade de Uso & 0,708 \\
\hline Estratégia Direcionada pela Tecnologia & 0,614 \\
\hline Hábito & 0,780 \\
\hline Intenção Comportamental de Uso & 0,734 \\
\hline Qualidade da Informação & 0,594 \\
\hline Satisfação & 0,657 \\
\hline Utilidade Percebida & 0,775 \\
\hline
\end{tabular}

Fonte: Dados coletados processados

Na sequência foram avaliadas as estatísticas de consistência interna: o alfa de Cronbach que mensura as intercorrelações entre as variáveis (Esposito Vinzi, Trinchera, \& Amato, 2010) e o indicador de confiabilidade composta (Composite Reliability - CR). De acordo com Hair, Ringle, \& Starstedt (2011). Esse segundo indicador é mais adequado ao modelo de equações estruturais visto que, diferentemente do alfa de Cronbach, prioriza as variáveis de acordo com as suas confiabilidades, sendo menos sensível ao número de variáveis em cada constructo. Para modelos desse tipo, um valor de alfa de Cronbach acima de 0,60 é considerado aceitável (Hair et al., 2011) e ainda, é desejável que o indicador de confiabilidade composta seja superior a 0,70 (Pereira, Ramos, Gouvêa, \& Costa, 2015), o que foi atingido pelo modelo, conforme mostrado na Tabela 12.

Tabela 12: Indicadores de Consistência Interna

\begin{tabular}{|l|c|c|}
\hline Constructo & $\begin{array}{c}\text { Alfa de } \\
\text { Cronbach }\end{array}$ & $\begin{array}{c}\text { Confiabilidade } \\
\text { Composta }\end{array}$ \\
\hline Confirmação & 0,865 & 0,917 \\
\hline Continuidade de Uso & 0,786 & 0,875 \\
\hline Estratégia Direcionada pela Tecnologia & 0,683 & 0,825 \\
\hline Hábito & 0,859 & 0,914 \\
\hline Intenção Comportamental de Uso & 0,818 & 0,892 \\
\hline Qualidade da Informação & 0,769 & 0,853 \\
\hline Satisfação & 0,737 & 0,851 \\
\hline Utilidade Percebida & 0,902 & 0,932 \\
\hline
\end{tabular}

Fonte: Dados coletados processados

O passo seguinte foi avaliar a validade discriminante do modelo construído, que indica se cada constructo é independente dos demais (Hair et al., 2014). Fornell \& Larcker (1981) e Teo (2009) apontam que, na avaliação desse indicador, a raiz quadrada da AVE 
de cada constructo deve ser maior que sua correlação de Pearson com qualquer outro constructo. A Tabela 13, a seguir, apresenta os resultados para o modelo construído. Na diagonal principal estão as raízes quadradas de cada AVE, e nas demais células estão as respectivas correlações.

Tabela 13: Validade Discriminante do Modelo (Critério de Fornell-Larcker)

\begin{tabular}{|c|c|c|c|c|c|c|c|c|}
\hline & 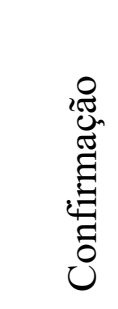 & 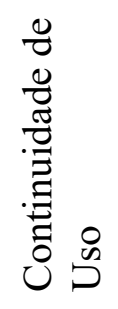 & 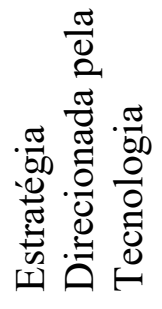 & $\begin{array}{l}\frac{0}{\pi} \\
\frac{0}{\pi} \\
\frac{\pi}{\pi}\end{array}$ & 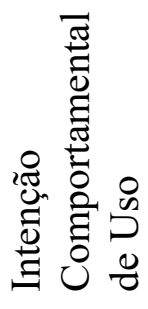 & 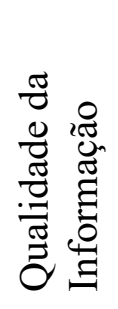 & 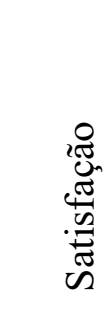 & 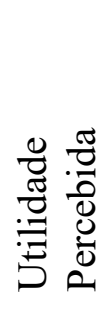 \\
\hline Confirmação & $\mathbf{0 , 8 8 7}$ & & & & & & & \\
\hline $\begin{array}{l}\text { Continuidade de } \\
\text { Uso }\end{array}$ & 0,502 & 0,842 & & & & & & \\
\hline $\begin{array}{l}\text { Estratégia } \\
\text { Direcionada pela } \\
\text { Tecnologia }\end{array}$ & 0,358 & 0,120 & 0,784 & & & & & \\
\hline Hábito & 0,580 & 0,604 & 0,349 & $\mathbf{0 , 8 8 3}$ & & & & \\
\hline $\begin{array}{l}\text { Intenção } \\
\text { Comportamental } \\
\text { de Uso }\end{array}$ & 0,749 & 0,630 & 0,290 & 0,712 & $\mathbf{0 , 8 5 7}$ & & & \\
\hline $\begin{array}{l}\text { Qualidade da } \\
\text { Informação }\end{array}$ & 0,714 & 0,457 & 0,527 & 0,583 & 0,715 & $\mathbf{0 , 7 7 1}$ & & \\
\hline Satisfação & 0,763 & 0,546 & 0,380 & 0,694 & 0,705 & 0,724 & $\mathbf{0 , 8 1 1}$ & \\
\hline $\begin{array}{l}\text { Utilidade } \\
\text { Percebida }\end{array}$ & 0,660 & 0,595 & 0,409 & 0,637 & 0,820 & 0,760 & 0,693 & $\mathbf{0 , 8 8 0}$ \\
\hline
\end{tabular}

Fonte: Dados coletados processados

A Tabela 13 mostra que os valores da diagonal principal são maiores que os valores apresentados na correlação entre os constructos, ressaltando a qualidade do modelo.

Com a garantia da validade discriminante, terminam-se os ajustes do modelo de mensuração e inicia-se a análise do modelo estrutural (Ringle et al., 2014). A primeira análise dessa fase é a dos coeficientes de determinação de Pearson $\left(\mathrm{R}^{2}\right)$. Essa estatística avalia a porção da variância explicada pelo modelo (Sharma, 1996). Segundo Cohen (1988), em estudos de ciências sociais e comportamento, $\mathrm{R}^{2}$ acima de $26 \%$ classifica-se como efeito grande. A Tabela 14 mostra os valores de $\mathrm{R}^{2}$ obtidos pelo SmartPLS, todos podendo ser classificados como grande efeito. 
Tabela 14: Coeficientes de Determinação de Pearson $\left(\mathrm{R}^{2}\right)$

\begin{tabular}{|l|r|}
\hline Constructo & $\mathbf{R}^{2}$ \\
\hline Continuidade de Uso & 0,467 \\
\hline Hábito & 0,482 \\
\hline Intenção Comportamental de Uso & 0,708 \\
\hline Satisfação & 0,645 \\
\hline Utilidade Percebida & 0,606 \\
\hline
\end{tabular}

Fonte: Dados coletados processados

Após avaliar os coeficientes de determinação, é necessária a análise do fator de inflação de variância (Variance Inflation Factor - VIF) para detectar se existe multicolinearidade no modelo (Sarstedt et al., 2014). Para este indicador, valores abaixo de 5 são desejáveis, pois sinalizam ausência de multicolinearidade entre os indicadores. A tabela 15 contém os valores calculados de VIF, e todos estão dentro dos valores desejáveis.

Tabela 155: Fator de Inflação de Variância (VIF)

\begin{tabular}{|c|c|c|c|c|c|c|c|c|}
\hline & 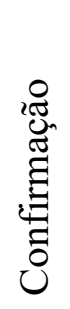 & 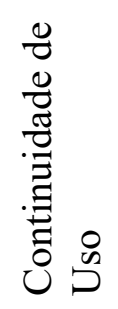 & 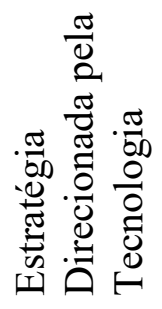 & 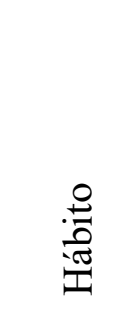 & 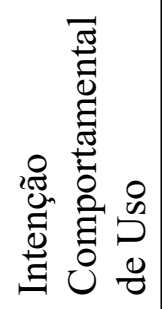 & 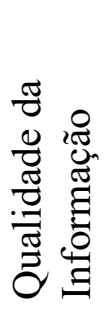 & 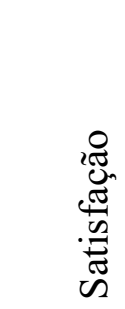 & 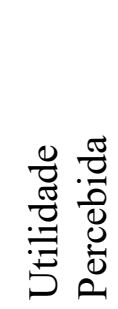 \\
\hline Confirmação & & & & & & & 1,773 & 2,045 \\
\hline $\begin{array}{l}\text { Continuidade de } \\
\text { Uso }\end{array}$ & & & & & & & & \\
\hline $\begin{array}{l}\text { Efeito Moderador } \\
\text { do Hábito }\end{array}$ & & 1,779 & & & & & & \\
\hline $\begin{array}{l}\text { Estratégia } \\
\text { Direcionada pela } \\
\text { Tecnologia }\end{array}$ & & & & & & & & 1,386 \\
\hline Hábito & & 2,255 & & & & & & \\
\hline $\begin{array}{l}\text { Intenção } \\
\text { Comportamental } \\
\text { de Uso }\end{array}$ & & 2,259 & & & & & & \\
\hline $\begin{array}{l}\text { Qualidade da } \\
\text { Informação }\end{array}$ & & & & & & & & 2,469 \\
\hline Satisfação & & & & 1,000 & 1,922 & & & \\
\hline $\begin{array}{l}\text { Utilidade } \\
\text { Percebida }\end{array}$ & & & & & 1,922 & & 1,773 & \\
\hline
\end{tabular}

Fonte: Dados coletados processados 
O passo seguinte para avaliação do modelo é a análise do indicador de Relevância ou Validade Preditiva $\left(\mathrm{Q}^{2}\right)$ e Tamanho do efeito $\left(\mathrm{f}^{2}\right)$ (Ringle et al., 2014). O indicador de validade preditiva indica a acurácia do modelo ajustado. De acordo com Hair et al. (2014), os valores obtidos devem ser maiores que 0 e quanto mais próximos de 1 , mais preciso o modelo.

Já o indicador de tamanho do efeito é obtido pela inclusão e exclusão de constructos do modelo (um a um) (Ringle et al., 2014). Valores de 0,02, 0,15 e 0,35 são considerados pequenos, médios e grandes, respectivamente (Hair et al., 2014). A Tabela 16, a seguir, mostra os valores dos indicadores de Relevância e Tamanho do efeito para cada constructo.

Tabela 166: Indicador de Validade Preditiva $\left(\mathrm{Q}^{2}\right)$ e Tamanho do efeito $\left(\mathrm{f}^{2}\right)$

\begin{tabular}{|l|r|r|}
\hline Constructo & \multicolumn{1}{|c|}{$\mathbf{Q}^{2}$} & $\mathbf{f}^{2}$ \\
\hline Confirmação & & 0,524 \\
\hline Continuidade de Uso & 0,269 & 0,442 \\
\hline Estratégia Direcionada pela Tecnologia & & 0,265 \\
\hline Hábito & 0,359 & 0,507 \\
\hline Intenção Comportamental de Uso & 0,485 & 0,439 \\
\hline Qualidade da Informação & & 0,334 \\
\hline Satisfação & 0,402 & 0,329 \\
\hline Utilidade Percebida & 0,433 & 0,583 \\
\hline
\end{tabular}

Fonte: Dados coletados processados

$\mathrm{Na}$ sequência, avalia-se o indicador de ajuste geral do modelo; Tenenhaus, Vinzi, Chatelin, \& Lauro (2005) propõem o indicador de adequação do modelo (GoF Goodness of Fit), que é calculado pela média geométrica entre o $\mathrm{R}^{2}$ médio (adequação do modelo estrutural) e a média ponderada das AVE (adequação do modelo de mensuração). Wetzels, Odekerken-Schröder, \& Oppen (2009) propõem o valor de 0,36 como adequado para as áreas de ciências sociais e do comportamento. Neste modelo, o cálculo do GoF chegou ao valor de 0,6401 , indicando um bom ajuste do modelo.

\subsection{AVALIAÇÃO DAS HIPÓTESES DO MODELO E COMPARAÇÃO COM ESTUDOS ANTERIORES}

Finalmente, é feita a avaliação das hipóteses do modelo, avaliando se as relações entre os constructos são significantes. De acordo com Ringle et al. (2014), para essa análise utiliza-se o módulo Bootstrapping do SmartPLS. Esse módulo, por meio de 
reamostragens, testa a hipótese nula que a correlação entre os constructos é igual a zero. Para isso, executa um teste t; valores $\mathrm{p}$ ( $\mathrm{p}$-values) inferiores a 0,05 rejeitam a hipótese que a correlação entre os constructos é igual a zero, com nível de significância de 5\%, corroborando a hipótese que está sendo testada. A Tabela 17, na sequência, aponta as conclusões para cada hipótese apresentada no item 4.3.

Tabela 17:Verificação das hipóteses - nível de significância de 5\%

\begin{tabular}{|l|r|r|l|}
\hline Hipótese & Estatística & p-value & Resultado \\
\hline $\begin{array}{l}\text { H1: A Estratégia direcionada pela Tecnologia influencia de forma } \\
\text { positiva a Utilidade Percebida. }\end{array}$ & 0,256 & 0,798 & Hipótese Rejeitada \\
\hline $\begin{array}{l}\text { H2: A Qualidade da Informação influencia de forma positiva a Utilidade } \\
\text { Percebida. }\end{array}$ & 4,593 & 0,000 & Hipótese Confirmada \\
\hline H3: Confirmação afeta de forma positiva a Utilidade Percebida. & 2,091 & 0,037 & Hipótese Confirmada \\
\hline H4: Confirmação afeta de forma positiva a Satisfação. & 5,079 & 0,000 & Hipótese Confirmada \\
\hline H5: A Utilidade Percebida tem efeito positivo na Satisfação. & 3,011 & 0,003 & Hipótese Confirmada \\
\hline $\begin{array}{l}\text { H6: A Utilidade Percebida impacta de forma positiva a Intenção } \\
\text { Comportamental de Uso. }\end{array}$ & 8,030 & 0,000 & Hipótese Confirmada \\
\hline $\begin{array}{l}\text { H7: Satisfação tem impacto positivo na Intenção Comportamental de } \\
\text { Uso. }\end{array}$ & 3,185 & 0,001 & Hipótese Confirmada \\
\hline H8: Satisfação influencia de forma positiva o Hábito. & 9,209 & 0,000 & Hipótese Confirmada \\
\hline $\begin{array}{l}\text { H9: A Intenção Comportamental de Uso afeta de forma positiva a } \\
\text { Continuidade de Uso. }\end{array}$ & 2,519 & 0,012 & Hipótese Confirmada \\
\hline $\begin{array}{l}\text { H10a: O Hábito tem efeito moderador na relação entre Intenção } \\
\text { Comportamental de Uso e Continuidade de Uso. }\end{array}$ & 1,171 & 0,242 & Hipótese Rejeitada \\
\hline \begin{tabular}{l} 
H10b: O Hábito tem efeito positivo na positiva a Continuidade de Uso. \\
\hline
\end{tabular} & 2,071 & 0,039 & Hipótese Confirmada \\
\hline
\end{tabular}

Fonte: Dados coletados processados

Baseando-se na bibliografia pesquisada, foram comparados os achados desta tese com pesquisas de aceitação de tecnologia que testaram hipóteses similares publicadas por outros autores.

Foi feita a seleção de artigos que utilizaram modelos similares e/ou fizeram pesquisas sobre sistemas de BI. Foram escolhidos artigos de forma que cada hipótese, exceto a primeira, aparecesse ao menos duas vezes. A primeira hipótese trata de uma proposta deste trabalho seguindo sugestão de Pejić Bach et al. (2016); na bibliografia consultada, este constructo de estratégia direcionada pela tecnologia é largamente pesquisado em trabalhos que o relacionam com o resultado da empresa. Esta tese apresenta o constructo relacionado à aceitação de tecnologia. A Figura 35 sintetiza os estudos pesquisados.

Figura 35: Resumo dos trabalhos consultados 


\begin{tabular}{|c|c|}
\hline Autor(es) & Resumo \\
\hline $\begin{array}{l}\text { Han et al. } \\
\text { (2016) }\end{array}$ & $\begin{array}{l}\text { Utiliza um modelo ECT adaptado com o constructo de Hábito; pesquisa a } \\
\text { adoção de sistema de BI; pesquisa feita em Taiwan onde foram entrevistados } \\
117 \text { usuários. }\end{array}$ \\
\hline $\begin{array}{l}\text { Hou } \\
(2016)\end{array}$ & $\begin{array}{l}\text { Combina os modelos ECT e TAM; investiga a adoção de sistemas de BI em } \\
\text { indústrias de eletrônicos taiwanesas; contou com } 330 \text { entrevistados. }\end{array}$ \\
\hline $\begin{array}{c}\text { Hou } \\
(2014 \mathrm{a})\end{array}$ & $\begin{array}{l}\text { Com auxílio do modelo UTAUT, estuda a adoção de sistemas de BI em } \\
\text { indústrias de eletrônicos taiwanesas; contou com } 330 \text { entrevistados. }\end{array}$ \\
\hline $\begin{array}{c}\text { Hou } \\
(2014 b)\end{array}$ & $\begin{array}{l}\text { Compara os modelos TAM, TPB e DTPB, também analisando a adoção de } \\
\text { sistemas de BI no mercado de eletrônicos em Taiwan, em um total de } 330 \\
\text { respondentes. }\end{array}$ \\
\hline $\begin{array}{l}\text { Venkatesh } \\
\text { et al. } \\
\text { (2012) }\end{array}$ & $\begin{array}{l}\text { Apresenta o modelo UTAUT2, uma evolução do modelo UTAUT, com a } \\
\text { incorporação de três constructos: hábito, motivação hedônica e preço. } \\
\text { Pesquisou usuários de internet móvel (celular), com } 1.512 \text { entrevistados. }\end{array}$ \\
\hline $\begin{array}{l}\text { Wixom \& } \\
\text { Todd } \\
(2005)\end{array}$ & $\begin{array}{l}\text { Por meio de entrevistas em sete empresas, os autores buscaram entender o uso } \\
\text { de sistemas de Data Warehouse, adaptando ao modelo TAM os constructos de } \\
\text { Satisfação e Qualidade da Informação. }\end{array}$ \\
\hline $\begin{array}{l}\text { Ahn, Ryu } \\
\text { \& Han } \\
(2007)\end{array}$ & $\begin{array}{l}\text { Em uma pesquisa com } 942 \text { usuários de uma página de compras online, } \\
\text { investigaram, com o auxílio de um modelo TAM adaptado, a aceitação deste } \\
\text { site. }\end{array}$ \\
\hline $\begin{array}{l}\text { Shiau \& } \\
\text { Luo } \\
(2013)\end{array}$ & $\begin{array}{l}\text { Para avaliar a intenção de um grupo de usuários de um blog em permanecer } \\
\text { utilizando-o, os autores adaptaram um modelo ECTe fizeram uma pesquisa } \\
\text { com } 430 \text { respondentes. }\end{array}$ \\
\hline $\begin{array}{l}\text { Limayem, } \\
\text { et al. } \\
(2007)\end{array}$ & $\begin{array}{l}\text { Utilizando um modelo ECT adaptado, incluindo o constructo de hábito, os } \\
\text { autores contaram com as respostas de } 229 \text { usuários de internet para avaliar as } \\
\text { percepções destes respondentes sobre a rede. }\end{array}$ \\
\hline
\end{tabular}

Fonte: Literatura Pesquisada

A Figura 36, a seguir, mostra as conclusões de outras pesquisas de aceitação de tecnologia, as hipóteses marcadas com um $\checkmark$ foram confirmadas pelos pesquisadores. Hipóteses marcadas com $\mathbf{X}$, foram rejeitadas no trabalho dos autores citados.

A análise da tabela mostra que a hipótese "A Utilidade Percebida impacta de forma positiva a Intenção Comportamental de Uso" foi testada em todos os trabalhos sendo que apenas em um deles não foi confirmada a relação positiva entre os constructos. Além dessa, as hipóteses: “A Utilidade Percebida tem efeito positivo na Satisfação", "A Intenção Comportamental de Uso afeta de forma positiva a Continuidade de Uso", "O Hábito tem efeito positivo na positiva a Continuidade de Uso.”, “O Hábito tem efeito 
moderador na relação entre Intenção Comportamental de Uso e Continuidade de Uso.”, também apresentaram resultados divergentes na literatura pesquisada. As demais hipóteses foram confirmadas em todos os estudos. 
Figura 36: Conclusões de pesquisas similares - considerando nível de significância de 5\%

\begin{tabular}{|c|c|c|c|c|c|c|c|c|c|}
\hline Hipótese & $\begin{array}{l}\text { Han et al. } \\
(2016)\end{array}$ & $\begin{array}{l}\text { Hou } \\
(2016)\end{array}$ & $\begin{array}{l}\text { Hou } \\
(2014 a)\end{array}$ & $\begin{array}{l}\text { Hou } \\
(2014 b)\end{array}$ & $\begin{array}{l}\text { Venkatesh, } \\
\text { Thong \& } \\
\text { Xu (2012) }\end{array}$ & $\begin{array}{l}\text { Wixom } \\
\& \text { Todd } \\
(2005)\end{array}$ & $\begin{array}{l}\text { Ahn, Ryu } \\
\& \text { Han } \\
(2007)\end{array}$ & $\begin{array}{l}\text { Shiau \& } \\
\text { Luo } \\
(2013)\end{array}$ & $\begin{array}{l}\text { Limayem, } \\
\text { et al. } \\
(2007)\end{array}$ \\
\hline $\begin{array}{l}\text { H1: A Estratégia direcionada pela Tecnologia } \\
\text { influencia de forma positiva a Utilidade Percebida. }\end{array}$ & \multicolumn{9}{|c|}{$\begin{array}{l}\text { Constructo proposto por Pejić Bach et al., (2016). Não testado anteriormente, contribuição desta } \\
\text { tese. }\end{array}$} \\
\hline $\begin{array}{l}\text { H2: A Qualidade da Informação influencia de forma } \\
\text { positiva a Utilidade Percebida. }\end{array}$ & & & & & & $\checkmark$ & $\checkmark$ & & \\
\hline $\begin{array}{l}\text { H3: Confirmação afeta de forma positiva a Utilidade } \\
\text { Percebida. }\end{array}$ & $\checkmark$ & $\checkmark$ & & & & & & $\checkmark$ & \\
\hline H4: Confirmação afeta de forma positiva a Satisfação. & $\checkmark$ & $\checkmark$ & & & & & & $\checkmark$ & $\checkmark$ \\
\hline $\begin{array}{l}\text { H5: A Utilidade Percebida tem efeito positivo na } \\
\text { Satisfação. }\end{array}$ & $\checkmark$ & $\mathbf{X}$ & & & & & & $\checkmark$ & $\checkmark$ \\
\hline $\begin{array}{l}\text { H6: A Utilidade Percebida impacta de forma positiva a } \\
\text { Intenção Comportamental de Uso. }\end{array}$ & $\checkmark$ & $\checkmark$ & $\mathbf{X}$ & $\checkmark$ & $\checkmark$ & $\checkmark$ & $\checkmark$ & $\checkmark$ & $\checkmark$ \\
\hline $\begin{array}{l}\text { H7: Satisfação tem impacto positivo na Intenção } \\
\text { Comportamental de Uso. }\end{array}$ & $\checkmark$ & $\checkmark$ & & & & & & $\sqrt{ }$ & $\checkmark$ \\
\hline H8: Satisfação influencia de forma positiva o Hábito. & $\checkmark$ & & & & & & & & $\checkmark$ \\
\hline $\begin{array}{l}\text { H9: A Intenção Comportamental de Uso afeta de forma } \\
\text { positiva a Continuidade de Uso. }\end{array}$ & $\mathbf{X}$ & & $\checkmark$ & $\checkmark$ & $\checkmark$ & & & & $\checkmark$ \\
\hline $\begin{array}{l}\text { H10a: O Hábito tem efeito moderador na relação entre } \\
\text { Intenção Comportamental de Uso e Continuidade de } \\
\text { Uso. }\end{array}$ & $\mathbf{X}$ & & & & & & & & $\checkmark$ \\
\hline $\begin{array}{l}\text { H10b: O Hábito tem efeito positivo na Continuidade } \\
\text { de Uso }\end{array}$ & $\mathbf{X}$ & & & & $\checkmark$ & & & & $\checkmark$ \\
\hline
\end{tabular}

Fonte: Literatura Pesquisada 


\section{CONCLUSÕES, IMPLICAÇÕES, LIMITAÇÕES E CONTRIBUIÇÕES PARA FUTURAS PESQUISAS}

No intuito de melhor organizar as considerações sobre os achados deste estudo, este capítulo foi dividido em quatro partes: 1) conclusões a partir da discussão dos resultados e implicações acadêmicas; 2) implicações gerenciais; 3) limitações do estudo; 4) contribuições para futuras pesquisas.

\subsection{CONCLUSÕES A PARTIR DA DISCUSSÃO DOS RESULTADOS E IMPLICAÇÕES ACADÊMICAS}

A principal contribuição acadêmica resultante do desenvolvimento deste estudo é o entendimento sobre a relação dos fatores que influenciam a aceitação de um sistema de BI no mercado brasileiro de serviços. Apesar de a literatura ser vasta na utilização de modelos de aceitação de tecnologia, a investigação sobre ferramentas de Business Intelligence ainda é pouco explorada. Em virtude de todos estes fatores, podem ser listados os seguintes pontos de importância acadêmica deste trabalho:

- Pesquisa sobre Sistemas de BI.

- Foco no mercado de serviços.

- Estudo sobre o mercado brasileiro.

- Adaptação do modelo ECT com os constructos de Estratégia, Qualidade da Informação e Hábito.

- Pesquisa com diversas empresas

\subsection{IMPLICAÇÕES GERENCIAIS}

Conforme será explicitado na próxima seção que discorre sobre as limitações, os resultados aqui obtidos não são extrapoláveis para a população. Entretanto, algumas das conclusões deste trabalho podem ser úteis para os gestores de empresas.

A conclusão que o fato de a estratégia da empresa ser direcionada pela tecnologia não afetar positivamente a utilidade percebida do sistema de BI pode ser um indício que, independentemente de como o empregado identifica a estratégia da empresa, ele percebe o valor do sistema de BI, o que indica que a ferramenta é útil não apenas para cenários de empresas tecnológicas. 
Outros fatores importantes como: qualidade da informação, satisfação do usuário e percepção do usuário em relação às suas expectativas prévias (confirmação) devem ser administrados pela companhia de forma a gerar no usuário uma percepção de utilidade da ferramenta e posteriormente uma continuidade de uso.

Por fim, o questionário apresentado nesta pesquisa pode ser utilizado internamente em uma empresa para entender não só cada constructo individualmente, como também a relação entre eles para o cenário específico daquela organização.

\subsection{LIMITAÇÕES}

De acordo com Nakagawa (2008), a combinação de mais de um modelo em um único, como feito nesta tese, modelo ECT adaptado com três novos constructos, agrega vantagens. Porém, traz limitações de ordem prática, como o aumento do número de constructos, e também teórica, uma vez que a intersecção entre constructos pré-existentes e respectivas escalas pode nem sempre ser a ideal.

Em relação à coleta de dados, como não existe um cadastro de usuários de sistema de BI, não é possível efetuar uma amostra aleatória para a seleção dos indivíduos, o que estaria mais de acordo com o rigor estatístico. O método de amostragem escolhido, conforme mencionado no capítulo 4, possui algumas limitações: o pesquisador não tem controle da amostra. Por ser um método não probabilístico não se podem extrapolar os resultados para a população, e há um viés de seleção, dado que as pessoas com uma rede de contatos maior têm maior probabilidade de serem indicadas para responder a pesquisa.

Ainda em relação à amostra coletada, por ser uma pesquisa voltada para funcionários empregados em instituições que adotam sistemas de BI, existe um risco de o respondente ficar desconfiado e responder não de acordo com suas percepções, mas sim como ele acredita que a "empresa" considera que ele deva responder. Para tentar controlar esse risco, foi explicado na carta de apresentação e no cabeçalho do questionário que se tratava de uma pesquisa meramente acadêmica, cujos respondentes não seriam identificados, não havia respostas certas ou erradas e que o respondente emitisse sua opinião sobre os pontos a ele apresentados.

Um último ponto a ser ressaltado refere-se às perguntas sobre direcionador da estratégia da empresa. Foi abordada a percepção do respondente em relação à estratégia adotada 
pela empresa, mas não se mensurou se o respondente conhece, de fato, essa estratégia. Estudos futuros podem incluir questões para mensurar esse fator.

\subsection{CONTRIBUIÇÕES PARA FUTURAS PESQUISAS}

Tão importante quanto a evolução tecnológica, a aceitação da tecnologia é um fator-chave para o sucesso das empresas (Venkatesh \& Morris, 2000). Partindo dessa assertiva, futuras pesquisas podem dar continuidade a esta, para detalhar seus resultados e entender mais profundamente os achados. Por exemplo, por quais razões a estratégia direcionada pela tecnologia não apresentou influência positiva na utilidade percebida?

Outra oportunidade de investigação poderia ser a adaptação de outros modelos teóricos, como UTAUT, para entender como outros fatores podem afetar a aceitação de sistemas de BI em uma empresa. Como cada modelo tem suas premissas diferentes de construção, uma tentativa de responder à pergunta sobre aceitação sob o prisma de outro arcabouço de hipóteses pode trazer diferentes perspectivas para o problema.

Não limitar as pesquisas apenas a sistemas de BI seria uma outra maneira de expandir este trabalho, realizando uma pesquisa que compare a aceitação de dois ou mais sistemas que uma empresa tenha adotado. Por exemplo, se o respondente preenchesse o mesmo questionário apresentado nesta tese duas vezes, considerando inicialmente o sistema de BI que a empresa possui e posteriormente o sistema de gestão (Enterprise Resource Planning- ERP) adotado pela empresa, os resultados poderiam ser comparados em relação à aceitação dos dois sistemas.

Finalmente, este trabalho focou em empresas do setor de serviços. Estudos futuros podem se basear em outros setores ou em áreas específicas das empresas (Marketing, Finanças, Recursos Humanos etc.) e comparar os resultados obtidos. 


\section{REFERÊNCIAS}

Ahn, T., Ryu, S., \& Han, I. (2007). The impact of Web quality and playfulness on user acceptance of online retailing. Information and Management, 44(3), 263-275. http://doi.org/10.1016/j.im.2006.12.008

Ajzen, I. (1991). The theory of planned behavior. Orgnizational Behavior and Human Decision Processes, 50, 179-211. http://doi.org/10.1016/0749-5978(91)90020-T

Allen, R. S., Helms, M. M., Takeda, M. B., White, C. S., \& White, C. (2006). A comparison of competitive strategies in Japan and the United States. SAM Advanced Management Journal, 71(1).

Awang, Z., Afthanorhan, A., \& Asri, M. A. M. (2015). Parametric and Non Parametric Approach in Structural Equation Modeling (SEM): The Application of Bootstrapping. Modern Applied Science, 9(9), 58-67. http://doi.org/10.5539/mas.v9n9p58

Banco Central. (2015). Série histórica dos Fluxos de investimento direto - distribuições por país ou por setor. Retrieved November 13, 2017, from http://www.bcb.gov.br/?SERIEFIND

Bandura, A. (1986). Social foundations of thought and action: A social cognitive theory. Englewood Cliffs: Prentice Hall. http://doi.org/http://dx.doi.org/10.1037/13273005

Benbasat, I., \& Barki, H. (2007). Quo vadis, TAM? Journal of the Association of Information Systems, 8(4), 211-218.

Bhattacherjee, A. (2001a). An empirical analysis of the antecedents of electronic commerce service continuance. Decision Support Systems, 32(2), 201-214.

Bhattacherjee, A. (2001b). Understanding Information Systems Continuance: An Expectation-Confirmation Model. MIS Quarterly, 25(3), 351-370.

Bhattacherjee, A., \& Premkumar, G. (2004). Understanding Changes in Belief and Attitude toward Information Technology Usage: A Theoretical Model and Longitudinal Test. MIS Quarterly, 28(2), 229-254. http://doi.org/Article

Biernacki, P., \& Waldorf, D. (1981). Snowball Sampling: Problems and Techniques of Chain Referral Sampling. Sociological Methods Research, 10(2), 141-163. http://doi.org/10.1177/004912418101000205

Biesdorf, S., Court, D., \& Willmott, P. (2013). Big data: What's your plan? McKinsey Quarterly, March. Retrieved from http://www.mckinsey.com/insights/business_technology/big_data_whats_your_pla $\mathrm{n}$

Breiman, L. (2001). Statistical Modeling: The Two Cultures. Statistical Science, 16(3), 199-215. http://doi.org/10.2307/2676681

Brenes, E. R., Montoya, D., \& Ciravegna, L. (2014). Differentiation strategies in emerging markets: The case of Latin American agribusinesses. Journal of Business 
Research, 67(5), 847-855. http://doi.org/10.1016/j.jbusres.2013.07.003

Bronzo, M., de Resende, P. T. V., de Oliveira, M. P. V., McCormack, K. P., de Sousa, P. R., \& Ferreira, R. L. (2013). Improving performance aligning business analytics with process orientation. International Journal of Information Management, 33(2), 300-307. http://doi.org/10.1016/j.ijinfomgt.2012.11.011

Brown, B., Chui, M., \& Manyika, J. (2011). Are you ready for the era of " big data "? McKinsey Quarterly, October(October), 1-12. http://doi.org/00475394

Bryson, J., Daniels, P., \& Warf, B. (2013). Service Worlds: People, Organisations, Technologies (1st ed.). Oxon: Routledge.

Cadogan, J. W. (2012). International marketing, strategic orientations and business success. International Marketing Review, 29(4), 340-348. http://doi.org/10.1108/02651331211242656

Camargos, M. A. de, \& Dias, A. T. (2003). Estratégia, administração estratégica e estratégia corporativa: uma síntese teórica. Caderno de Pesquisas Em Administracão, 10(1), 27-39.

Casadesus-Masanell, R., \& Ricart, J. (2010). From Strategy to Business Models and onto Tactics. Long Range Planning, 43(2-3), 195-215. http://doi.org/10.1016/j.lrp.2010.01.004

Chakraborty, I., Hu, P. J.-H., \& Cui, D. (2008). Examining the effects of cognitive style in individuals' technology use decision making. Decision Support Systems, 45(2), 228-241. http://doi.org/10.1016/j.dss.2007.02.003

Chand, S. (n.d.). Reasons for the Growth of Service Economy (with statistics). Retrieved February 19, 2016, from http://www.yourarticlelibrary.com/economy/reasons-for-the-growth-of-serviceeconomy-with-statistics/33987/

Chen, H., Chiang, R. H. L., \& Storey, V. C. (2012). Business Intelligence And Analytics: From Big Data To Big Impact. MIS Quarterly, 36(4), 1165-1188.

Cheon, J., Lee, S., Crooks, S. M., \& Song, J. (2012). An investigation of mobile learning readiness in higher education based on the theory of planned behavior. Computers and Education, 59(3), 1054-1064. http://doi.org/10.1016/j.compedu.2012.04.015

Chuttur, M. (2009). Overview of the Technology Acceptance Model: Origins, Developments and Future Directions. Sprouts: Working Papers on Information Systems, 9(2009), 1-23. http://doi.org/10.1021/jf001443p

CIA. (n.d.). World Fact Book. Retrieved February 17, 2016, from www.cia.gov/library/publications/the-world-factbook/fields/2012.html

Cohen, J. (1988). Statistical Power Analysis for the Behavioral Sciences (2nd ed.). New York: Psychology Press,.

Cohen, J., Dolan, B., Dunlap, M., Hellerstein, J. M., \& Welton, C. (2009). MAD skills: new analysis practices for big data. Proceedings of the VLDB Endowment, 2(2), 1481-1492. http://doi.org/10.14778/1687553.1687576

Compeau, D., \& Higgins, C. (1995). Computer Self Efficacy: Development of a Measure and Initial Test. Management Information Systems Quarterly. 
Davenport, T. H. (2006). Competing on analytics. Harvard Business Review, 84, 98 107. http://doi.org/Article

Davis, F., Bagozzi, R., \& Warshaw, P. (1989). User acceptance of computer technology: a comparison of two theoretical models. Management Science, 35(8), 982-1003. http://doi.org/10.1287/mnsc.35.8.982

Davis, F. D. (1989). Perceived Usefulness , Perceived Ease Of Use , And User Acceptance. MIS Quarterly, 13(3), 319-339. http://doi.org/10.2307/249008

Davis, F. D., Bagozzi, R. P., \& Warshaw, P. R. (1992). Extrinsic and Intrinsic Motivation to Use Computers in the Workplace1. Journal of Applied Social Psychology, 22(14), 1111-1132. http://doi.org/10.1111/j.15591816.1992.tb00945.x

Deutscher, F., Zapkau, F. B., Schwens, C., Baum, M., \& Kabst, R. (2016). Strategic orientations and performance: A configurational perspective. Journal of Business Research, 69(2), 849-861. http://doi.org/10.1016/j.jbusres.2015.07.005

Dias, G. A., \& Vieira, A. A. N. (2013, August 6). Big data: questões éticas e legais emergentes. Ciência da Informação. Retrieved from http://revista.ibict.br/index.php/ciinf/article/view/2284

Diebold, F. (2012). On the Origin (s) and Development of the Term Big Data. Penn Institute for Economic Research, Pier Working Paper.

Dumbill, E. (2012). What is big data? - An introduction to the big data landscape. Retrieved February 3, 2016, from https://www.oreilly.com/ideas/what-is-big-data

Dutta, D. K. (2015). Hypercompetitive Environments, Coopetition Strategy, and the Role of Complementary Assets in Building Competitive Advantage : Insights From the Resource-Based View. Strategic Management Review, 9(1), 1-11.

Esposito Vinzi, V. ., Trinchera, L. ., \& Amato, S. (2010). PLS Path Modeling: From Foundations to Recent Developments and Open Issues for Model Assessment and Improvement. In Heidelber (Ed.), Handbook of partial least squares (1st ed.). Berlin: Springer.

Exame. (2017). Melhores \& Maiores 2017. Retrieved November 14, 2017, from https://exame.abril.com.br/revista-exame/50-maiores-setoriais/

Faul, F., Erdfelder, E., Buchner, A., \& Lang, A.-G. (2009). Statistical power analyses using G*Power 3.1: Tests for correlation and regression analyses. Behavior Research Methods, 41(4), 1149-1160. http://doi.org/10.3758/BRM.41.4.1149

Fishbein, M., \& Ajzen, I. (1975). Belief, attitude, intention, and behavior: an introduction to theory and research. Addison-Wesley Pub. Co.

Fitzsimmons, J. A., \& Fitzsimmons, M. J. (2014). Administração de Serviços Operações, Estratégia e Tecnologia da Informação (7th ed.). Porto Alegre: Bookman.

Flint, D. J., Blocker, C. P., \& Boutin, P. J. (2011). Customer value anticipation, customer satisfaction and loyalty: An empirical examination. Industrial Marketing Management, 40(2), 219-230. http://doi.org/10.1016/j.indmarman.2010.06.034

Fornell, C., \& Larcker, D. F. (1981). Evaluating Structural Equation Models with Unobservable Variables and Measurement Error. Journal of Marketing Research, 
18(1), 39. http://doi.org/10.2307/3151312

Forster, M. R. (2002). Predictive Accuracy as an Achievable Goal of Science.

Philosophy of Science, 69(S3), S124-S134. http://doi.org/10.1086/341840

Gadiesh, O., \& Gilbert, J. L. (2001). Transforming Corner-Office Strategy into Frontline Action. Harvard Business Review, 5.

Gatignon, H., \& Xuereb, J. (1997). Strategic Orientation of the Firm and New Product Performance. Journal of Marketing Research, 34(1), 77-90.

Gebauer, H., Gustafsson, A., \& Witell, L. (2011). Competitive advantage through service differentiation by manufacturing companies. Journal of Business Research, 64(12), 1270-1280. http://doi.org/10.1016/j.jbusres.2011.01.015

Ghemawat, P. (2002). Competition and Business Strategy in Historical Perspective. Business History Review, 76(1).

Goodman, L. (1961). Snowball Sampling. The Annals of Mathematical Statistics, 32(1), $148-170$.

Gregor, S. (2006). The Nature of Theory in Information Systems. MIS Quarterly, 30(3), 611-642. http://doi.org/10.1080/0268396022000017725

Grubljesic, T., \& Jaklic, J. (2015). Conceptualization of the Business Intelligence Extended Use Model. JOURNAL OF COMPUTER INFORMATION SYSTEMS, 55(3), 72-82.

Grublješič, T., \& Jaklič, J. (2014). Business Intelligence Acceptance: The Prominence of Organizational Factors. Information Systems Management, 530(January). http://doi.org/10.1080/10580530.2015.1080000

Gutman, L. F. D., Joia, L. A., \& Moreno Jr, V. A. (2014). Antecedentes da intenção de uso de sistemas de home broker sob a ótica dos investidores do mercado acionário. Revista de Administração, 49(2), 353-368. http://doi.org/10.5700/rausp1151

Hair, J. F., Black, W. C., Babin, B. J., \& Anderson, R. E. (2010). Multivariate Data Analysis. (Pearson, Ed.).

Hair, J., Hult, T. M., Ringle, C. M., \& Sarstedt, M. (2014). A primer on partial least squares structural equations modeling (PLS-SEM). SAGE.

Hair, J., Ringle, C., \& Starstedt, M. (2011). PLS-SEM: Indeed a Silver Bullet. Faculty Publications. Retrieved from http://digitalcommons.kennesaw.edu/facpubs/2387

Hakala, H. (2011). Strategic Orientations in Management Literature: Three Approaches to Understanding the Interaction between Market, Technology, Entrepreneurial and Learning Orientations. International Journal of Management Reviews, 13(2), 199 217. http://doi.org/10.1111/j.1468-2370.2010.00292.x

Hakala, H., \& Kohtamäki, M. (2011). Configurations of entrepreneurial- customer- and technology orientation. International Journal of Entrepreneurial Behavior \& Research, 17(1), 64-81. http://doi.org/10.1108/13552551111107516

Hamann, R. (2016). Das toneladas aos microchips: A evolução dos computadores. Retrieved September 4, 2016, from http://www.tecmundo.com.br/infografico/9421-a-evolucao-dos-computadores.htm

Han, Y.-M., Shen, C.-S., \& Farn, C.-K. (2016). Determinants of continued usage of 
pervasive business intelligence systems. Information Development, 32(3), 424439. http://doi.org/10.1177/0266666914554811

Hao, S., \& Song, M. (2016). Technology-driven strategy and firm performance: Are strategic capabilities missing links? Journal of Business Research, 69(2), 751-759. http://doi.org/10.1016/j.jbusres.2015.07.043

Henseler, J.; Ringle, C. M.; Sinkovics, R. (2009). The use of partial least squares path modeling in international marketing. Advances in International Marketing, 20, 277-319. http://doi.org/10.1016/0167-8116(92)90003-4

Heskett, J., Sasser, W. E., \& Schlesinger, L. A. (1997). The Service Profit Chain: How Leading Companies Link Profit and Growth to Loyalty, Satisfaction, and Value. (F. Press, Ed.). New York.

Hou, C. (2014a). Exploring the user acceptance of business intelligence systems in Taiwan's electronics industry: applying the UTAUT model. International Journal of Internet and Enterprise Management, 8(3), 195. http://doi.org/10.1504/IJIEM.2014.059177

Hou, C. (2014b). User Acceptance of Business Intelligence Systems in Taiwan's Electronics Industry. Social Behavior and Personality, 42(949), 583-596. http://doi.org/10.2224/sbp.2014.42.4.583

Hou, C. (2016). Understanding business intelligence system continuance intention : An empirical study of Taiwan' s electronics industry. Information Developmen, 32(5), 1359-1371. http://doi.org/10.1177/0266666915599588

Hsu, H., Chang, C., \& Lin, T. (2013). An Empirical Study of Users â€ $€^{\mathrm{TM}}$ Continuance Intention and Word of Mouth Toward Sna ( Social Network App ). In Proceedings of 2013 International Conference on Technology Innovation and Industrial Management (pp. 174-183).

IBGE : Instituto Brasileiro de Geografia e Estatística. (n.d.). Retrieved November 13, 2017, from https://www.ibge.gov.br/estatisticas-novoportal/economicas/contasnacionais/9300-contas-nacionais-trimestrais.html?\&t=resultados

Iqbal, M., \& Nieves, M. (2011). Service Strategies. (ITIL, Ed.) (2nd ed.). High Wycombe: The Stationery Office. http://doi.org/10.1016/j.im.2003.02.002

Iriondo, J. M., Albert, M. J., \& Escudero, A. (2003). Structural equation modelling: An alternative for assessing causal relationships in threatened plant populations. Biological Conservation, 113(3), 367-377. http://doi.org/10.1016/S00063207(03)00129-0

Işik, Ö., Jones, M. C., \& Sidorova, A. (2013). Business intelligence success: The roles of BI capabilities and decision environments. Information and Management, 50(1), 13-23. http://doi.org/10.1016/j.im.2012.12.001

Jen, W., Lu, T., \& Liu, P. (2009). An Integrated Analysis of Technology Acceptance Behaviour Models : Comparison of Three Major Models. MIS Review, 15(1), 89121.

Johnston, R., Clark, G., \& Shulver, M. (2012). Service Operations Management: Improving Service Delivery. Harlow: Pearson.

Kaplan, D. (2008). Structural equation modeling : foundations and extensions (2nd ed.). 
Sage Publications.

Kaplan, R. S., \& Norton, D. P. (2008). Mastering the management system. Harvard Business Review, 86(1). http://doi.org/617-783-7500

Kellogg, D. L., \& Nie, W. (1995). A framework for strategic service management. Journal of Operations Management, 13(4), 323-337. http://doi.org/10.1016/02726963(95)00036-4

Kim, W. C., \& Mauborgne, R. (2004). Blue Ocean Strategy. Harvard Business Review, October 20.

Kon, A. (2004). Economia de serviços. Teoria e evolução no Brasil. (Elsevier/Campus, Ed.) (1st ed.). Rio de Janeiro.

Kon, A. (2006). Mudanças recentes no perfil da distribuição ocupacional da população brasileira. Revista Brasileira de Estudos de População, 23(2), 247-267. http://doi.org/10.1590/S0102-30982006000200004

Kon, A. (2007). Sobre a economia política do desenvolvimento e a contribuição dos serviços. Revista de Economia Política, 27(1), 130-146. http://doi.org/10.1590/S0101-31572007000100007

Koufteros, X. A. (1999). Testing a model of pull production: a paradigm for manufacturing research using structural equation modeling. Journal of Operations Management, 17, 467-488.

Kuo, R., \& Lee, G. (2009). KMS adoption: the effects of information quality. Management Decision, 47(10), 1633-1651. http://doi.org/10.1108/00251740911004727

Laney, D. (2001). 3-D Data Management: Controlling Data Volume, Velocity and Variety. META Group Research Note. http://doi.org/10.1016/j.infsof.2008.09.005

Lapponi, J. C. (2005). Estatística usando Excel. São Paulo: Elsevier.

Lechner, C., \& Gudmundsson, S. V. (2012). Entrepreneurial orientation, firm strategy and small firm performance. International Small Business Journal, 32(1), 36-60. http://doi.org/10.1177/0266242612455034

Li, J. P., \& Kishore, R. (2006). How Robust is the UTAUT Instrument? A Multigroup Invariance Analysis in the Context of Acceptance and Use of Online Community Weblog Systems. 2006 ACM SIGMIS CPR Conference on Computer Personnel Research: Forty Four Years of Computer Personnel Research: Achievements, Challenges \& the Future, 183-189. http://doi.org/1125170.1125218

Liao, J., Welsch, H., \& Stoica, M. (2008). Environmental Turbulence and Scanning Behavior: The Moderating Effects of Organizational Maturity. Journal of Small Business Strategy, 19(1), 15-31.

Limayem, M., Hirt, S. G., \& Cheung, C. M. K. (2007). How Habit Limits the Predictive Power of Intention: The Case of Information Systems Continuance. MIS Quarterly, 31(4), 705-737.

Lovelock, C., Patterson, P. G., \& Wirtz, J. (2014). Services Marketing. Melbourne: Pearson.

Loveman, G. W. (2004). Hay diamantes en la mina de datos. Harvard Business Review. 
Impact Media Comercial S.A.

Lugli, V. M. (2015). Mudança estrutural e o setor de serviços no Brasil. Dissertação de Mestrado, UNICAMP, Faculdade de Ciêncis Econômicas.

Madden, S. (2012). From Databases to Big Data. IEEE Internet Computing, 16(3), 4-6. http://doi.org/10.1109/MIC.2012.50

Malaeb, Z. A., Summers, J. K., \& Pugesek, B. H. (2000). Using structural equation modeling to investigate relationships among ecological variables. Environmental and Ecological Statistics, 7(1), 93-11. http://doi.org/10.1023/A

Mankins, M. C., \& Steele, R. (2005). Turning great strategy into great performance. Harvard Business Review, 83(7-8).

http://doi.org/10.4025/actascibiolsci.v30i4.5869

Manyika, J., Chui, M., Brown, B., Bughin, J., Dobbs, R., Roxburgh, C., \& Byers, A. H. (2011). Big data: The next frontier for innovation, competition, and productivity. Retrieved October 15, 2015, from http://www.mckinsey.com/insights/business_technology/big_data_the_next_fronti er_for_innovation

Meirelles, D. S. e. (2006). O conceito de Serviço. Revista de Economia E Política, 26(1), 119-136.

Melo, H. P. De, Frederico, C., Rocha, L., Sabbato, A. Di, Dweck, R. H., \& Gomes, G. M. (1997). É Possível uma Politica Para o Setor Serviços? (No. 457).

Melo, H. P. De, Rocha, F., Sabbato, A. Di, \& Dweck, R. (1998). O Setor Serviços No Brasil : Uma Visão Global - 1985 / 95 (No. 549).

Miles, R. E., Snow, C. C., Meyer, A. D., \& Coleman Jr., H. J. (1978). Organizational Strategy, Structure, and Process. The Academy of Management Review. http://doi.org/10.2307/257544

Mintzberg, H. (1987). The Strategy Concept I: Five Ps For Strategy. CALIFORNIA MANAGEMENT REVIEW, 30, 11-24.

$\mathrm{Mu}$, J., \& Di Benedetto, C. A. (2011). Strategic orientations and new product commercialization: Mediator, moderator, and interplay. $R$ and D Management, 41(4), 337-359. http://doi.org/10.1111/j.1467-9310.2011.00650.x

Nakagawa, S. S. Y. (2008). A Lealdade De Consumidores Nos Ambientes De Comércio Online E Offline. Tese de Doutorado em Administração. Universidade de São Paulo.

Negri, J. A. De, Kubota, L. C., \& Silva, A. M. (2006). Estrutura e dinâmica do setor de serviços no Brasil. (IPEA, Ed.) (1st ed.). Brasilia. Retrieved from $\mathrm{http}: / / \mathrm{www}$. ipea.gov.br/portal/index.php?option $=$ com_content\&view $=$ article $\& \mathrm{id}=5$ 513

Neilson, G. L., Martin, K. L., \& Powers, E. (2008). The Secrets to Successful Strategy Execution.

Norusis, M. (2011). IBM SPSS Statistics 19 Guide to Data Analysis. Pearson.

Oei, M. H. H. (2014). Finding factors that determine acceptance of Operational Business Intelligence in organisations. Delft. 
Oliver, R. L. (1977). Effect of expectation and disconfirmation on postexposure product evaluations: An alternative interpretation. Journal of Applied Psychology, 62(4), 480-486.

Oliver, R. L. (1980). A Cognitive Model of the Antecedents and Consequences of Satisfaction Decisions. Journal of Marketing Research, 17(4), 460-469.

Payandeh, F. (2013). BI vs. Big Data vs. Data Analytics By Example. Retrieved February 15, 2016, from http://www.datasciencecentral.com/profiles/blogs/bi-vsbig-data-vs-data-analytics-by-example

Pejić Bach, M., Čeljo, A., \& Zoroja, J. (2016). Technology Acceptance Model for Business Intelligence Systems : Preliminary Research. Procedia - Procedia Computer Science, 100, 995-1001. http://doi.org/10.1016/j.procs.2016.09.270

Pereira, F. A. de M., Ramos, A. S. M., Gouvêa, M. A., \& Costa, M. F. da. (2015). Satisfaction and continuous use intention of e-learning service in Brazilian public organizations. Computers in Human Behavior, 46, 139-148. http://doi.org/10.1016/j.chb.2015.01.016

Pestana, M. H., \& Gageiro, J. N. (2008). Análise de Dados para Ciências Sociais A complementaridade do SPSS. EDIÇÕES SÍLABO 5 Edição. Lisboa.

Pilati, R., \& Laros, J. A. (2007). Modelos de Equações Estruturais em Psicologia: Conceitos e Aplicações. Psicologia: Teoria E Pesquisa, 23(2), 205-216.

Popovič, A., Hackney, R., Coelho, P. S., \& Jaklič, J. (2012). Towards business intelligence systems success: Effects of maturity and culture on analytical decision making. Decision Support Systems, 54(1), 729-739.

http://doi.org/10.1016/j.dss.2012.08.017

Porter, M. E. (1980). Competitive strategy: Techniques for analyzing industries and companies. (F. Press, Ed.)New York. New York. http://doi.org/10.1002/smj.4250020110

Porter, M. E. (1996). What Is Strategy? Harvard Business Review, (NovemberDecember 1996).

Porter, M. E. (2008). The Five Competitive Forces That Shape Strategy. Harvard Business Review, 86(1).

Ramakrishnan, T., Jones, M. C., \& Sidorova, A. (2012). Factors influencing business intelligence (BI) data collection strategies: An empirical investigation. Decision Support Systems, 52(2), 486-496. http://doi.org/10.1016/j.dss.2011.10.009

Ringle, C. M., Da Silva, D., \& Bido, D. D. S. (2014). Structural Equation Modeling with the Smartpls. Revista Brasileira de Marketing, 13(2), 56-73. http://doi.org/10.5585/remark.v13i2.2717

Rogers, E. M. (2003). Diffusion of innovations. New York: Newyork Free Press. http://doi.org/citeulike-article-id:126680

Rubalcaba, L., \& Kox, H. (2007). Business Services in European Economic Growth. (PALGRAVE MACMILLAN, Ed.). New York.

Sá, L. F. J. de. (2007, February 6). The internet adoption barriers: broad band in small companies. Universidade de São Paulo. Retrieved from http://www.teses.usp.br/teses/disponiveis/12/12139/tde-23042007-104121/ 
Salavou, H. E. (2015). Competitive strategies and their shift to the future. European Business Review, 27(1), 80-99. http://doi.org/10.1108/EBR-04-2013-0073

Salganik, M. J., \& Heckathorn, D. D. (2004). Sampling and estimation in hidden populations using respondent-driven sampling. Sociological Methodology, 34(1), 193-240. http://doi.org/10.1111/j.0081-1750.2004.00152.x

Sarstedt, M., Ringle, C. M., Smith, D., Reams, R., \& Hair, J. F. (2014). Partial least squares structural equation modeling (PLS-SEM): A useful tool for family business researchers. Journal of Family Business Strategy, 5(1), 105-115. http://doi.org/10.1016/j.jfbs.2014.01.002

SEBRAE. (2008). A Competitividade nos Setores de Comércio, de Serviços e do Turismo no Brasil: Perspectivas até 2015.

SEBRAE. (2012). Empresas de serviços serão a maioria no mercado paulista em 2020. Retrieved March 6, 2016, from http://www.sebraesp.com.br/index.php/23noticias/comercio-e-servicos/1264-empresas-de-servicos-serao-a-maioria-nomercado-paulista-em-2020

Serasa Experian. (2015). Serasa ExperianQuantidade de novas empresas abertas no Brasil cresce... Retrieved November 12, 2017, from http://noticias.serasaexperian.com.br/blog/2015/01/30/24715/

Sharma, S. (1996). Applied Multivariate Techniques. Toronto: John Wiley \& Sons.

Shiau, W. L., \& Luo, M. M. (2013). Continuance intention of blog users: The impact of perceived enjoyment, habit, user involvement and blogging time. Behaviour and Information Technology, 32(6), 570-583. http://doi.org/10.1080/0144929X.2012.671851

Shmueli, G. (2010). To Explain or to Predict? Statistical Science, 25(3), 289-310. http://doi.org/10.1214/10-STS330

Shmueli, G., \& Koppius, O. R. (2011). Predictive Analytics in Information Systems Research. MIS Quarterly, 35(3), 553-572.

Shu, Q., Tu, Q., \& Wang, K. (2011). The Impact of Computer Self-Efficacy and Technology Dependence on Computer-Related Technostress: A Social Cognitive Theory Perspective. International Journal of Human-Computer Interaction, 27(10), 923-939. http://doi.org/10.1080/10447318.2011.555313

Siemens. (2014). Pictures of the Future: From Big Data to Smart Data. Retrieved October 29, 2015, from http://www.siemens.com/innovation/en/home/pictures-ofthe-future/digitalization-and-software/from-big-data-to-smart-datainfographic.html

Silveira, J. (2006). MODELAGEM DE EQUAÇÕES ESTRUTURAIS : apresentação de uma metodologia. Dissertação de Mestrado UFRS, 1-105.

Statistics, B. of L. (n.d.). International Comparisons of Annual Labor Force Statistics, 1970-2012 : U.S. Bureau of Labor Statistics. Retrieved October 5, 2017, from https://www.bls.gov/fls/flscomparelf.htm\#table06

Stoelting, R. (2002). Structural Equation Modeling/Path Analysis. Retrieved September 28, 2017, from http://online.sfsu.edu/efc/classes/biol710/path/SEMwebpage.htm

Taylor, S., \& Todd, P. A. (1995). Understanding information technology usage: A test 
of competing models. Information Systems Research, 6(2), 144-176.

http://doi.org/10.1287/isre.6.2.144

Tenenhaus, M., Vinzi, V. E., Chatelin, Y. M., \& Lauro, C. (2005). PLS path modeling. Computational Statistics and Data Analysis, 48(1), 159-205.

http://doi.org/10.1016/j.csda.2004.03.005

Teo, T. (2009). Modelling technology acceptance in education: A study of pre-service teachers. Computers and Education, 52(2), 302-312. http://doi.org/10.1016/j.compedu.2008.08.006

Thompson, R. L., Higgins, C. A., \& Howell, J. M. (1991). Personal computing: Toward a conceptual model of utilization. MIS Quarterly, 15(125-143).

Triandis, H. C. (1971). Attitude an Attitude Change. New York: John Wiley and Sons.

Troilo, M., Bouchet, A., Urban, T. L., \& Sutton, W. A. (2016). Perception, reality, and the adoption of business analytics: Evidence from North American professional sport organizations. Omega (United Kingdom), 59, 72-83. http://doi.org/10.1016/j.omega.2015.05.011

Turban, E., Sharda, R., Aronson, J. E., \& King, D. (2009). Business Intelligence - Um Enfoque Gerencial Para a Inteligência do Negócio. (Bookman, Ed.) (1st ed.). Porto Alegre.

Venkatesh, V., \& Davis, F. D. (2000). A theoretical extension of the technology acceptance model: Four longitudinal Studies. Management Science, 46(2), 186205.

Venkatesh, V., \& Morris, M. G. (2000). Why don't men ever stop to ask for directions? Gender, social influence, and their role in technology acceptance and usage behavior. MIS Quarterly Vol., 24(1), 115-139.

Venkatesh, V., Morris, M. G., Davis, G. B., \& Davis, F. D. (2003). User acceptance of information technology: Toward a unified view. MIS Quarterly, 27(3), 425-478. http://doi.org/10.2307/30036540

Venkatesh, V., Thong, J., \& Xu, X. (2012). Consumer acceptance and use of information technology: Extending the unified theory of acceptance and use of technology. MIS Quarterly, 36(1), 157-178.

Verma, H. (2007). Services Marketing: Text And Cases. New Delhi: Pearson Education India.

Vieira, V. A. (2010). Mensuração da qualidade de serviço no varejo eletrônico e seu impacto sobre as intenções comportamentais. Revista de Administração de Empresas, 50(2), 199-214. http://doi.org/10.1590/S0034-75902010000200006

Vitolo, C., Elkhatib, Y., Reusser, D., Macleod, C. J. A., \& Buytaert, W. (2015). Web technologies for environmental Big Data. Environmental Modelling \& Software, 63, 185-198. http://doi.org/10.1016/j.envsoft.2014.10.007

Wetzels, M., Odekerken-Schröder, G., \& Oppen, C. van. (2009). Using PLS Path Modeling for Assesing Hierarchical Construct Models : Guidelines and Empirical Illustration. MIS Quarterly, 33(1), 177-195. http://doi.org/Article

Williams, M., Rana, N., \& Dwivedi, Y. K. (2015). The unified theory of acceptance and use of technology (UTAUT): a literature review. Journal of Enterprise 
Manegement, 30(3), pp443-488.

http://doi.org/http://dx.doi.org/10.1108/02683940010305270

Wixom, B. H., \& Todd, P. A. (2005). A theoretical integration of user satisfaction and technology acceptance. Information System Research, 16(1), 85-102.

Wright, P., Kroll, M. J., \& Parnell, J. A. (1998). Strategic Management. Prentice Hall.

Wu, X., Zhu, X., Wu, G.-Q., \& Ding, W. (2014). Data mining with big data. IEEE Transactions on Knowledge and Data Engineering, 26(1), 97-107. http://doi.org/10.1109/TKDE.2013.109

Yoon, T. E., Ghosh, B., \& Jeong, B. (2014). User Acceptance of Business Intelligence ( BI ) Application: Technology, Individual Difference, Social Influence, and Situational Constraints. In 47th Hawaii International Conference on System Sciences (HICSS). Hawaii. http://doi.org/10.1109/HICSS.2014.467

Zhou, K. Z., Kin, C., Yim, B., \& Tse, D. K. (2005). The Effects of Strategic Orientations on Technology-and Market-Based Breakthrough Innovations. Journal of Marketing, 42(69), 42-60.

Ziama, A., \& Kasher, J. (2004). Data Mining Primer for the Data Warehouse Professional. Daytona: Teradata.

Zikopoulos, P., Eaton, C., DeRoos, D., Lapis, G., \& Deutsch, T. (2012). Understanding big data. New York: McGraw-Hill.

Zwicker, R., Souza, C. A. de, \& Bido, D. de S. (2008). Uma revisão do Modelo do Grau de Informatização de Empresas: novas propostas de estimação e modelagem usando PLS (partial least squares). In XXXII Enanpad (pp. 1-16). 


\section{APÊNDICE}

\section{APÊNDICE 1: QUESTIONÁRIO DA PESQUISA}

\section{UTILIZAÇX̃O DE INTELIGÉNCIA DE NEGOCIOS EM EMPRESAS DE SERVIÇOS}

Esta é uma pesquisa para uma tese de doutorado em administraçăo de empresas na FEAMSP. Ela visa entender a utilizaçâo de sistemas de Bl (Business inteiligence) em empresas na visalo dos usuarios.

Niba existem respostas certas e erradas, tesponda de acordo com sua percepçalo, a tempo de resposta do questionario $6 \mathrm{em}$ tarno de cinco minutos.

As respostas năo serăo identificadas.

* 1, Sobee a uso do sisterna de Business intelligence, para carda afirmaçăo, escolna uma nota de 1 a 10

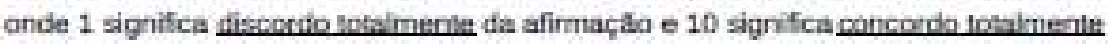

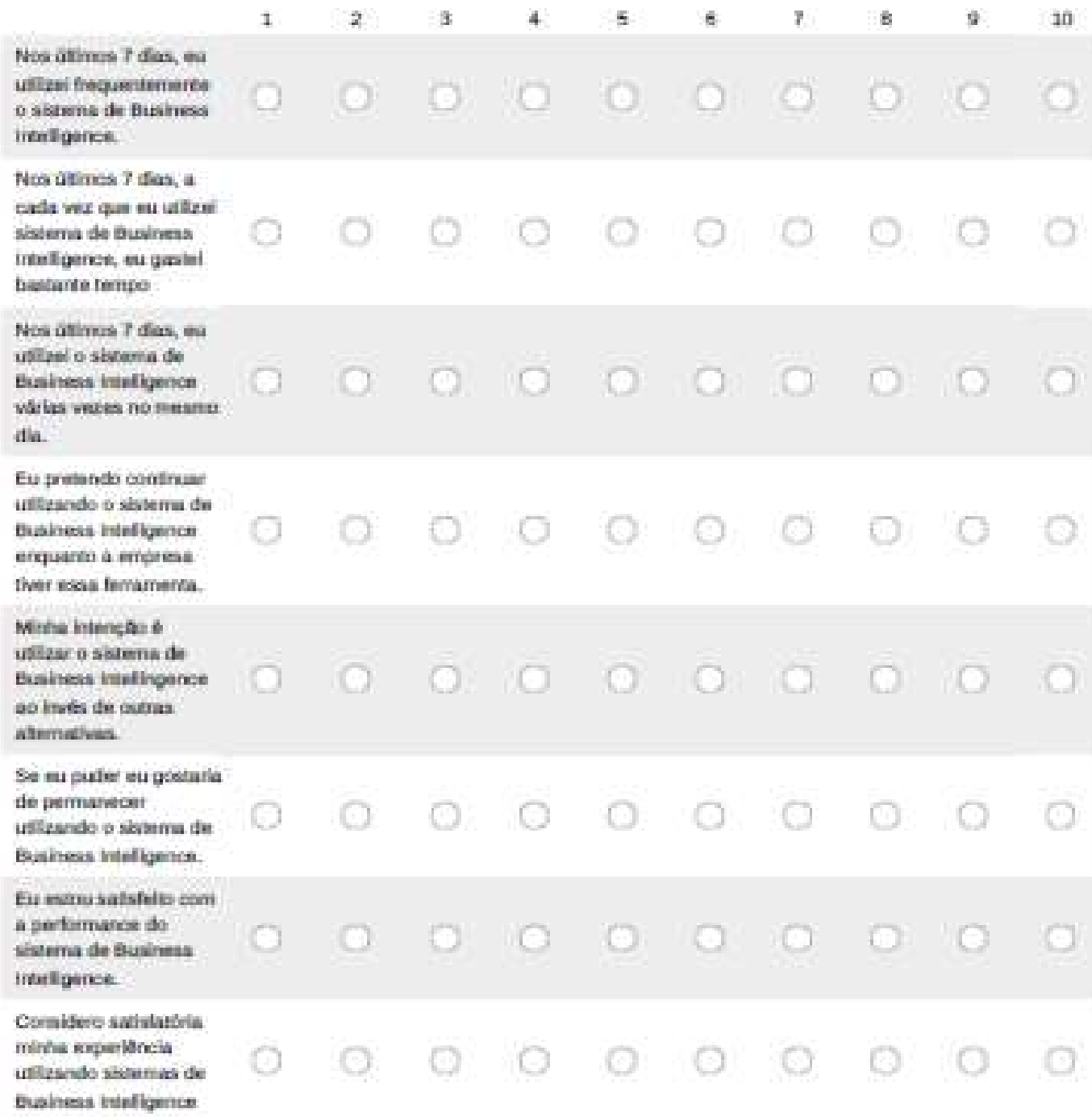




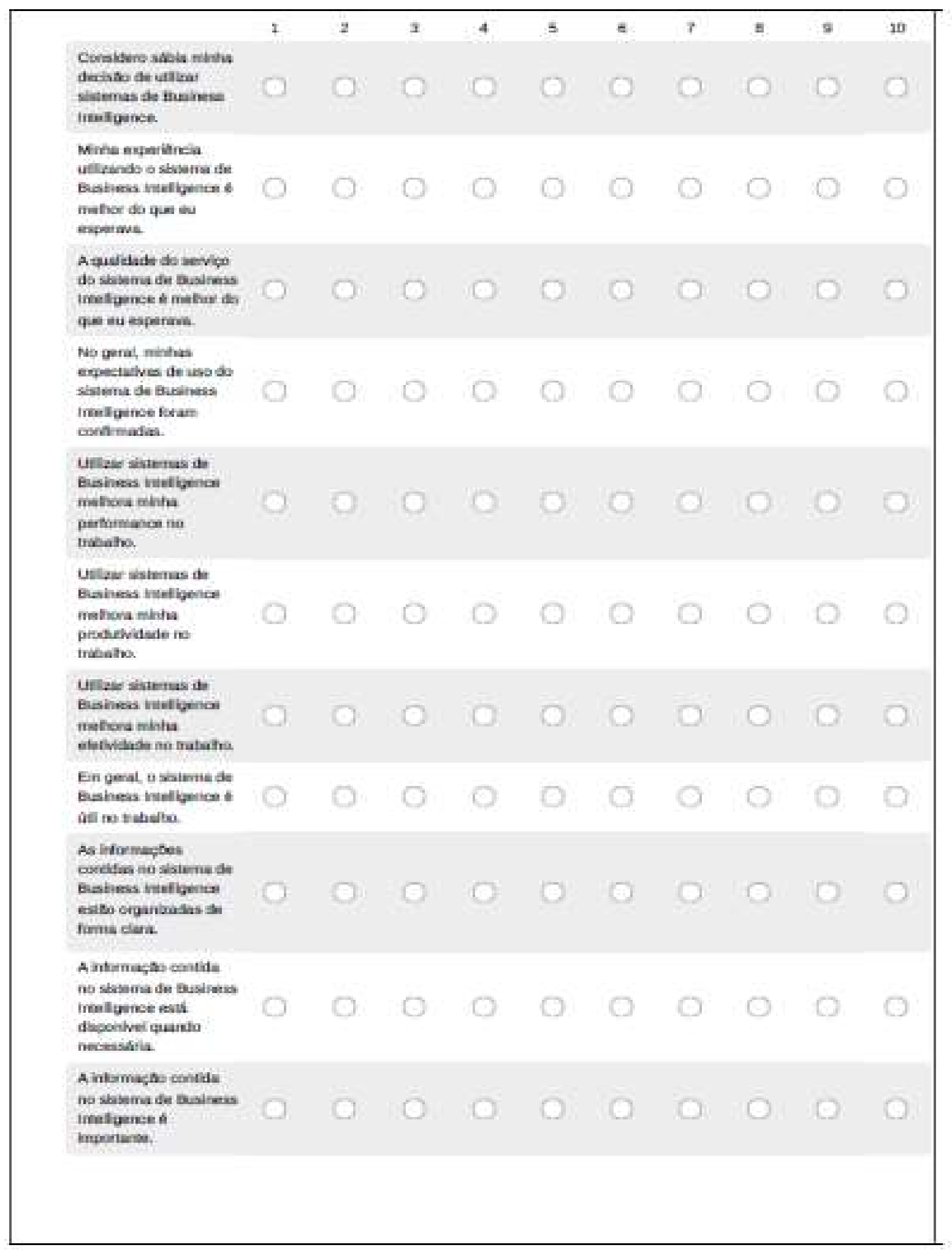




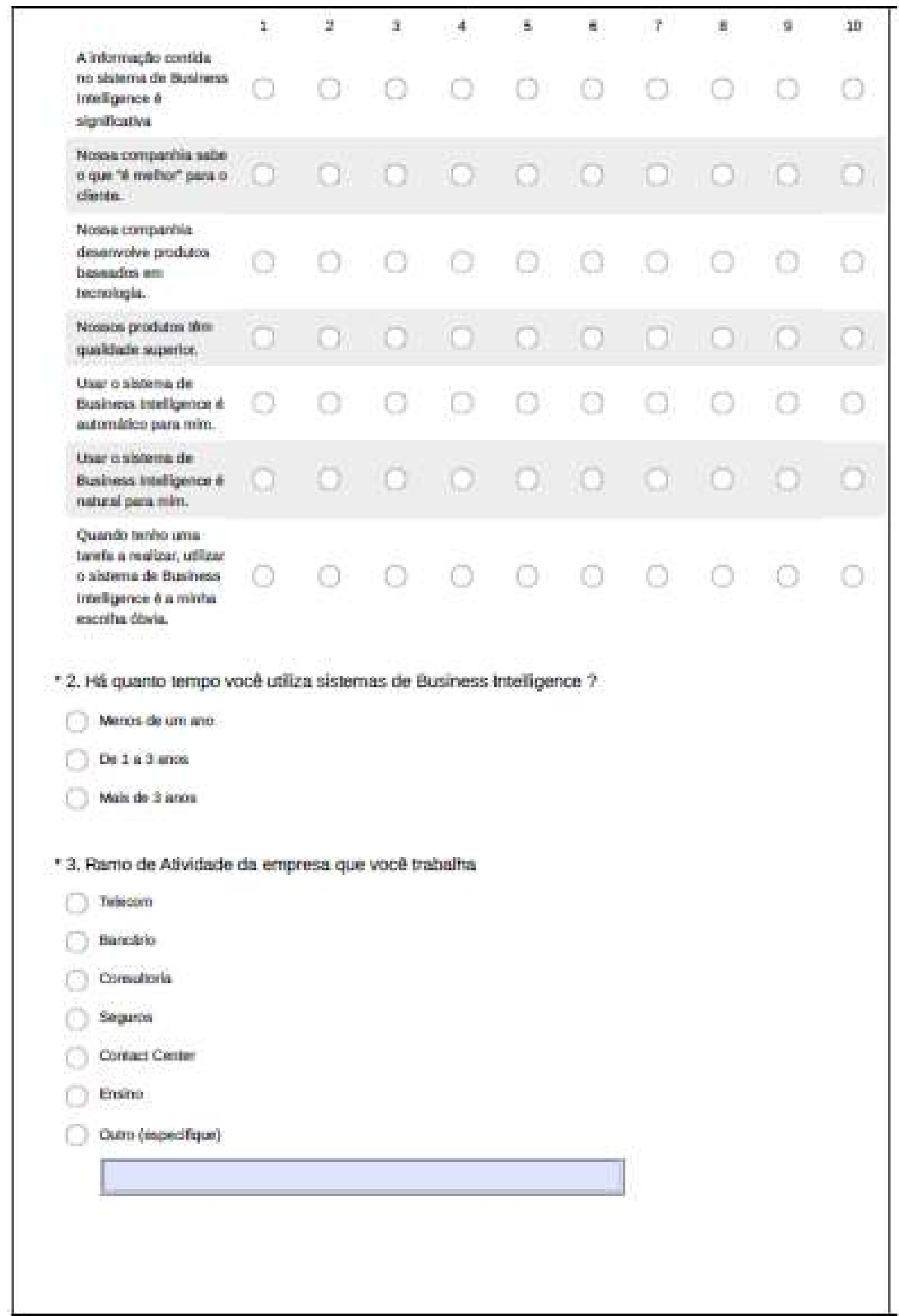




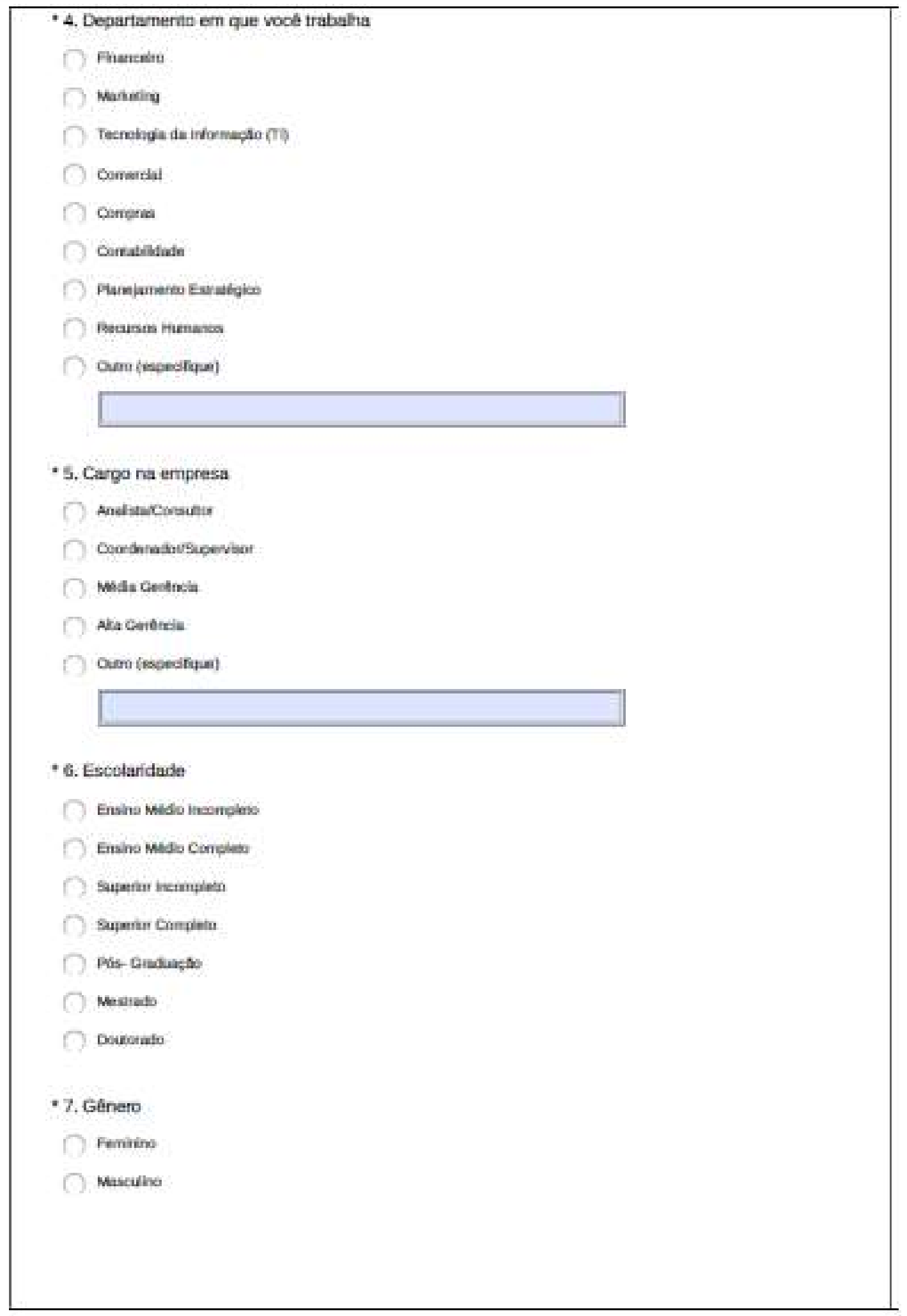




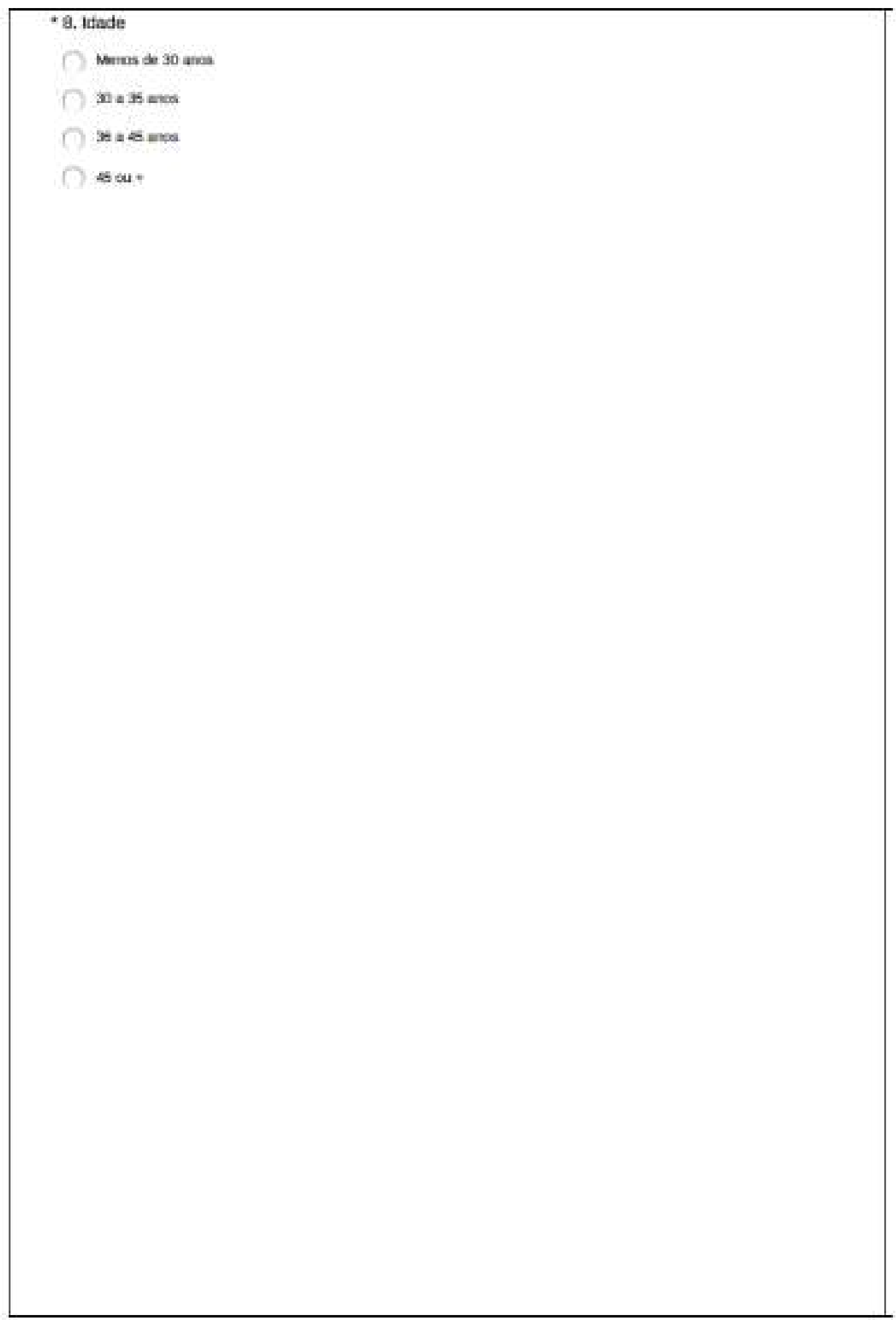

